\title{
Aranhas (Araneae, Arachnida) do Estado de São Paulo, Brasil: diversidade, esforço amostral e estado do conhecimento
}

\author{
Antonio Domingos Brescovit ${ }^{1,4}$, Ubirajara de Oliveira ${ }^{2,3}$ \& Adalberto José dos Santos ${ }^{2}$ \\ ${ }^{1}$ Laboratório de Artrópodes, Instituto Butantan, \\ Av.Vital Brasil, n. 1500, CEP 05503-900, São Paulo, SP, Brasil,e-mail: anyphaenidae@butantan.gov.br \\ ${ }^{2}$ Departamento de Zoologia, Instituto de Ciências Biológicas, Universidade Federal de Minas Gerais - UFMG, \\ Av. Antonio Carlos, n. 6627, CEP 31270-901, Belo Horizonte, MG, Brasil, \\ e-mail: ubiologia@yahoo.com.br,oxyopes@yahoo.com \\ ${ }^{3}$ Pós-graduação em Ecologia, Conservação e Manejo da Vida Silvestre, Instituto de Ciências Biológicas, \\ Universidade Federal de Minas Gerais - UFMG \\ ${ }^{4}$ Autor para correspondência: Antonio Domingos Brescovit,e-mail: adbresc@terra.com.br
}

BRESCOVIT, A.D., OLIVEIRA, U. \& SANTOS, A.J. Spiders (Araneae, Arachnida) from São Paulo State, Brazil: diversity, sampling efforts, and state-of-art. Biota Neotrop. 11(1a): http://www.biotaneotropica.org. br/v11n1a/en/abstract?inventory+bn0381101a2011.

\begin{abstract}
In this study we present a database of spiders described and registered from the Neotropical region between 1757 and 2008. Results are focused on the diversity of the group in the State of São Paulo, compared to other Brazilian states. Data was compiled from over 25,000 records, published in scientific papers dealing with Neotropical fauna. These records enabled the evaluation of the current distribution of the species, the definition of collection gaps and priority biomes, and even future areas of endemism for Brazil. A total of 875 species, distributed in 50 families, have been described from the State of São Paulo. A total of 11,280 species have been recorded from the Neotropical region (almost $1 / 3$ of the species described worldwide). Brazil is the Neotropical country with the highest diversity (3,203 spp.), followed by Mexico (1,951 spp.) and Panama (1,325 spp.). Seven thousand five hundred species were recorded from South America and Brazil holds the highest diversity (3,203 spp., in 72 families), followed by Argentina (1,316 spp.), and Peru (1,066 spp.).
\end{abstract}

Keywords: spiders, araneae, biodiversity of the State of São Paulo, BIOTA/FAPESP Program.

Number of species: in the world: 41,719, in Brazil: 3,203, estimated in São Paulo State: 1,200.

BRESCOVIT, A.D., OLIVEIRA, U. \& SANTOS, A.J. Aranhas (Araneae, Arachnida) do Estado de São Paulo, Brasil: diversidade, esforço amostral e estado do conhecimento. Biota Neotrop. 11(1a): http://www. biotaneotropica.org.br/v11n1a/pt/abstract?inventory+bn0381101a2011.

Resumo: Neste trabalho são apresentadas informações oriundas de um banco de dados das aranhas descritas e registradas para a região neotropical entre 1757 e 2008. O enfoque será na diversidade do grupo no Estado de São Paulo, comparado com outros estados brasileiros. Os resultados são oriundos de mais de 25.000 registros publicados em artigos científicos na Região Neotropical. Estes dados permitem avaliar a distribuição atual do grupo, identificar lacunas de coleta, definir biomas prioritários para estudo e até delimitar áreas de endemismo para o Brasil no futuro. O Estado de São Paulo apresenta 875 espécies descritas, distribuídas em 50 famílias. A região neotropical possui 11.280 espécies (quase $1 / 3$ das espécies propostas para o mundo). O Brasil é o país neotropical com maior diversidade (3.203 spp.), seguido do México (1.951 spp.) e Panamá (1.325 spp.). Na América do Sul temos atualmente mais de 7.500 espécies de aranhas e o Brasil apresenta a maior diversidade (3.203 espécies registradas em 72 famílias), seguido da Argentina (1.316 spp.) e Peru (1.066 spp.).

Palavras-chave: aranhas, araneae, biota paulista, Programa BIOTA/FAPESP.

Número de espécies: no mundo: 41.719, no Brasil: 3.203, estimadas no Estado de São Paulo: 1.200. 


\section{Introdução}

Dentre os Arachnida, a ordem Araneae é a segunda mais diversa e conta hoje no mundo com quase 42.000 espécies descritas, distribuídas em 110 famílias (Platnick 2010, Miller et al. 2010). Este número de espécies ainda está longe da real diversidade do grupo. Estimativas de diversidade total em todo o planeta variam entre 60.000 e 80.000 espécies (Platnick 1999), ou mesmo 170.000 espécies (Coddington \& Levi 1991). Portanto, a porcentagem da diversidade total de aranhas descritas varia, dependendo da estimativa que se leve em conta, entre 20 e $60 \%$.

A ordem está dividida em três infraordens: Mesothelae, Mygalomorphae e Araneomorphae. Destas apenas Mesothelae não tem representantes neotropicais, ocorrendo exclusivamente na região asiática (Platnick 2010). As aranhas da infraordem Mygalomorphae (popularmante conhecidas como caranguejeiras, aranhas-peludas, aranhas de buracos ou tocas) são facilmente diagnosticadas pelas quelíceras dispostas paralelamente e pela presença de apenas quatro fiandeiras. As Araneomorphae estão representadas por quase $90 \%$ das aranhas conhecidas e são caracterizadas pelas quelíceras verticais, opostas uma em relação à outra, e por apresentar normalmente seis fiandeiras (Foelix 1996).

A ordem Araneae é um dos poucos grupos taxonômicos em que todas as espécies descritas estão relacionadas em um catálogo disponível on-line, com atualização semestral (Platnick 2010). Neste catálogo as informações de distribuição geográfica para cada espécie se restringe aos países em que estas ocorrem. Para obter registros mais refinados sobre ocorrência das espécies dentro dos países é necessário consultar a literatura primária. Embora este catálogo seja uma importante ferramenta para consulta sobre a diversidade de aranhas em diferentes partes do planeta, suas informações são insuficientes para estudos comparativos da diversidade dentro de países, ou mesmo para o diagnóstico do estado de conhecimento do grupo em determinadas regiões.

Brescovit (1999) apresentou uma síntese do conhecimento de aranhas para o Brasil, com informações relevantes para o Estado de São Paulo. Até aquele período a maioria dos dados ainda estava dispersa e não havia suporte de um banco de dados atualizado, que permitisse determinar o número de espécies ou registros de ocorrência de aranhas em diferentes regiões do país. Dez anos se passaram e, com auxilio do Programa BIOTA/FAPESP, foi possível compilar informações tanto da literatura quanto a partir de amplas coletas realizadas no estado. Como resultado, foi construído um banco de dados das espécies descritas para o Brasil, baseado em informações da literatura. Nesta síntese procuramos reunir dados de distribuição das espécies descritas até o momento para o Brasil, a fim de determinar quantas espécies existem no país e na Região Neotropical.

Atendendo à solicitação do Programa BIOTA/FAPESP para o Ano Internacional da Biodiversidade apresentamos aqui as informações oriundas de nosso banco de dados das aranhas descritas e registradas para a região neotropical entre 1757 e 2008. Nosso enfoque será na diversidade do grupo no Estado de São Paulo, comparado com outros estados do Brasil. Os resultados têm origem em mais de 25.000 registros publicados para aranhas da Região Neotropical. Estes dados já permitem avaliar o conhecimento atual do grupo, identificar lacunas de coleta, definir biomas prioritários para estudo e, talvez de forma ambiciosa, num futuro próximo delimitar áreas de endemismo para aranhas do Brasil.

\section{Metodologia}

O levantamento de dados foi iniciado em dezembro de 2000 com a compilação de registros de ocorrência de espécies retirados de publicações listadas em catálogos impressos (Roewer 1954, Bonnet
1956, 1957, 1958, 1959, Brignoli 1983, Platnick, 1989, 1993) e no catalogo eletrônico de Platnick (2010). Informações adicionais foram obtidas a partir de inventários faunísticos considerados confiáveis.

Os registros foram dispostos em planilhas no programa Excel. Os dados estão dispostos em 17 colunas, nesta ordem: 1) família, 2) gênero, 3) espécie, 4) sub-espécie 5) sinonímias 6) autor 7) ano, 8) sexo, 9) país, 10) estado, 11) município, 12) localidade específica, 13) coordenadas, 14) instituição depositária, 15) referência bibliográfica, 16) LSID (Life Science Identifier, de acordo com Platnick 2010); e 17) critério de georreferenciamento. Os itens 10 a 12 e 14 foram obtidos por consulta direta nos trabalhos científicos e livros. Cada linha da planilha significa um registro, salientando que o número de registros não é o mesmo do número de nomes específicos, uma vez que os nomes específicos são repetidos a cada registro novo incluído. Com esta disposição, o banco de dados permite atualmente uma busca rápida de dados para, por exemplo, obter o numero total de espécies e/ou registros para os municípios, estados ou países, ou, mostrar quais autores descreveram mais espécies na região neotropical e no Brasil. As referencias bibliográficas citadas na lista de espécies (Tabela 1) seguem o formato de Platnick (2010), e podem ser obtidas em http://research.amnh.org/iz/spiders/catalog/BIBLIO.html, com exceção de citações marcadas com *, que se referem a inventários.

Os registros que não apresentavam coordenadas geográficas na publicação original foram georreferenciados utilizando banco de dados de coordenadas geográficas, seguindo quatro critérios de georreferenciamento:

- Critério 1: Alguns registros não-georreferenciados foram obtidos de localidades com coordenadas geográficas conhecidas a partir de outros registros. Nestes casos, foram usadas as coordenadas disponíveis. Por exemplo, uma espécie A apresenta um registro publicado para uma localidade, sem as coordenadas. Entretanto, o banco de dados inclui um registro para a espécie $\mathrm{B}$, publicado para a mesma localidade e com coordenadas. Assim, considera-se pelo Critério 1 que as mesmas coordenadas para o registro da espécie A. Neste critério foram considerados apenas registros com exatamente a mesma informação na coluna "Localidade".

- Critério 2: Registros em localidades sem coordenadas no banco de dados foram georreferenciado por meio de consulta ao Google Earth®.

- Critério 3: Nos casos em que não foi possível localizar as localidades no Google Earth ${ }^{\circledR}$, os registros foram georreferenciados através da ferramenta Geoloc (disponível em http://splink.cria.org.br/tools?criaLANG=pt), utilizando os bancos de dados do IBGE e do SpeciesLink.

- Critério 4: Os registros sem localidade específica foram georreferenciados a partir do Geoloc, com base nas coordenadas para os municípios.

Assim, foram excluídos das análises todos os registros que não apresentavam informações de localidade e/ou do município, já que não seria possível seu georreferenciamento a posteriori. Para verificar se as coordenadas presentes no banco de dados estavam corretas, os registros obtidos foram dispostos em um mapa de divisão política dos estados e municípios do Brasil (IBGE) usando um SIG (Sistema de Informação Geográfica). Assim, as coordenadas discrepantes foram corrigidas por meio de novas consultas às fontes de dados geográficos (ver Canhos 2001).

Nós mapeamos a riqueza de espécies, e o número de registros de aranhas para o Estado de São Paulo em grades de quadrículas de $0,5^{\circ}\left(\approx 2.916 \mathrm{Km}^{2}\right)$. Estas foram classificadas em 5 categorias segundo a divisão natural de intervalos calculada pelo programa DIVA-GIS (Hijmans et al. 2005) ArcGIS 9.3. 
Tabela 1. Lista das espécies de aranhas registradas para o Estado de São Paulo.

Table 1. List of species of spiders recorded from the State of São Paulo.

\begin{tabular}{|c|c|c|c|c|c|}
\hline Família & spp. & Autor & Data & Destaque & Referências \\
\hline Actinopodidae & Actinopus crassipes & (Keyserling) & 1891 & & Mello-Leitão, 1923a \\
\hline Actinopodidae & Actinopus dubiomaculatus & Mello-Leitão & 1923 & registro único & Mello-Leitão, 1923a \\
\hline Actinopodidae & $\begin{array}{l}\text { Actinopus } \\
\text { fractus }\end{array}$ & Mello-Leitão & 1920 & & $\begin{array}{c}\text { Mello-Leitão, 1923a; } \\
\text { Indicatti \& Brescovit, 2008 }\end{array}$ \\
\hline Actinopodidae & Actinopus pusillus & Mello-Leitão & 1920 & & Mello-Leitão, 1920b \\
\hline Actinopodidae & Actinopus tarsalis & Perty & 1833 & & Mello-Leitão, 1923a \\
\hline Agelenidae & $\begin{array}{l}\text { Tegenaria } \\
\text { domestica }\end{array}$ & (Clerck) & 1757 & $\begin{array}{l}\text { introduzida, } \\
\text { sinantrópica }\end{array}$ & Indicatti \& Brescovit 2008 \\
\hline Titanoecidae & $\begin{array}{l}\text { Goeldia } \\
\text { luteipes }\end{array}$ & Keyserling & 1891 & sinantrópica & $\begin{array}{c}\text { Mello-Leitão, 1919; } \\
\text { Indicatti \& Brescovit, } 2008\end{array}$ \\
\hline Anyphaenidae & Anyphaenoides clavipes & (Mello-Leitão) & 1922 & & Brescovit, 1997a; Brescovit, 1992d \\
\hline Anyphaenidae & Arachosia bergi & (Simon) & 1880 & & Ramirez, 2003 \\
\hline Anyphaenidae & Arachosia honesta & Keyserling & 1891 & & Ramirez, 2003 \\
\hline Anyphaenidae & Aysha albovittata & Mello-Leitão & 1944 & & Brescovit, 1992c \\
\hline Anyphaenidae & Aysha boraceia & Brescovit & 1992 & & Brescovit, 1992c \\
\hline Anyphaenidae & $\begin{array}{l}\text { Aysha } \\
\text { borgmeyeri }\end{array}$ & (Mello-Leitão) & 1926 & & $\begin{array}{l}\text { Brescovit, 1992c; } \\
\text { Rinaldi \& Forti, } 1997\end{array}$ \\
\hline Anyphaenidae & Aysha clarovittata & (Keyserling) & 1891 & & Brescovit, 1992c \\
\hline Anyphaenidae & $\begin{array}{c}\text { Aysha } \\
\text { diversicolor }\end{array}$ & (Keyserling) & 1891 & & $\begin{array}{c}\text { Rinaldi \& Forti, 1997; } \\
\text { Indicatti \& Brescovit, } 2008\end{array}$ \\
\hline Anyphaenidae & $\begin{array}{l}\text { Aysha } \\
\text { ericae }\end{array}$ & Brescovit & 1992 & & $\begin{array}{c}\text { Brescovit, 1992c; Indicatti \& } \\
\text { Brescovit, } 2088\end{array}$ \\
\hline Anyphaenidae & Aysha fortis & (Keyserling) & 1891 & & Brescovit, 1992c \\
\hline Anyphaenidae & Aysha garruchos & Brescovit & 1992 & & Brescovit, 1992c \\
\hline Anyphaenidae & Aysha guarapuava & Brescovit & 1992 & & Brescovit, 1992c \\
\hline Anyphaenidae & Aysha helvola & (Keyserling) & 1891 & & Indicatti \& Brescovit 2008 \\
\hline Anyphaenidae & Aysha marinonii & Brescovit & 1992 & & Rinaldi \& Forti, 1997 \\
\hline Anyphaenidae & Aysha piassaguera & Brescovit & 1992 & & Brescovit, 1992c \\
\hline Anyphaenidae & Aysha pirassununga & Brescovit & 1992 & & Brescovit, 1992c \\
\hline Anyphaenidae & Aysha proseni & Mello-Leitão & 1944 & & Brescovit, 1992c \\
\hline Anyphaenidae & Aysha prospera & Keyserling & 1891 & & Brescovit, 1992c \\
\hline Anyphaenidae & $\begin{array}{l}\text { Aysha } \\
\text { robusta }\end{array}$ & (Keyserling) & 1891 & & $\begin{array}{c}\text { Rinaldi \& Forti, 1997; } \\
\text { Indicatti \& Brescovit, } 2008\end{array}$ \\
\hline Anyphaenidae & $\begin{array}{l}\text { Aysha } \\
\text { rubromaculata }\end{array}$ & (Keyserling) & 1891 & & $\begin{array}{c}\text { Rinaldi \& Forti, 1997; } \\
\text { Indicatti \& Brescovit, } 2008\end{array}$ \\
\hline Anyphaenidae & Aysha striolata & (Keyserling) & 1891 & & Rinaldi \& Forti, 1997 \\
\hline Anyphaenidae & Aysha tertulia & Brescovit & 1992 & & $\begin{array}{l}\text { Brescovit, 1992c; } \\
\text { Rinaldi \& Forti, } 1997\end{array}$ \\
\hline Anyphaenidae & Aysha triunfo & Brescovit & 1992 & & Brescovit, 1992c; Brescovit, 1997a \\
\hline Anyphaenidae & $\begin{array}{l}\text { Aysha } \\
\text { zenzesi }\end{array}$ & (Mello-Leitão) & 1945 & & $\begin{array}{l}\text { Brescovit, 1992c; } \\
\text { Rinaldi \& Forti, } 1997\end{array}$ \\
\hline Anyphaenidae & Bromelina oliola & Brescovit & 1993 & & Brescovit, 1993e \\
\hline Anyphaenidae & Buckupiella imperatriz & Brescovit & 1997 & & Brescovit, 1997a \\
\hline Anyphaenidae & Hibana melloleitaoi & (Caporiacco) & 1947 & & Brescovit, 1991b; Brescovit, 1993b \\
\hline Anyphaenidae & Iguarima censoria & (Keyserling) & 1891 & & Brescovit, 1997a \\
\hline Anyphaenidae & $\begin{array}{l}\text { Italaman } \\
\text { santamaria }\end{array}$ & Brescovit & 1997 & & $\begin{array}{c}\text { Brescovit, 1997a; Indicatti \& } \\
\text { Brescovit, } 2008\end{array}$ \\
\hline Anyphaenidae & Jessica erythrostoma & (Mello-Leitão) & 1939 & & Brescovit, 1999b \\
\hline Anyphaenidae & Jessica fidelis & (Mello-Leitão) & 1929 & & Brescovit, 1999b \\
\hline Anyphaenidae & Jessica glabra & (Keyserling) & 1891 & & Brescovit, 1999b \\
\hline Anyphaenidae & Jessica osoriana & (Mello-Leitão) & 1922 & & Brescovit, 1997a; Brescovit, 1999b \\
\hline
\end{tabular}


Tabela 1. Continuação...

\begin{tabular}{|c|c|c|c|c|c|}
\hline Família & spp. & Autor & Data & Destaque & Referências \\
\hline Anyphaenidae & Jessica pachecoi & Brescovit & 1999 & & Brescovit, 1999b \\
\hline Anyphaenidae & Osoriella domingos & Brescovit & 1998 & & Brescovit, 1998a \\
\hline Anyphaenidae & Osoriella pallidoemanu & Mello-Leitão & 1926 & registro único & Mello-Leitão, 1926b \\
\hline Anyphaenidae & $\begin{array}{l}\text { Osoriella } \\
\text { rubella }\end{array}$ & (Keyserling) & 1891 & & $\begin{array}{l}\text { Mello-Leitão, 1939h; } \\
\text { Brescovit, 1998a }\end{array}$ \\
\hline Anyphaenidae & Osoriella tahela & Brescovit & 1998 & & Brescovit, 1998a \\
\hline Anyphaenidae & Patrera cita & (Keyserling) & 1891 & & Indicatti \& Brescovit 2008 \\
\hline Anyphaenidae & $\begin{array}{l}\text { Patrera } \\
\text { longipes }\end{array}$ & (Keyserling) & 1891 & & $\begin{array}{c}\text { Rinaldi \& Forti, 1997; } \\
\text { Indicatti \& Brescovit 2008 }\end{array}$ \\
\hline Anyphaenidae & Patrera procera & (Keyserling) & 1891 & & Rinaldi \& Forti, 1997 \\
\hline Anyphaenidae & Sanogasta maculatipes & (Keyserling) & 1891 & & Indicatti \& Brescovit 2008 \\
\hline Anyphaenidae & Sanogasta minuta & (Keyserling) & 1891 & & Ramirez, 2003 \\
\hline Anyphaenidae & Sanogasta puma & Ramirez & 2003 & & Ramirez, 2003 \\
\hline Anyphaenidae & Sanogasta tenuis & Ramirez & 2003 & registro único & Ramirez, 2003 \\
\hline Anyphaenidae & Sanogasta $x$-signata & (Keyserling) & 1891 & & Ramirez, 2003 \\
\hline Anyphaenidae & Tasata fuscotaeniata & (Keyserling) & 1891 & & Indicatti \& Brescovit 2008 \\
\hline Anyphaenidae & Tasata unipunctata & (Simon) & 1896 & & Ramirez, 2003 \\
\hline Anyphaenidae & Tasata variolosa & Mello-Leitão & 1943 & & Ramirez, 2003 \\
\hline Anyphaenidae & Teudis angusticeps & (Keyserling) & 1891 & & Brescovit, 1997a \\
\hline Anyphaenidae & Umuara fasciata & (Blackwall) & 1862 & & Brescovit, 1997a \\
\hline Anyphaenidae & Umuara juquia & Brescovit & 1997 & registro único & Brescovit, 1997a \\
\hline Anyphaenidae & Wulfila albus & Platnick & 1978 & & Brescovit, 1997a \\
\hline Anyphaenidae & Wulfilopsis pygmaea & (Keyserling) & 1891 & & Brescovit, 1997b \\
\hline Anyphaenidae & Wulfilopsis tenuipes & (Keyserling) & 1891 & & Brescovit, 1997a \\
\hline Anyphaenidae & Wulfilopsis tripunctata & (Mello-Leitão) & 1947 & & Brescovit, 1997b \\
\hline Anyphaenidae & $\begin{array}{l}\text { Xiruana } \\
\text { gracilipes }\end{array}$ & (Keyserling) & 1891 & & $\begin{array}{c}\text { Brescovit, 1997a; } \\
\text { Rinaldi \& Forti, } 1997\end{array}$ \\
\hline Anyphaenidae & $\begin{array}{l}\text { Xiruana } \\
\text { hirsuta }\end{array}$ & (Mello-Leitão) & 1938 & & $\begin{array}{c}\text { Mello-Leitão, 1938b; } \\
\text { Indicatti \& Brescovit 2008 }\end{array}$ \\
\hline Araneidae & Acacesia cornigera & Petrunkevitch & 1925 & & Glueck, 1994 \\
\hline Araneidae & Acacesia hamata & (Hentz) & 1847 & & Glueck, 1994 \\
\hline Araneidae & Acacesia villalobosi & Glueck & 1996 & & Glueck, 1994 \\
\hline Araneidae & $\begin{array}{l}\text { Acacesia } \\
\text { yacuiensis }\end{array}$ & Glueck & 1996 & & $\begin{array}{c}\text { Glueck, 1994; } \\
\text { Indicatti \& Brescovit, } 2008\end{array}$ \\
\hline Araneidae & Actinosoma pentacanthum & (Walckenaer) & 1841 & & Levi, $1995 b$ \\
\hline Araneidae & $\begin{array}{l}\text { Aculepeira } \\
\text { travassosi }\end{array}$ & $\begin{array}{l}\text { (Soares \& } \\
\text { Camargo) }\end{array}$ & 1948 & & Levi, 1991a \\
\hline Araneidae & $\begin{array}{l}\text { Aculepeira } \\
\quad \text { vittata }\end{array}$ & $\begin{array}{l}\text { (Gerschman \& } \\
\text { Schiapelli) }\end{array}$ & 1948 & & Levi, 1991a \\
\hline Araneidae & $\begin{array}{l}\text { Alpaida } \\
\text { alticeps }\end{array}$ & (Keyserling) & 1879 & & $\begin{array}{c}\text { Levi, 1988; } \\
\text { Indicatti \& Brescovit, } 2008\end{array}$ \\
\hline Araneidae & Alpaida angra & Levi & 1988 & & Levi, 1988 \\
\hline Araneidae & Alpaida biasii & Levi & 1988 & & Levi, 1988 \\
\hline Araneidae & Alpaida bischoffi & Levi & 1988 & & Levi, 1988 \\
\hline Araneidae & Alpaida boraceia & Levi & 1988 & & Levi, 1988 \\
\hline Araneidae & Alpaida carminea & (Taczanowski) & 1878 & & Levi, 1988 \\
\hline Araneidae & Alpaida citrina & (Keyserling) & 1892 & & Mello-Leitão, $1939 \mathrm{~h}$ \\
\hline Araneidae & Alpaida gallardoi & Levi & 1988 & & Indicatti \& Brescovit 2008 \\
\hline Araneidae & Alpaida grayi & (Blackwall) & 1863 & & Levi, 1988 \\
\hline Araneidae & Alpaida hoffmanni & Levi & 1988 & & Indicatti \& Brescovit 2008 \\
\hline Araneidae & Alpaida itauba & Levi & 1988 & & Levi, 1988 \\
\hline Araneidae & Alpaida keyserlingi & Levi & 1988 & & Levi, 1988 \\
\hline
\end{tabular}


Tabela 1. Continuação...

\begin{tabular}{|c|c|c|c|c|c|}
\hline Família & spp. & Autor & Data & Destaque & Referências \\
\hline Araneidae & Alpaida lanei & Levi & 1988 & & Levi, 1988 \\
\hline Araneidae & Alpaida latro & (Fabricius) & 1775 & & Levi, 1988 \\
\hline Araneidae & $\begin{array}{c}\text { Alpaida } \\
\text { leucogramma }\end{array}$ & (White) & 1841 & & $\begin{array}{c}\text { Levi, 1988; } \\
\text { Indicatti \& Brescovit, } 2008\end{array}$ \\
\hline Araneidae & Alpaida nonoai & Levi & 1988 & & Levi, 1988 \\
\hline Araneidae & Alpaida quadrilorata & (Simon) & 1897 & & Levi, 1988 \\
\hline Araneidae & $\begin{array}{l}\text { Alpaida } \\
\text { scriba }\end{array}$ & (Mello-Leitão) & 1940 & & $\begin{array}{l}\text { Levi, 1988; Buckup \& Meyer, 1993; } \\
\text { Indicatti \& Brescovit, } 2008\end{array}$ \\
\hline Araneidae & Alpaida tijuca & Levi & 1988 & & Indicatti \& Brescovit 2008 \\
\hline Araneidae & Alpaida truncata & (Keyserling) & 1865 & & Levi, 1988 \\
\hline Araneidae & Alpaida vanzolinii & Levi & 1988 & & Levi, 1988 \\
\hline Araneidae & $\begin{array}{l}\text { Alpaida } \\
\text { veniliae }\end{array}$ & (Keyserling) & 1865 & & $\begin{array}{c}\text { Levi, 1988; } \\
\text { Gonzaga \& Vasconcellos-Neto, } 2005\end{array}$ \\
\hline Araneidae & Alpaida versicolor & (Keyserling) & 1877 & & Indicatti \& Brescovit 2008 \\
\hline Araneidae & Araneus abeicus & Levi & 1991 & registro único & Levi, 1991a \\
\hline Araneidae & Araneus bandelieri & (Simon) & 1891 & & Levi, 1991a \\
\hline Araneidae & Araneus bogotensis & (Keyserling) & 1863 & & Levi, 1991a \\
\hline Araneidae & Araneus castilho & Levi & 1991 & registro único & Levi, 1991a \\
\hline Araneidae & Araneus corporosus & (Keyserling) & 1892 & & Levi, 1991a \\
\hline Araneidae & Araneus guttatus & (Keyserling) & 1865 & & Levi, 1991a \\
\hline Araneidae & Araneus iguacu & Levi & 1991 & & Indicatti \& Brescovit 2008 \\
\hline Araneidae & Araneus lenkoi & Levi & 1991 & registro único & Levi, 1991a \\
\hline Araneidae & Araneus omnicolor & (Keyserling) & 1893 & & Levi, 1991a \\
\hline Araneidae & Araneus orgaos & Levi & 1991 & & Levi, 1991a \\
\hline Araneidae & Araneus stabilis & (Keyserling) & 1892 & & Levi, 1991a \\
\hline Araneidae & Araneus unanimus & (Keyserling) & 1879 & & Levi, 1991a \\
\hline Araneidae & Araneus uniformis & (Keyserling) & 1879 & & Levi, 1991a \\
\hline Araneidae & Araneus venatrix & (C.L. Koch) & 1839 & & Levi, 1991a \\
\hline Araneidae & $\begin{array}{l}\text { Araneus } \\
\text { vincibilis }\end{array}$ & (Keyserling) & 1893 & & $\begin{array}{c}\text { Levi, 1991a; } \\
\text { Gonzaga \& Vasconcellos-Neto, } 2005\end{array}$ \\
\hline Araneidae & Araneus workmani & (Keyserling) & 1884 & & Levi, 1991a \\
\hline Araneidae & $\begin{array}{l}\text { Argiope } \\
\text { argentata }\end{array}$ & (Fabricius) & 1775 & sinantrópica & $\begin{array}{c}\text { Mello-Leitão, 1919; Levi, 2004; } \\
\text { Rinaldi, Mendes \& Cady, 2002; } \\
\text { Gonzaga e Vasconcellos-Neto, } 2005\end{array}$ \\
\hline Araneidae & Argiope ericae & Levi & 2004 & & Levi, 2004 \\
\hline Araneidae & Argiope savignyi & Levi & 1968 & & Levi, 2004 \\
\hline Araneidae & Argiope trifasciata & (Forskal) & 1775 & & Levi, 2004 \\
\hline Araneidae & Bertrana rufostriata & Simon & 1893 & & Levi, 1989 \\
\hline Araneidae & Bertrana striolata & Keyserling & 1884 & & Levi, 1989 \\
\hline Araneidae & Cyclosa bifurcata & (Walckenaer) & 1842 & & Levi, 1999 \\
\hline Araneidae & Cyclosa camargoi & Levi & 1999 & & Levi, 1999 \\
\hline Araneidae & Cyclosa caroli & (Hentz) & 1850 & & Levi, 1999 \\
\hline Araneidae & $\begin{array}{l}\text { Cyclosa } \\
\text { diversa }\end{array}$ & $\begin{array}{c}\text { (O.P. - } \\
\text { Cambridge) }\end{array}$ & 1894 & & Levi, 1999 \\
\hline Araneidae & Cyclosa espumoso & Levi & 1999 & & Levi, 1999 \\
\hline Araneidae & $\begin{array}{l}\text { Cyclosa } \\
\text { fililineata }\end{array}$ & Hingston & 1932 & & $\begin{array}{c}\text { Levi, 1999; } \\
\text { Gonzaga \& Vasconcellos-Neto, } 2005\end{array}$ \\
\hline Araneidae & Cyclosa machadinho & Levi & 1999 & & Levi, 1999 \\
\hline Araneidae & $\begin{array}{l}\text { Cyclosa } \\
\text { morretes }\end{array}$ & Levi & 1999 & & $\begin{array}{c}\text { Levi, 1999; } \\
\text { Gonzaga \& vasconcellos-Neto, } 2005\end{array}$ \\
\hline Araneidae & Cyclosa tapetifaciens & Hingston & 1932 & & Indicatti \& Brescovit 2008 \\
\hline Araneidae & Cyclosa vicente & Levi & 1999 & & Levi, 1999 \\
\hline
\end{tabular}


Tabela 1. Continuação...

\begin{tabular}{|c|c|c|c|c|c|}
\hline Família & spp. & Autor & Data & Destaque & Referências \\
\hline Araneidae & Enacrosoma anomalum & (Taczanowski) & 1873 & & Levi, 1999 \\
\hline Araneidae & Eriophora fuliginea & (C.L. Koch) & 1839 & & Mello-Leitão, 1919 \\
\hline Araneidae & $\begin{array}{l}\text { Eustala } \\
\text { clavispina }\end{array}$ & $\begin{array}{c}(\text { O.P. - } \\
\text { Cambridge })\end{array}$ & 1889 & & $\begin{array}{l}\text { Mello-Leitão, 1919; } \\
\text { Mello-Leitão, } 1920\end{array}$ \\
\hline Araneidae & $\begin{array}{c}\text { Eustala } \\
\text { guttata }\end{array}$ & $\begin{array}{l}\text { F.O.P. - } \\
\text { Cambridge }\end{array}$ & 1904 & registro único & Camargo, 1953 \\
\hline Araneidae & Eustala minuscula & (Keyserling) & 1892 & & Mello-Leitão, 1919 \\
\hline Araneidae & $\begin{array}{l}\text { Eustala } \\
\text { taquara }\end{array}$ & (Keyserling) & 1892 & & $\begin{array}{l}\text { Mello-Leitão, 191; } \\
\text { Mello-Leitão, } 1920\end{array}$ \\
\hline Araneidae & $\begin{array}{c}\text { Eustala } \\
\text { ulecebrosa }\end{array}$ & (Keyserling) & 1892 & & $\begin{array}{l}\text { Mello-Leitão, 1919; } \\
\text { Mello-Leitão, } 1920\end{array}$ \\
\hline Araneidae & Eustala vegeta & (Keyserling) & 1865 & & Mello-Leitão, 1919 \\
\hline Araneidae & $\begin{array}{l}\text { Gasteracantha } \\
\text { cancriformis }\end{array}$ & (Linnaeus) & 1758 & sinantrópica & $\begin{array}{c}\text { Badcock, 1932; } \\
\text { Indicatti \& Brescovit, } 2008\end{array}$ \\
\hline Araneidae & Hypognatha alho & Levi & 1996 & & Levi, 1996b \\
\hline Araneidae & Hypognatha mozamba & Levi & 1996 & & Levi, 1996b \\
\hline Araneidae & Hypognatha scutata & (Perty) & 1833 & & Mello-Leitão, 1939h; Levi, 1996b \\
\hline Araneidae & Hypognatha viamao & Levi & 1996 & & Levi, 1996b \\
\hline Araneidae & Kaira altiventer & O.P.- Cambridge & 1889 & & Levi, 1993c \\
\hline Araneidae & $\begin{array}{l}\text { Kaira } \\
\text { conica }\end{array}$ & $\begin{array}{l}\text { Gerschman \& } \\
\text { Schiapelli }\end{array}$ & 1948 & & Levi, 1993c \\
\hline Araneidae & Kapogea alayoi & (Archer) & 1958 & & Levi, 1997 \\
\hline Araneidae & $\begin{array}{l}\text { Kapogea } \\
\text { sellata }\end{array}$ & (Simon) & 1895 & & $\begin{array}{l}\text { Mello-Leitão, 1919; Levi, 1997; } \\
\text { Indicatti \& Brescovit, } 2008\end{array}$ \\
\hline Araneidae & Larinia directa & (Hentz) & 1847 & & Harrod, Levi \& Leibensperger, 1991 \\
\hline Araneidae & $\begin{array}{l}\text { Larinia } \\
\text { montecarlo }\end{array}$ & (Levi) & 1988 & & $\begin{array}{l}\text { Harrod, Levi \& Leibensperger, 1991; } \\
\text { Indicatti \& Brescovit, } 20008\end{array}$ \\
\hline Araneidae & Larinia t-notata & (Tullgren) & 1905 & & Harrod, Levi \& Leibensperger, 1991 \\
\hline Araneidae & $\begin{array}{l}\text { Larinia } \\
\text { tucuman }\end{array}$ & $\begin{array}{l}\text { Harrod, Levi \& } \\
\text { Leibensperger }\end{array}$ & 1991 & & Indicatti \& Brescovit 2008 \\
\hline Araneidae & Mangora blumenau & Levi & 2007 & & Levi, 2007 \\
\hline Araneidae & Mangora bocaina & Levi & 2007 & & Levi, 2007 \\
\hline Araneidae & Mangora botelho & Levi & 2007 & registro único & Levi, 2007 \\
\hline Araneidae & Mangora caxias & Levi & 2007 & & Levi, 2007 \\
\hline Araneidae & Mangora chacobo & Levi & 2007 & & Levi, 2007 \\
\hline Araneidae & Mangora enseada & Levi & 2007 & & Levi, 2007 \\
\hline Araneidae & Mangora florestal & Levi & 2007 & registro único & Levi, 2007 \\
\hline Araneidae & Mangora lactea & Mello-Leitão & 1944 & & Levi, 2007 \\
\hline Araneidae & Mangora melanocephala & (Taczanowski) & 1874 & & Levi, 2007 \\
\hline Araneidae & Mangora missa & Levi & 2007 & & Levi, 2007 \\
\hline Araneidae & Mangora nonoai & Levi & 2007 & & Levi, 2007 \\
\hline Araneidae & Mangora ramirezi & Levi & 2007 & & Levi, 2007 \\
\hline Araneidae & Mangora sobradinho & Levi & 2007 & & Levi, 2007 \\
\hline Araneidae & Mangora strenua & (Keyserling) & 1893 & & Levi, 2007 \\
\hline Araneidae & Mangora $v$-signata & Mello-Leitão & 1943 & & Levi, 2007 \\
\hline Araneidae & Manogea porracea & (C.L. Koch) & 1839 & & Levi, 1997 \\
\hline Araneidae & Mastophora carpogaster & Mello-Leitão & 1925 & & Mello-Leitão, 1931b; Levi, 2003 \\
\hline Araneidae & Mastophora corumbatai & Levi & 2003 & registro único & Levi, 2003 \\
\hline Araneidae & Mastophora felis & Piza & 1976 & & Piza, 1976c; Levi, 2003 \\
\hline Araneidae & Mastophora longiceps & Mello-Leitão & 1939 & registro único & Mello-Leitão, 1940a \\
\hline Araneidae & Mastophora piras & Levi & 2003 & & Levi, 2003 \\
\hline Araneidae & Mastophora satan & Canals & 1931 & & Levi, 2003 \\
\hline
\end{tabular}


Tabela 1. Continuação...

\begin{tabular}{|c|c|c|c|c|c|}
\hline Família & spp. & Autor & Data & Destaque & Referências \\
\hline Araneidae & Mastophora ypiranga & Levi & 2003 & & Levi, 2003 \\
\hline Araneidae & Mecynogea bigibba & Simon & 1903 & & Levi, 1997 \\
\hline Araneidae & Mecynogea lemniscata & (Walckenaer) & 1842 & & Levi, 1997 \\
\hline Araneidae & Metazygia bahia & Levi & 1995 & & Levi, 1995a \\
\hline Araneidae & Metazygia barueri & Levi & 1995 & registro único & Levi, 1995a \\
\hline Araneidae & Metazygia crabroniphila & Strand & 1916 & & Levi, 1995a \\
\hline Araneidae & Metazygia cunha & Levi & 1995 & registro único & Levi, 1995a \\
\hline Araneidae & $\begin{array}{l}\text { Metazygia } \\
\text { gregalis }\end{array}$ & $\begin{array}{c}\text { (O.P. - } \\
\text { Cambridge })\end{array}$ & 1889 & sinantrópica & $\begin{array}{l}\text { Levi, 1995a; Mello-Leitão, 1949; } \\
\text { Indicatti \& Brescovit, } 2008\end{array}$ \\
\hline Araneidae & Metazygia ipanga & Levi & 1995 & registro único & Levi, 1995a \\
\hline Araneidae & Metazygia rogenhoferi & (Keyserling) & 1878 & & Levi, 1995a \\
\hline Araneidae & Metazygia viriosa & (Keyserling) & 1892 & & Levi, 1995a \\
\hline Araneidae & Metazygia voluptifica & (Keyserling) & 1892 & & Indicatti \& Brescovit 2008 \\
\hline Araneidae & Metazygia yobena & Levi & 1995 & & Levi, 1995a \\
\hline Araneidae & Metepeira compsa & (Chamberlin) & 1916 & & Piel, 2001 \\
\hline Araneidae & Metepeira glomerabilis & (Keyserling) & 1892 & & Piel, 2001 \\
\hline Araneidae & Micrathena acuta & (Walckenaer) & 1842 & & Petrunkevitch, 1910 \\
\hline Araneidae & Micrathena annulata & Reimoser & 1917 & & Levi, 1985 \\
\hline Araneidae & Micrathena brevispina & (Keyserling) & 1864 & & Petrunkevitch, 1910; Levi, 1985 \\
\hline Araneidae & Micrathena crassispina & (C.L. Koch) & 1836 & & Petrunkevitch, 1910; Levi, 1985 \\
\hline Araneidae & Micrathena digitata & (C.L. Koch) & 1839 & & Levi, 1985 \\
\hline Araneidae & Micrathena excavata & (C.L. Koch) & 1836 & & Levi, 1985 \\
\hline Araneidae & Micrathena fissispina & (C.L. Koch) & 1836 & & Levi, 1985 \\
\hline Araneidae & $\begin{array}{l}\text { Micrathena } \\
\text { flaveola }\end{array}$ & (C.L. Koch) & 1839 & & $\begin{array}{c}\text { Petrunkevitch, 1910; Mello-Leitão, } \\
\text { 1939h; Levi, } 1985\end{array}$ \\
\hline Araneidae & Micrathena furcata & (Hahn) & 1822 & & Petrunkevitch, 1910; Levi, 1985 \\
\hline Araneidae & Micrathena horrida & (Taczanowski) & 1873 & & Levi, 1985 \\
\hline Araneidae & Micrathena jundiai & Levi & 1985 & & Levi, 1985 \\
\hline Araneidae & Micrathena lata & Chickering & 1960 & & Levi, 1985 \\
\hline Araneidae & Micrathena lucasi & (Keyserling) & 1864 & & Levi, 1985 \\
\hline Araneidae & Micrathena macfarlanei & Chickering & 1961 & & Levi, 1985 \\
\hline Araneidae & Micrathena nigrichelis & Strand & 1908 & sinantrópica & Camargo, 1950a; Levi, 1985 \\
\hline Araneidae & Micrathena patruelis & (C.L. Koch) & 1839 & & Petrunkevitch, 1910; Levi, 1985 \\
\hline Araneidae & Micrathena peregrinatorum & (Holmberg) & 1883 & & Mello-Leitão, 1939h \\
\hline Araneidae & $\begin{array}{l}\text { Micrathena } \\
\text { plana }\end{array}$ & (C.L. Koch) & 1836 & & $\begin{array}{c}\text { Levi, 1985; } \\
\text { Gonzaga \& Vasconcellos-Neto, } 2005\end{array}$ \\
\hline Araneidae & Micrathena reali & Levi & 1985 & & Levi, 1985 \\
\hline Araneidae & Micrathena schenkeli & Mello-Leitão & 1939 & & Levi, 1985 \\
\hline Araneidae & Micrathena soaresi & Levi & 1985 & registro único & Levi, 1985 \\
\hline Araneidae & Micrathena spitzi & Mello-Leitão & 1932 & & Levi, 1985 \\
\hline Araneidae & Micrathena swainsoni & (Perty) & 1833 & & Levi, 1985 \\
\hline Araneidae & Micrathena teresopolis & Levi & 1985 & & Levi, 1985 \\
\hline Araneidae & Micrathena triangularis & (C.L. Koch) & 1836 & & Petrunkevitch, 1910; Levi, 1985 \\
\hline Araneidae & Neoscona moreli & (Vinson) & 1863 & & Levi, 1993a \\
\hline Araneidae & $\begin{array}{l}\text { Neoscona } \\
\text { nautica }\end{array}$ & (L.Koch) & 1875 & & $\begin{array}{c}\text { Levi, 1993a; } \\
\text { Indicatti \& Brescovit } 2008\end{array}$ \\
\hline Araneidae & Ocrepeira fiebrigi & (Dahl) & 1906 & & Levi, $1993 b$ \\
\hline Araneidae & Ocrepeira galianoae & Levi & 1993 & & Levi, 1993b \\
\hline Araneidae & Ocrepeira gnomo & (Mello-Leitão) & 1943 & & Levi, 1993b \\
\hline Araneidae & Ocrepeira hirsuta & (Mello-Leitão) & 1942 & & Indicatti \& Brescovit 2008 \\
\hline Araneidae & Ocrepeira jacara & Levi & 1993 & & Levi, $1993 b$ \\
\hline Araneidae & Ocrepeira venustula & (Keyserling) & 1879 & & Levi, 1993b \\
\hline
\end{tabular}


Tabela 1. Continuação...

\begin{tabular}{|c|c|c|c|c|c|}
\hline Família & spp. & Autor & Data & Destaque & Referências \\
\hline Araneidae & $\begin{array}{l}\text { Parawixia } \\
\text { audax }\end{array}$ & (Blackwall) & 1863 & & $\begin{array}{c}\text { Levi, 1992b; Rinaldi, } \\
\text { Mendes \& Cady, 2002; } \\
\text { Gonzaga \& Vasconcellos-Neto, } 2005\end{array}$ \\
\hline Araneidae & $\begin{array}{l}\text { Parawixia } \\
\text { bistriata }\end{array}$ & (Rengger) & 1836 & & $\begin{array}{l}\text { Levo, 1992b; } \\
\text { Rinaldi, Mendes \& Cady, 2002; } \\
\text { Indicatti \& Brescovit, } 2008\end{array}$ \\
\hline Araneidae & Parawixia inopinata & Camargo & 1950 & & Levi, 1992b \\
\hline Araneidae & Parawixia monticola & (Keyserling) & 1892 & & Levi, 1992b \\
\hline Araneidae & Parawixia undulata & (Keyserling) & 1892 & & Levi, 1992b \\
\hline Araneidae & $\begin{array}{l}\text { Parawixia } \\
\text { velutina }\end{array}$ & (Taczanowski) & 1878 & & $\begin{array}{c}\text { Levi, 1992b; } \\
\text { Indicatti \& Brescovit } 2008\end{array}$ \\
\hline Araneidae & Pozonia bacillifera & (Simon) & 1897 & & Levi, 1993b \\
\hline Araneidae & Scoloderus cordatus & (Taczanowski) & 1879 & & Traw, 1995 \\
\hline Araneidae & Taczanowskia mirabilis & Simon & 1897 & & Levi, 1996a \\
\hline Araneidae & Tatepeira itu & Levi & 1995 & & Levi, 1995b \\
\hline Araneidae & Verrucosa arenata & (Walckenaer) & 1842 & & Gonzaga \& Vasconcellos-Neto, 2005 \\
\hline Araneidae & Verrucosa meridionalis & (Keyserling) & 1892 & & Kessler, 1990 \\
\hline Araneidae & Verrucosa zebra & (Keyserling) & 1892 & & Kessler, 1990 \\
\hline Araneidae & Wagneriana eupalaestra & (Mello-Leitão) & 1943 & & Levi, 1991b \\
\hline Araneidae & Wagneriana gavensis & (Camargo) & 1950 & & Levi, 1991b \\
\hline Araneidae & Wagneriana heteracantha & (Mello-Leitão) & 1943 & & Levi, 1991b \\
\hline Araneidae & Wagneriana iguape & Levi & 1991 & & Levi, 1991b \\
\hline Araneidae & Wagneriana janeiro & Levi & 1991 & & Levi, 1991b \\
\hline Araneidae & Wagneriana juquia & Levi & 1991 & & Levi, 1991b \\
\hline Araneidae & Wagneriana neglecta & (Mello-Leitão) & 1939 & & Indicatti \& Brescovit 2008 \\
\hline Araneidae & Wagneriana taim & Levi & 1991 & & Levi, 1991b \\
\hline Araneidae & Wagneriana transitoria & (C.L. Koch) & 1839 & & Levi, 1991b \\
\hline Araneidae & Xylethrus ameda & Levi & 1996 & registro único & Levi, 1996b \\
\hline Araneidae & Xylethrus superbus & Simon & 1895 & & Levi, 1996b \\
\hline Barychelidae & Psalistops crassimanus & Mello-Leitão & 1923 & registro único & Mello-Leitão, 1923b \\
\hline Barychelidae & Psalistops nigrifemuratus & Mello-Leitão & 1939 & registro único & Mello-Leitão, 1939f \\
\hline Caponiidae & Nops meridionalis & Keyserling & 1891 & & Mello-Leitão, 1919 \\
\hline Clubionidae & $\begin{array}{l}\text { Elaver } \\
\text { brevipes }\end{array}$ & (Keyserling) & 1891 & & $\begin{array}{l}\text { Brescovit \& Bonaldo, 1992; } \\
\text { Indicatti \& Brescovit, } 2008\end{array}$ \\
\hline Corinnidae & $\begin{array}{c}\text { Abapeba } \\
\text { rioclaro }\end{array}$ & Bonaldo & 2000 & & $\begin{array}{c}\text { Bonaldo, 2000; } \\
\text { Indicatti \& Brescovit, } 2008\end{array}$ \\
\hline Corinnidae & Abapeba sicarioides & (Mello-Leitão) & 1935 & & Indicatti \& Brescovit 2008 \\
\hline Corinnidae & Attacobius attarum & (Roewer) & 1935 & & Indicatti \& Brescovit 2008 \\
\hline Corinnidae & Attacobius luederwaldti & (Mello-Leitão) & 1923 & & Platnick \& Baptista, 1995 \\
\hline Corinnidae & $\begin{array}{c}\text { Castianeira } \\
\text { littoralis }\end{array}$ & Mello-Leitão & 1926 & registro único & $\begin{array}{c}\text { Mello-Leitão, 1926b; } \\
\text { Indicatti \& Brescovit, } 2008\end{array}$ \\
\hline Corinnidae & Castianeira maculata & Keyserling & 1891 & & Keyserling, 1891 \\
\hline Corinnidae & Castianeira obscura & Keyserling & 1891 & & Camargo, 1953 \\
\hline Corinnidae & Castianeira pyriformis & Keyserling & 1891 & & Keyserling, 1891 \\
\hline Corinnidae & Castianeira scutata & Schmidt & 1971 & registro único & Schmidt, 1971 \\
\hline Corinnidae & Corinna bicincta & Simon & 1896 & & Camargo, 1953 \\
\hline Corinnidae & Corinna botucatensis & (Keyserling) & 1891 & registro único & Keyserling, 1891 \\
\hline Corinnidae & $\begin{array}{c}\text { Corinna } \\
\text { bristoweana }\end{array}$ & Mello-Leitão & 1926 & registro único & $\begin{array}{c}\text { Mello-Leitão, 1926b; } \\
\text { Indicatti \& Brescovit, } 2008\end{array}$ \\
\hline Corinnidae & Corinna capito & (Lucas) & 1856 & & Camargo, 1950a; Bonaldo, 2000 \\
\hline Corinnidae & $\begin{array}{l}\text { Corinna } \\
\text { colombo }\end{array}$ & Bonaldo & 2000 & & $\begin{array}{c}\text { Bonaldo, 2000; } \\
\text { Indicatti \& Brescovit, } 2008\end{array}$ \\
\hline
\end{tabular}


Tabela 1. Continuação...

\begin{tabular}{|c|c|c|c|c|c|}
\hline Família & spp. & Autor & Data & Destaque & Referências \\
\hline Corinnidae & Corinna ignota & Mello-Leitão & 1922 & & Mello-Leitão, 1922b \\
\hline Corinnidae & Corinna loricata & (Bertkau) & 1880 & & Keyserling, 1891; Mello-Leitão, 1920 \\
\hline Corinnidae & $\begin{array}{l}\text { Corinna } \\
\text { mourai }\end{array}$ & Bonaldo & 2000 & & $\begin{array}{c}\text { Bonaldo, 2000; } \\
\text { Indicatti \& Brescovit, } 2008\end{array}$ \\
\hline Corinnidae & Corinna nitens & (Keyserling) & 1891 & sinantrópica & Bonaldo, 2000 \\
\hline Corinnidae & Creugas gulosus & Thorell & 1878 & sinantrópica & Bonaldo, 2000 \\
\hline Corinnidae & Creugas lisei & Bonaldo & 2000 & & Bonaldo, 2000 \\
\hline Corinnidae & $\begin{array}{l}\text { Falconina } \\
\text { gracilis }\end{array}$ & (Keyserling) & 1891 & sinantrópica & $\begin{array}{l}\text { Bonaldo, 2000; Rinaldi, Mendes \& } \\
\text { Cady, 2002; Indicatti \& Brescovit, } \\
2008\end{array}$ \\
\hline Corinnidae & Ianduba varia & (Keyserling) & 1891 & sinantrópica & Bonaldo, 1997a \\
\hline Corinnidae & Meriola cetiformis & (Strand) & 1908 & & Platnick \& Ewing, 1995 \\
\hline Corinnidae & Myrmecium gounellei & Simon & 1896 & & Camargo, 1953 \\
\hline Corinnidae & Myrmecium rufum & Latreille & 1824 & & Camargo, 1953 \\
\hline Corinnidae & $\begin{array}{l}\text { Paradiestus } \\
\text { aurantiacus }\end{array}$ & Mello-Leitão & 1915 & & $\begin{array}{c}\text { Bonaldo, 2000; } \\
\text { Indicatti \& Brescovit } 2008\end{array}$ \\
\hline Corinnidae & $\begin{array}{l}\text { Paradiestus } \\
\text { giganteus }\end{array}$ & (Karsch) & 1880 & & $\begin{array}{c}\text { Bonaldo, 2000; } \\
\text { Indicatti \& Brescovit } 2008\end{array}$ \\
\hline Corinnidae & $\begin{array}{l}\text { Paradiestus } \\
\text { penicillatus }\end{array}$ & (Mello-Leitão) & 1939 & & $\begin{array}{c}\text { Camargo, 1953; } \\
\text { Indicatti \& Brescovit } 2008\end{array}$ \\
\hline Corinnidae & Trachelas robustus & Keyserling & 1891 & & Camargo, 1953 \\
\hline Corinnidae & Trachelas rugosus & Keyserling & 1891 & & Camargo, 1953 \\
\hline Corinnidae & $\begin{array}{l}\text { Trachelopachys } \\
\text { caviunae }\end{array}$ & (Mello-Leitão) & 1947 & & $\begin{array}{l}\text { Platnick \& Rocha, 1995; } \\
\text { Rinaldi \& Forti, } 1997\end{array}$ \\
\hline Corinnidae & Trachelopachys ignacio & Platnick & 1975 & & Rinaldi \& Forti, 1996 \\
\hline Corinnidae & Xeropigo flavipes & (Keyserling) & 1891 & & Mello-Leitão, 1923a \\
\hline Corinnidae & $\begin{array}{l}\text { Xeropigo } \\
\text { tridentiger }\end{array}$ & $\begin{array}{c}\text { (O.P.- } \\
\text { Cambridge) }\end{array}$ & 1869 & sinantrópica & $\begin{array}{l}\text { Bonaldo, 2000; Souza \& Bonaldo, } \\
\text { 2007; Indicatti \& Brescovit } 2008\end{array}$ \\
\hline Ctenidae & Acanthoctenus mammiferus & Mello-Leitão & 1939 & & Mello-Leitão, 1939f \\
\hline Ctenidae & $\begin{array}{l}\text { Ancylometes } \\
\text { concolor }\end{array}$ & Perty & 1833 & & $\begin{array}{c}\text { Cambridge F.O.P, 1897b; Hofer \& } \\
\text { Brescovit, } 2000\end{array}$ \\
\hline Ctenidae & Ancylometes rufus & (Walckenaer) & 1837 & & Hofer \& Brescovit, 2000 \\
\hline Ctenidae & $\begin{array}{l}\text { Asthenoctenus } \\
\text { borellii }\end{array}$ & Simon & 1897 & & $\begin{array}{l}\text { Brescovit \& Simó, 1998; } \\
\text { Indicatti \& Brescovit, } 2008\end{array}$ \\
\hline Ctenidae & Centroctenus sai & Brescovit & 1996 & & Brescovit, 1996 \\
\hline Ctenidae & $\begin{array}{l}\text { Ctenus } \\
\text { fasciatus }\end{array}$ & Mello-Leitão & 1943 & & $\begin{array}{l}\text { Mello-Leitão, 1943; Pinto-Da-Rocha, } \\
\text { 1995; Gnaspini \& Trajano, } 1994\end{array}$ \\
\hline Ctenidae & Ctenus griseolus & Mello-Leitão & 1936 & & Pinto-Da-Rocha, 1995 \\
\hline Ctenidae & Ctenus longipes & Strand & 1915 & & Indicatti \& Brescovit 2008 \\
\hline Ctenidae & Ctenus medius & Keyserling & 1891 & sinantrópica & Bescovit \& Simó, 2007 \\
\hline Ctenidae & Ctenus ornatus & Keyserling & 1877 & sinantrópica & Bescovit \& Simó, 2007 \\
\hline Ctenidae & Ctenus sanguineus & Walckenaer & 1837 & & Strand, 1936 \\
\hline Ctenidae & $\begin{array}{l}\text { Ctenus } \\
\text { semiornatus }\end{array}$ & Mello-Leitão & 1939 & registro único & $\begin{array}{c}\text { Mello-Leitão, 1939f; } \\
\text { Indicatti \& Brescovit, } 2008\end{array}$ \\
\hline Ctenidae & $\begin{array}{l}\text { Ctenus } \\
\text { tarsalis }\end{array}$ & $\begin{array}{l}\text { F.O.P. - } \\
\text { Cambridge }\end{array}$ & 1902 & & Indicatti \& Brescovit 2008 \\
\hline Ctenidae & $\begin{array}{l}\text { Enoploctenus } \\
\text { cyclothorax }\end{array}$ & (Bertkau) & 1897 & & $\begin{array}{c}\text { Strand, 1936; } \\
\text { Indicatti \& Brescovit, } 2008\end{array}$ \\
\hline Ctenidae & $\begin{array}{l}\text { Gephyroctenus } \\
\text { philodromoides }\end{array}$ & Mello-Leitão & 1936 & & Polotow \& Brescovit, 2008 \\
\hline Ctenidae & $\begin{array}{l}\text { Isoctenus } \\
\text { coxalis }\end{array}$ & $\begin{array}{c}\text { F.O. P. } \\
\text { Cambridge }\end{array}$ & 1902 & & $\begin{array}{l}\text { Polotow, Brescovit \& Pelleganti- } \\
\text { Franco, 2005; } \\
\text { Polotow \& Brescovit, } 2009\end{array}$ \\
\hline
\end{tabular}


Tabela 1. Continuação...

\begin{tabular}{|c|c|c|c|c|c|}
\hline Família & spp. & Autor & Data & Destaque & Referências \\
\hline Ctenidae & Isoctenus eupalaestrus & Mello-Leitão & 1936 & & Polotow \& Brescovit, 2009 \\
\hline Ctenidae & Isoctenus foliifer & Bertkau & 1880 & & Mello-Leitão, 1936a \\
\hline Ctenidae & $\begin{array}{l}\text { Isoctenus } \\
\text { janeirus }\end{array}$ & Walckenaer & 1837 & & $\begin{array}{c}\text { Mello-Leitão, 1936a; } \\
\text { Polotow \& Brescovit, } 2009\end{array}$ \\
\hline Ctenidae & $\begin{array}{l}\text { Isoctenus } \\
\text { ordinario }\end{array}$ & $\begin{array}{c}\text { Polotow \& } \\
\text { Brescovit }\end{array}$ & 2005 & sinantrópica & $\begin{array}{l}\text { Polotow \& Brescovit, 2005; } \\
\text { Polotow \& Brescovit, } 2009\end{array}$ \\
\hline Ctenidae & Isoctenus strandi & Mello-Leitão & 1936 & & Polotow \& Brescovit, 2009 \\
\hline Ctenidae & $\begin{array}{l}\text { Itatiaya } \\
\text { apidema }\end{array}$ & $\begin{array}{c}\text { Polotow \& } \\
\text { Brescovit }\end{array}$ & 2006 & & Polotow \& Brescovit, 2006 \\
\hline Ctenidae & $\begin{array}{l}\text { Itatiaya } \\
\text { iuba }\end{array}$ & $\begin{array}{c}\text { Polotow \& } \\
\text { Brescovit }\end{array}$ & 2006 & & Polotow \& Brescovit, 2006 \\
\hline Ctenidae & Itatiaya modesta & Mello-Leitão & 1915 & & Polotow \& Brescovit, 2006 \\
\hline Ctenidae & $\begin{array}{l}\text { Nothroctenus } \\
\text { marshii }\end{array}$ & $\begin{array}{c}\text { (F.O.P. - } \\
\text { Cambridge) }\end{array}$ & 1897 & & $\begin{array}{c}\text { Mello-Leitão, 1936c; } \\
\text { Indicatti \& Brescovit, } 2008\end{array}$ \\
\hline Ctenidae & Parabatinga brevipes & Keyserling & 1891 & & Polotow \& Brescovit, 2009 \\
\hline Ctenidae & $\begin{array}{l}\text { Phoneutria } \\
\text { boliviensis }\end{array}$ & $\begin{array}{c}\text { (F.O.P. - } \\
\text { Cambridge) }\end{array}$ & 1897 & & Simó \& Brescovit, 2001 \\
\hline Ctenidae & Phoneutria fera & Perty & 1833 & & Simó \& Brescovit, 2001 \\
\hline Ctenidae & $\begin{array}{l}\text { Phoneutria } \\
\text { keyserlingi }\end{array}$ & $\begin{array}{c}\text { (F.O.P. - } \\
\text { Cambridge) }\end{array}$ & 1897 & sinantrópica & Martins \& Bertani, 2007 \\
\hline Ctenidae & $\begin{array}{l}\text { Phoneutria } \\
\text { nigriventer }\end{array}$ & (Keyserling) & 1891 & sinantrópica & $\begin{array}{l}\text { Simó \& Brescovit, 2001; } \\
\text { Martins \& Bertani, } 2007\end{array}$ \\
\hline Ctenidae & Phoneutria rufibarbis & (Perty) & 1833 & & Mello-Leitão, 1923b \\
\hline Ctenizidae & Ctenochelus maculatus & Mello-Leitão & 1923 & & Mello-Leitão, 1923a \\
\hline Cyrtaucheniidae & Fufius lucasae & (Simon) & 1891 & & Indicatti \& Brescovit 2008 \\
\hline Deinopidae & Deinopis pallida & Mello-Leitão & 1939 & registro único & Mello-Leitão, 1939f \\
\hline Dipluridae & Diplura garbei & Mello-Leitão & 1923 & & Mello-Leitão, 1923a \\
\hline Dipluridae & Diplura studiosa & (Mello-Leitão) & 1920 & & Mello-Leitão, 1923a \\
\hline Dipluridae & Diplura taunayi & (Mello-Leitão) & 1923 & registro único & Mello-Leitão, 1923a \\
\hline Dipluridae & Diplura uniformis & (Mello-Leitão) & 1923 & & Mello-Leitão, 1941c \\
\hline Dipluridae & Ischnothele annulata & Tullgren & 1905 & & Coyle, 1995 \\
\hline Dipluridae & Linothele paulistana & (Mello-Leitão) & 1924 & registro único & Mello-Leitão, 1926a \\
\hline Dipluridae & $\begin{array}{l}\text { Trechona } \\
\text { rufa }\end{array}$ & Vellard & 1924 & & $\begin{array}{l}\text { Vellard, 1924a; Pedroso, } \\
\text { Baptista \& Ferreira, } 2008\end{array}$ \\
\hline Dipluridae & $\begin{array}{l}\text { Trechona } \\
\text { uniformis }\end{array}$ & Mello-Leitão & 1935 & registro único & $\begin{array}{c}\text { Mello-Leitão, 1923a; Pedroso, } \\
\text { Baptista \& Ferreira, } 2008\end{array}$ \\
\hline Filistatidae & $\begin{array}{l}\text { Kukulcania } \\
\text { hibernalis }\end{array}$ & (Hentz) & 1842 & $\begin{array}{l}\text { introduzida, } \\
\text { sinantrópica }\end{array}$ & Indicatti \& Brescovit 2008 \\
\hline Filistatidae & Misionella mendensis & (Mello-Leitão) & 1920 & sinantrópica & Grismado \& Ramirez, 2000 \\
\hline Gnaphosidae & $\begin{array}{l}\text { Apodrassodes } \\
\text { guatemalensis }\end{array}$ & $\begin{array}{c}\text { (F.O.P. - } \\
\text { Cambridge) }\end{array}$ & 1899 & & $\begin{array}{l}\text { Platnick \& Shadab, 1983b; } \\
\text { Brescovit \& Lise, 1993a }\end{array}$ \\
\hline Gnaphosidae & Apodrassodes mono & Müller & 1987 & & Brescovit \& Lise, 1993a \\
\hline Gnaphosidae & $\begin{array}{l}\text { Apopyllus } \\
\text { iheringi }\end{array}$ & (Mello-Leitão) & 1943 & & $\begin{array}{c}\text { Platnick \& Shadab, 1984; } \\
\text { Rinaldi, Mendes \& Cady, } 2002\end{array}$ \\
\hline Gnaphosidae & Apopyllus isabelae & Brescovit \& Lise & 1993 & registro único & Brescovit \& Lise, 1993a \\
\hline Gnaphosidae & $\begin{array}{l}\text { Camillina } \\
\text { chilensis }\end{array}$ & (Simon) & 1902 & & $\begin{array}{l}\text { Platnick \& Shadab, 1982b; } \\
\text { Indicatti \& Brescovit, } 2008\end{array}$ \\
\hline Gnaphosidae & $\begin{array}{l}\text { Camillina } \\
\text { claro }\end{array}$ & $\begin{array}{l}\text { Platnick \& } \\
\text { Shadab }\end{array}$ & 1982 & & $\begin{array}{l}\text { Platnick \& Shadab, 1982b; } \\
\text { Rinaldi \& Forti, } 1997\end{array}$ \\
\hline Gnaphosidae & $\begin{array}{l}\text { Camillina } \\
\text { cordoba }\end{array}$ & $\begin{array}{l}\text { Platnick \& } \\
\text { Shadab }\end{array}$ & 1987 & registro único & Rinaldi \& Forti, 1997 \\
\hline Gnaphosidae & Camillina major & (Keyserling) & 1891 & & Mello-Leitão, 1919 \\
\hline Gnaphosidae & Camillina minuta & (Mello-Leitão) & 1941 & registro único & Rinaldi \& Forti, 1997 \\
\hline
\end{tabular}


Tabela 1. Continuação...

\begin{tabular}{|c|c|c|c|c|c|}
\hline Família & spp. & Autor & Data & Destaque & Referências \\
\hline Gnaphosidae & $\begin{array}{l}\text { Camillina } \\
\text { nova }\end{array}$ & $\begin{array}{l}\text { Platnick \& } \\
\text { Shadab }\end{array}$ & 1982 & & $\begin{array}{l}\text { Platnick \& Shadab, 1982b; } \\
\text { Platnick \& Murphy, } 1987\end{array}$ \\
\hline Gnaphosidae & $\begin{array}{l}\text { Camillina } \\
\text { pilar }\end{array}$ & $\begin{array}{l}\text { Platnick \& } \\
\text { Murphy }\end{array}$ & 1987 & registro único & Rinaldi \& Forti, 1997 \\
\hline Gnaphosidae & $\begin{array}{l}\text { Camillina } \\
\text { pulchra }\end{array}$ & (Keyserling) & 1891 & & $\begin{array}{l}\text { Rinaldi \& Forti, 1997; Rinaldi, } \\
\text { Mendes \& Cady, } 2002\end{array}$ \\
\hline Gnaphosidae & Echemus inermis & Mello-Leitão & 1939 & registro único & Mello-Leitão, 1939h \\
\hline Gnaphosidae & $\begin{array}{l}\text { Eilica } \\
\text { maculipes }\end{array}$ & (Vellard) & 1925 & & $\begin{array}{c}\text { Platnick, 1977h; } \\
\text { Rinaldi \& Forti, } 1997\end{array}$ \\
\hline Gnaphosidae & Eilica modesta & Keyserling & 1891 & & Platnick, 1975c; Platnick, 1977h \\
\hline Gnaphosidae & Urozelotes rusticus & (L.Koch) & 1872 & sinantrópica & Platnick \& Murphy, 1984 \\
\hline Gnaphosidae & $\begin{array}{l}\text { Vectius } \\
\text { niger }\end{array}$ & Simon & 1880 & & $\begin{array}{l}\text { Mello-Leitão, 1917; } \\
\text { Mello-Leitão, 1939h }\end{array}$ \\
\hline Gnaphosidae & $\begin{array}{l}\text { Zimiromus } \\
\text { buzios }\end{array}$ & $\begin{array}{l}\text { Brescovit \& } \\
\text { Buckup }\end{array}$ & 1998 & registro único & Brescovit \& Buckup, 1998 \\
\hline Gnaphosidae & Zimiromus medius & (Keyserling) & 1891 & & Platnick \& Shadab, 1976e \\
\hline Gnaphosidae & $\begin{array}{l}\text { Zimiromus } \\
\text { montenegro }\end{array}$ & $\begin{array}{l}\text { Brescovit \& } \\
\text { Buckup }\end{array}$ & 1993 & & Buckup \& Brescovit, 1993 \\
\hline Gnaphosidae & $\begin{array}{l}\text { Zimiromus } \\
\text { sununga }\end{array}$ & $\begin{array}{l}\text { Brescovit \& } \\
\text { Buckup }\end{array}$ & 1993 & & Buckup \& Brescovit, 1993 \\
\hline Gnaphosidae & $\begin{array}{l}\text { Zimiromus } \\
\text { tapirape }\end{array}$ & $\begin{array}{l}\text { Brescovit \& } \\
\text { Buckup }\end{array}$ & 1998 & & Brescovit \& Buckup, 1998 \\
\hline Hahniidae & Hahnia simoni & Mello-Leitão & 1919 & registro único & Mello-Leitão, 1919 \\
\hline Hersiliidae & $\begin{array}{l}\text { Iviraiva } \\
\text { pachyura }\end{array}$ & (Mello-Leitão) & 1935 & & $\begin{array}{c}\text { Piza, 1937c; } \\
\text { Rheims \& Brescovit, } 2004\end{array}$ \\
\hline Hersiliidae & $\begin{array}{l}\text { Neotama } \\
\text { cunhabebe }\end{array}$ & $\begin{array}{l}\text { Rheims \& } \\
\text { Brescovit }\end{array}$ & 2004 & & Rheims \& Brescovit, 2004 \\
\hline Hersiliidae & Ypypuera crucifera & (Vellard) & 1924 & & Rheims \& Brescovit, 2004 \\
\hline Idiopidae & $\begin{array}{l}\text { Idiops } \\
\text { camelus }\end{array}$ & (Mello-Leitão) & 1937 & & $\begin{array}{c}\text { Mello-Leitão, 1937a; } \\
\text { Indicatti \& Brescovit, } 2008\end{array}$ \\
\hline Idiopidae & Idiops montealegrensis & Soares & 1944 & & Soares, 1944a \\
\hline Idiopidae & Neocteniza australis & Goloboff & 1987 & registro único & Fukami, Lucas \& Indicatti, 2004 \\
\hline Linyphiidae & $\begin{array}{l}\text { Anodoration } \\
\text { claviferum }\end{array}$ & Millidge & 1991 & & $\begin{array}{c}\text { Millidge, 1991; } \\
\text { Indicatti \& Brescovit, } 2008\end{array}$ \\
\hline Linyphiidae & Anodoration tantillum & (Millidge) & 1991 & registro único & Millidge, 1991 \\
\hline Linyphiidae & Sphecozone castanea & Millidge & 1991 & registro único & Millidge, 1991 \\
\hline Linyphiidae & Dubiaranea argenteovittata & Mello-Leitão & 1943 & & Indicatti \& Brescovit 2008 \\
\hline Linyphiidae & Eurymorion nobile & (Millidge) & 1991 & registro único & Millidge, 1991 \\
\hline Linyphiidae & Linyphia cylindrata & (Keyserling) & 1891 & registro único & Keyserling, 1891 \\
\hline Linyphiidae & Lygarina silvicola & Millidge & 1991 & registro único & Millidge, 1991 \\
\hline Linyphiidae & Neriene redacta & Chamberlin & 1925 & registro único & Rinaldi, Mendes \& Cady, 2002 \\
\hline Linyphiidae & Notiohyphantes laudatus & Millidge & 1991 & registro único & Millidge, 1991 \\
\hline Linyphiidae & Pseudotyphistes cristatus & Ott \& Lise & 1997 & & Indicatti \& Brescovit 2008 \\
\hline Linyphiidae & Scolecura parilis & Millidge & 1991 & & Millidge, 1991 \\
\hline Linyphiidae & Sphecozone cristata & Millidge & 1991 & & Millidge, 1991 \\
\hline Linyphiidae & Sphecozone ignigena & Millidge & 1991 & & Indicatti \& Brescovit 2008 \\
\hline Linyphiidae & Sphecozone nigriceps & Millidge & 1991 & & Millidge, 1991 \\
\hline Linyphiidae & Sphecozone personata & (Simon) & 1894 & & Indicatti \& Brescovit 2008 \\
\hline Linyphiidae & $\begin{array}{l}\text { Sphecozone } \\
\text { rubescens }\end{array}$ & O.P.- Cambridge & 1870 & & $\begin{array}{l}\text { Rinaldi, Mendes \& Cady, 2002; } \\
\text { Indicatti \& Brescovit, } 2008\end{array}$ \\
\hline Linyphiidae & Sphecozone venialis & (Keyserling) & 1886 & & Indicatti \& Brescovit 2008 \\
\hline Linyphiidae & Tutaibo tristis & Millidge & 1991 & & Millidge, 1991 \\
\hline Linyphiidae & Vesicapalpus simplex & Millidge & 1991 & & Indicatti \& Brescovit 2008 \\
\hline
\end{tabular}


Tabela 1. Continuação...

\begin{tabular}{|c|c|c|c|c|c|}
\hline Família & spp. & Autor & Data & Destaque & Referências \\
\hline Lycosidae & Aglaoctenus castaneus & (Mello-Leitão) & 1942 & & Santos \& Brescovit, 2001 \\
\hline Lycosidae & $\begin{array}{l}\text { Aglaoctenus } \\
\text { lagotis }\end{array}$ & (Holmberg) & 1876 & & $\begin{array}{c}\text { Mello-Leitão, 1917a; Capocasale, } \\
\text { 2001; Santos \& Brescovit, 2001; } \\
\text { Gonzaga \& Vasconcellos-Neto, } 2005\end{array}$ \\
\hline Lycosidae & Allocosa brasiliensis & (Petrunkevitch) & 1910 & registro único & Petrunkevitch, 1910 \\
\hline Lycosidae & $\begin{array}{l}\text { Arctosa } \\
\text { humicola }\end{array}$ & (Bertkau) & 1880 & & $\begin{array}{c}\text { Mello-Leitão, 1943a; } \\
\text { Indicatti \& Brescovit, 2008 }\end{array}$ \\
\hline Lycosidae & $\begin{array}{c}\text { Hogna } \\
\text { pardalina }\end{array}$ & (Bertkau) & 1880 & & $\begin{array}{c}\text { Mello-Leitão, 1943a; } \\
\text { Indicatti \& Brescovit, } 2008\end{array}$ \\
\hline Lycosidae & Hogna sternalis & (Bertkau) & 1880 & & Indicatti \& Brescovit 2008 \\
\hline Lycosidae & $\begin{array}{c}\text { Lycosa } \\
\text { auroguttata }\end{array}$ & (Keyserling) & 1891 & & $\begin{array}{c}\text { Mello-Leitão, 1943a; } \\
\text { Indicatti \& Brescovit, 2008 }\end{array}$ \\
\hline Lycosidae & Lycosa erythrognatha & Lucas & 1836 & sinantrópica & Indicatti \& Brescovit 2008 \\
\hline Lycosidae & $\begin{array}{l}\text { Lycosa } \\
\text { nordenskjoldi }\end{array}$ & Tullgren & 1905 & & $\begin{array}{c}\text { Zimber, 1963; } \\
\text { Indicatti \& Brescovit, } 2008\end{array}$ \\
\hline Lycosidae & $\begin{array}{l}\text { Lycosa } \\
\text { sericovittata }\end{array}$ & Mello-Leitão & 1939 & registro único & $\begin{array}{c}\text { Mello-Leitão, 1939f; } \\
\text { Indicatti \& Brescovit, } 2008\end{array}$ \\
\hline Lycosidae & Lycosa tarantuloides & Perty & 1833 & & Indicatti \& Brescovit 2008 \\
\hline Lycosidae & $\begin{array}{l}\text { Lycosa } \\
\text { thorelli }\end{array}$ & (Keyserling) & 1877 & & $\begin{array}{l}\text { Mello-Leitão, 1919; Mello-Leitão, } \\
\text { 1923b; Indicatti \& Brescovit, } 2008\end{array}$ \\
\hline Lycosidae & Molitorosa molitor & (Bertkau) & 1880 & & Indicatti \& Brescovit 2008 \\
\hline Lycosidae & Schizocosa chelifasciata & (Mello-Leitão) & 1943 & & Indicatti \& Brescovit 2008 \\
\hline Lycosidae & Trochosa pardaloides & (Mello-Leitão) & 1937 & & Indicatti \& Brescovit 2008 \\
\hline Mimetidae & Arochoides integrans & Mello-Leitão & 1935 & registro único & Mello-Leitão, 1935b \\
\hline Mimetidae & Ero catharinae & Keyserling & 1886 & & Mello-Leitão, 1941c \\
\hline Mimetidae & Ero lata & Keyserling & 1891 & & Mello-Leitão, 1941c \\
\hline Mimetidae & Gelanor insularis & Mello-Leitão & 1929 & registro único & Mello-Leitão, 1929b \\
\hline Mimetidae & Gelanor lanei & Soares & 1941 & registro único & Soares, 1941 \\
\hline Mimetidae & Gelanor zonatus & (C.L.Koch) & 1845 & & Mello-Leitão, 1939h \\
\hline Mimetidae & Oarces ornatus & Mello-Leitão & 1935 & registro único & Mello-Leitão, 1935b \\
\hline Miturgidae & $\begin{array}{l}\text { Cheiracanthium } \\
\text { inclusum }\end{array}$ & (Hentz) & 1847 & sinantrópica & $\begin{array}{l}\text { Bonaldo \& Brescovit, 1992; } \\
\text { Rinaldi \& Forti, 1997; } \\
\text { Rinaldi, Mendes \& Cady, } 2002\end{array}$ \\
\hline Miturgidae & Cheiracanthium montanum & Keyserling & 1891 & & Keyserling, 1891 \\
\hline Miturgidae & Eutichurus ibiuna & Bonaldo & 1994 & registro único & Bonaldo, 1994 \\
\hline Miturgidae & Eutichurus ravidus & Simon & 1897 & & Bonaldo, 1994 \\
\hline Miturgidae & $\begin{array}{l}\text { Radulphius } \\
\text { barueri }\end{array}$ & $\begin{array}{l}\text { Bonaldo \& } \\
\text { Buckup }\end{array}$ & 1995 & registro único & $\begin{array}{l}\text { Bonaldo \& Buckup, 1995; } \\
\text { Indicatti \& Brescovit, } 2008\end{array}$ \\
\hline Miturgidae & Radulphius bicolor & Keyserling & 1891 & & Keyserling, 1891 \\
\hline Miturgidae & $\begin{array}{l}\text { Radulphius } \\
\text { boraceia }\end{array}$ & $\begin{array}{l}\text { Bonaldo \& } \\
\text { Buckup }\end{array}$ & 1995 & registro único & Bonaldo \& Buckup, 1995 \\
\hline Miturgidae & Radulphius camacan & Bonaldo & 1994 & & Bonaldo \& Buckup, 1995 \\
\hline Miturgidae & $\begin{array}{l}\text { Radulphius } \\
\text { lane }\end{array}$ & $\begin{array}{l}\text { Bonaldo \& } \\
\text { Buckup }\end{array}$ & 1995 & registro único & $\begin{array}{l}\text { Bonaldo \& Buckup, 1995; } \\
\text { Brescovit \& Bonaldo, } 2005\end{array}$ \\
\hline Miturgidae & $\begin{array}{l}\text { Radulphius } \\
\text { laticeps }\end{array}$ & Keyserling & 1891 & & $\begin{array}{l}\text { Bonaldo \& Buckup, 1995; } \\
\text { Brescovit \& Bonaldo, } 2005\end{array}$ \\
\hline Miturgidae & $\begin{array}{l}\text { Radulphius } \\
\quad \text { latus }\end{array}$ & $\begin{array}{l}\text { Bonaldo \& } \\
\text { Buckup }\end{array}$ & 1995 & registro único & Bonaldo \& Buckup, 1995 \\
\hline Miturgidae & Strotarchus tropicus & Mello-Leitão & 1917 & & Indicatti \& Brescovit 2008 \\
\hline Miturgidae & $\begin{array}{l}\text { Teminius } \\
\text { insularis }\end{array}$ & (Lucas) & 1857 & sinantrópica & $\begin{array}{c}\text { Platnick \& Shadab, 1989; } \\
\text { Rinaldi, Mendes \& Cady, } 2002\end{array}$ \\
\hline Mysmenidae & $\begin{array}{l}\text { Trogloneta } \\
\text { cantareira }\end{array}$ & $\begin{array}{c}\text { Brescovit \& } \\
\text { Lopardo }\end{array}$ & 2008 & & $\begin{array}{l}\text { Brescovit \& Lopardo, 2008; } \\
\text { Indicatti \& Brescovit, } 2008\end{array}$ \\
\hline
\end{tabular}


Tabela 1. Continuação...

\begin{tabular}{|c|c|c|c|c|c|}
\hline Família & spp. & Autor & Data & Destaque & Referências \\
\hline Mysmenidae & $\begin{array}{l}\text { Trogloneta } \\
\text { mourai }\end{array}$ & $\begin{array}{l}\text { Brescovit \& } \\
\text { Lopardo }\end{array}$ & 2008 & & Brescovit \& Lopardo, 2008 \\
\hline Nemesiidae & $\begin{array}{l}\text { Neostothis } \\
\quad \text { gigas }\end{array}$ & Vellard & 1925 & & $\begin{array}{l}\text { Vellard, 1925; Lucas, Passanha, Janini } \\
\text { \& Indicatti, } 2008\end{array}$ \\
\hline Nemesiidae & Prorachias bristowei & Mello-Leitão & 1924 & & Indicatti \& Brescovit 2008 \\
\hline Nemesiidae & $\begin{array}{l}\text { Psalistopoides } \\
\text { fulvimanus }\end{array}$ & Mello-Leitão & 1934 & & $\begin{array}{l}\text { Mello-Leitão, 1934c; } \\
\text { Lucas \& Indicatti, } 2006\end{array}$ \\
\hline Nemesiidae & $\begin{array}{l}\text { Pycnothele } \\
\text { perdita }\end{array}$ & Chamberlin & 1917 & & $\begin{array}{c}\text { Mello-Leitão, 1935a; } \\
\text { Indicatti \& Brescovit, } 2008\end{array}$ \\
\hline Nemesiidae & Pycnothele piracicabensis & (Piza) & 1938 & registro único & Piza, 1938a \\
\hline Nemesiidae & $\begin{array}{c}\text { Pycnothele } \\
\text { singularis }\end{array}$ & (Mello-Leitão) & 1934 & registro único & $\begin{array}{c}\text { Mello-Leitão, 1934c; } \\
\text { Indicatti \& Brescovit, } 2008\end{array}$ \\
\hline Nemesiidae & $\begin{array}{l}\text { Rachias } \\
\text { brachytelus }\end{array}$ & (Mello-Leitão) & 1937 & registro único & $\begin{array}{c}\text { Mello-Leitão, 1937a; } \\
\text { Indicatti \& Brescovit, } 2008\end{array}$ \\
\hline Nemesiidae & Rachias caudatus & (Piza) & 1939 & registro único & Piza, 1939a \\
\hline Nemesiidae & Rachias piracicabensis & (Mello-Leitão) & 1937 & & Indicatti \& Brescovit 2008 \\
\hline Nemesiidae & $\begin{array}{l}\text { Stenoteromata } \\
\text { melloleitaoi }\end{array}$ & $\begin{array}{l}\text { Guadanucci \& } \\
\text { Indicatti }\end{array}$ & 2004 & & Indicatti \& Brescovit 2008 \\
\hline Nephilidae & Nephila clavipes & (Linnaeus) & 1767 & sinantrópica & Indicatti \& Brescovit 2008 \\
\hline Nephilidae & Nephila sexpunctata & Giebel & 1867 & & Levi \& Eickstedt, 1989 \\
\hline Nephilidae & $\begin{array}{l}\text { Nephilengys } \\
\text { cruentata }\end{array}$ & (Fabricius) & 1775 & $\begin{array}{l}\text { introduzida, } \\
\text { sinantrópica }\end{array}$ & $\begin{array}{l}\text { Levi \& Eickstedt, 1989; } \\
\text { Kuntner, } 2007\end{array}$ \\
\hline Nesticidae & Eidmannella pallida & (Emerton) & 1875 & sinantrópica & Indicatti \& Brescovit 2008 \\
\hline Nesticidae & $\begin{array}{l}\text { Nesticus } \\
\text { brasiliensis }\end{array}$ & Brignoli & 1979 & & $\begin{array}{c}\text { Gnaspini \& Trajano, 1994; } \\
\text { Pinto-Da-Rocha, 1995; } \\
\text { Indicatti \& Brescovit, } 2008\end{array}$ \\
\hline Nesticidae & Nesticus brignolii & Ott \& Lise & 2002 & & Indicatti \& Brescovit 2008 \\
\hline Oecobiidae & $\begin{array}{l}\text { Oecobius } \\
\text { concinnus }\end{array}$ & Simon & 1892 & sinantrópica & $\begin{array}{l}\text { Santos \& Gonzaga, 2003; } \\
\text { Indicatti \& Brescovit, } 2008\end{array}$ \\
\hline Oecobiidae & $\begin{array}{l}\text { Oecobius } \\
\text { marathaus }\end{array}$ & Tikader & 1962 & sinantrópica & $\begin{array}{l}\text { Santos \& Gonzaga, 2003; } \\
\text { Indicatti \& Brescovit, } 2008\end{array}$ \\
\hline Oecobiidae & $\begin{array}{l}\text { Oecobius } \\
\text { navus }\end{array}$ & Blackwall & 1859 & $\begin{array}{l}\text { introduzida, } \\
\text { sinantrópica }\end{array}$ & $\begin{array}{l}\text { Keyserling, 1891; Mello-Leitão, } \\
\text { 1915a; Santos \& Gonzaga, } 2003\end{array}$ \\
\hline Oonopidae & $\begin{array}{l}\text { Escaphiella } \\
\text { morro }\end{array}$ & $\begin{array}{l}\text { Platnick \& } \\
\text { Dupérré }\end{array}$ & 2009 & & Platnick \& Duperré, 2009 \\
\hline Oxyopidae & Oxyopes m-fasiatus & Piza & 1938 & registro único & Piza, 1938b \\
\hline Oxyopidae & Oxyopes salticus & Hentz & 1845 & & Indicatti \& Brescovit 2008 \\
\hline Oxyopidae & Oxyopes sectus & Mello-Leitão & 1929 & & Mello-Leitão, 1929a \\
\hline Oxyopidae & $\begin{array}{l}\text { Peucetia } \\
\text { flava }\end{array}$ & Keyserling & 1877 & & $\begin{array}{l}\text { Santos \& Brescovit, 2002; } \\
\text { Indicatti \& Brescovit } 2008\end{array}$ \\
\hline Oxyopidae & $\begin{array}{c}\text { Peucetia } \\
\text { rubrolineata }\end{array}$ & Keyserling & 1877 & & $\begin{array}{c}\text { Piza, 1938b; } \\
\text { Santos \& Brescovit, } 2002\end{array}$ \\
\hline Palpimanidae & Otiothops birabeni & Mello-Leitão & 1945 & & Brescovit \& Bonaldo, 1993 \\
\hline Philodromidae & Fageia clara & Mello-Leitão & 1937 & registro único & Mello-Leitão, 1937a \\
\hline Philodromidae & Gephyrellula paulistana & Soares & 1943 & registro único & Soares, 1943a \\
\hline Pholcidae & Carapoia genitalis & (Moenkhaus) & 1898 & & Huber, 2000; Huber, 2005 \\
\hline Pholcidae & Carapoia ubatuba & Huber & 2005 & registro único & Huber, 2005 \\
\hline Pholcidae & Coryssocnemis altiventer & (Keyserling) & 1891 & & Mello-Leitão, 1946a \\
\hline Pholcidae & Coryssocnemis banksi & Moenkhaus & 1898 & & Mello-Leitão, 1946a \\
\hline Pholcidae & $\begin{array}{c}\text { Crossopriza } \\
\text { lyoni }\end{array}$ & (Blackwall) & 1867 & $\begin{array}{l}\text { introduzida, } \\
\text { sinantrópica }\end{array}$ & Indicatti \& Brescovit 2008 \\
\hline Pholcidae & Mesabolivar banksi & (Moenkhaus) & 1898 & & Huber, 2000 \\
\hline Pholcidae & $\begin{array}{c}\text { Mesabolivar } \\
\text { brasiliensis }\end{array}$ & (Moenkhaus) & 1898 & & $\begin{array}{c}\text { Huber, 2000: } \\
\text { Indicatti \& Brescovit, } 2008\end{array}$ \\
\hline
\end{tabular}


Tabela 1. Continuação...

\begin{tabular}{|c|c|c|c|c|c|}
\hline Família & spp. & Autor & Data & Destaque & Referências \\
\hline Pholcidae & $\begin{array}{c}\text { Mesabolivar } \\
\text { camussi }\end{array}$ & $\begin{array}{l}\text { Machado, } \\
\text { Yamamoto, } \\
\text { Brescovit \& } \\
\text { Huber }\end{array}$ & 2007 & registro único & $\begin{array}{c}\text { Machado, Yamamoto, Brescovit \& } \\
\text { Huber, } 2007\end{array}$ \\
\hline Pholcidae & $\begin{array}{l}\text { Mesabolivar } \\
\text { cantharus }\end{array}$ & $\begin{array}{l}\text { Machado, } \\
\text { Yamamoto, } \\
\text { Brescovit \& } \\
\text { Huber }\end{array}$ & 2007 & registro único & $\begin{array}{c}\text { Machado, Yamamoto, Brescovit \& } \\
\text { Huber, } 2007\end{array}$ \\
\hline Pholcidae & $\begin{array}{c}\text { Mesabolivar } \\
\text { cuarassu }\end{array}$ & $\begin{array}{c}\text { Huber, Brescovit } \\
\text { \& Rheims }\end{array}$ & 2005 & registro único & Huber, Brescovit \& Rheims, 2005 \\
\hline Pholcidae & $\begin{array}{c}\text { Mesabolivar } \\
\text { cyaneotaeniatus }\end{array}$ & (Keyserling) & 1891 & & Indicatti \& Brescovit 2008 \\
\hline Pholcidae & Mesabolivar forceps & & & & Indicatti \& Brescovit 2008 \\
\hline Pholcidae & Mesabolivar guapiara & Huber & 2000 & registro único & Huber, 2000 \\
\hline Pholcidae & $\begin{array}{l}\text { Mesabolivar } \\
\quad \text { luteus }\end{array}$ & (Keyserling) & 1891 & & $\begin{array}{l}\text { Mello-Leitão, 1918c; Huber, 2000; } \\
\text { Indicatti \& Brescovit, } 2008\end{array}$ \\
\hline Pholcidae & Mesabolivar mairyara & & & & Indicatti \& Brescovit 2008 \\
\hline Pholcidae & $\begin{array}{l}\text { Mesabolivar } \\
\text { samatiaguassu }\end{array}$ & $\begin{array}{c}\text { Huber, Brescovit } \\
\text { \& Rheims }\end{array}$ & 2005 & registro único & Huber, Brescovit \& Rheims, 2005 \\
\hline Pholcidae & Mesabolivar simoni & (Moenkhaus) & 1898 & registro único & Huber, 2000 \\
\hline Pholcidae & Metagonia argentinensis & Mello-Leitão & 1945 & & Indicatti \& Brescovit 2008 \\
\hline Pholcidae & Metagonia bicornis & (Keyserling) & 1891 & & Mello-Leitão, 1946a \\
\hline Pholcidae & $\begin{array}{c}\text { Metagonia } \\
\text { paranapiacaba }\end{array}$ & $\begin{array}{l}\text { Huber, Rheims } \\
\text { \& Brescovit }\end{array}$ & 2005 & registro único & Huber, Rheims \& Brescovit, 2005 \\
\hline Pholcidae & $\begin{array}{l}\text { Micropholcus } \\
\text { fauroti }\end{array}$ & (Simon) & 1887 & $\begin{array}{l}\text { introduzida, } \\
\text { sinantrópica }\end{array}$ & Indicatti \& Brescovit 2008 \\
\hline Pholcidae & $\begin{array}{c}\text { Modisimus } \\
\text { culicinus }\end{array}$ & (Simon) & 1893 & $\begin{array}{l}\text { introduzida, } \\
\text { sinantrópica }\end{array}$ & Indicatti \& Brescovit 2008 \\
\hline Pholcidae & $\begin{array}{l}\text { Pholcus } \\
\text { phalangioides }\end{array}$ & (Fuesslin) & 1775 & $\begin{array}{l}\text { introduzida, } \\
\text { sinantrópica }\end{array}$ & $\begin{array}{c}\text { Piza, 1938a; } \\
\text { Indicatti \& Brescovit } 2008\end{array}$ \\
\hline Pholcidae & $\begin{array}{l}\text { Physocyclus } \\
\text { globosus }\end{array}$ & (Taczanowski) & 1873 & $\begin{array}{l}\text { introduzida, } \\
\text { sinantrópica }\end{array}$ & Indicatti \& Brescovit 2008 \\
\hline Pholcidae & $\begin{array}{l}\text { Psilochorus } \\
\text { itaguyrussu }\end{array}$ & $\begin{array}{l}\text { Huber, Rheims } \\
\text { \& Brescovit. }\end{array}$ & 2005 & registro único & Huber, Rheims \& Brescovit, 2005 \\
\hline Pholcidae & $\begin{array}{l}\text { Psilochorus } \\
\text { ybytyriguara }\end{array}$ & $\begin{array}{l}\text { Huber, Rheims } \\
\text { \& Brescovit. }\end{array}$ & 2005 & registro único & Huber, Rheims \& Brescovit, 2005 \\
\hline Pholcidae & $\begin{array}{l}\text { Smeringopus } \\
\text { pallidus }\end{array}$ & (Blackwall) & 1858 & $\begin{array}{l}\text { introduzida, } \\
\text { sinantrópica }\end{array}$ & $\begin{array}{c}\text { Mello-Leitão, 1946a; } \\
\text { Indicatti \& Brescovit } 2008\end{array}$ \\
\hline Pholcidae & $\begin{array}{l}\text { Spermophora } \\
\text { maculata }\end{array}$ & Keyserling & 1891 & $\begin{array}{l}\text { introduzida, } \\
\text { sinantrópica }\end{array}$ & Mello-Leitão, 1946a \\
\hline Pholcidae & $\begin{array}{l}\text { Tupigea } \\
\text { cantareira }\end{array}$ & $\begin{array}{l}\text { Machado, } \\
\text { Yamamoto, } \\
\text { Brescovit \& } \\
\text { Huber }\end{array}$ & 2007 & registro único & $\begin{array}{c}\text { Machado, Yamamoto, Brescovit \& } \\
\text { Huber, } 2007\end{array}$ \\
\hline Pholcidae & Tupigea nadleri & Huber & 2000 & & Indicatti \& Brescovit 2008 \\
\hline Pholcidae & Mesabolivar cavicelatus & & & & Indicatti \& Brescovit 2008 \\
\hline Pisauridae & Architis brasiliensis & (Mello-Leitão) & 1940 & & Santos, 2007a \\
\hline Pisauridae & Architis capricorna & Carico & 1981 & & Carico, 1981; Santos, 2007a \\
\hline Pisauridae & Architis fritzmuelleri & Santos & $2007 b$ & & Santos, 2007b \\
\hline Pisauridae & Architis spinipes & (Taczanowski) & 1874 & & Santos, 2007b \\
\hline Pisauridae & Architis tenuis & Simon & 1898 & & Santos, 2007a \\
\hline Pisauridae & Thaumasia marginella & (C.L. Koch) & 1847 & & Mello-Leitão, 1919 \\
\hline Salticidae & $\begin{array}{l}\text { Agelista } \\
\text { andina }\end{array}$ & Simon & 1900 & & $\begin{array}{c}\text { Rinaldi, Mendes \& Cady, 2002; } \\
\text { Rinaldi \& Forti, 1997; } \\
\text { Indicatti \& Brescovit, } 2008\end{array}$ \\
\hline
\end{tabular}


Tabela 1. Continuação...

\begin{tabular}{|c|c|c|c|c|c|}
\hline Família & spp. & Autor & Data & Destaque & Referências \\
\hline Salticidae & Aillutticus nitens & Galiano & 1987 & & Galiano, 1987a \\
\hline Salticidae & Aillutticus rotundus & Galiano & 1987 & & Ruiz, Brescovit , 2006 \\
\hline Salticidae & Akela ruricola & Galiano & 1999 & & Galiano, 1999b \\
\hline Salticidae & $\begin{array}{l}\text { Amatorculus } \\
\text { stygius }\end{array}$ & Ruiz \& Brescovit & 2005 & & $\begin{array}{l}\text { Ruiz \& Brescovit, 2005; } \\
\text { Ruiz \& Brescovit, } 2006\end{array}$ \\
\hline Salticidae & Aphirape boliviensis & Galiano & 1981 & registro único & Rinaldi, Mendes \& Cady, 2002 \\
\hline Salticidae & $\begin{array}{l}\text { Aphirape } \\
\text { misionensis }\end{array}$ & Galiano & 1981 & & $\begin{array}{l}\text { Galiano, 1981e; Rinaldi \& Forti, } \\
\text { 1997; Rinaldi, Mendes \& Cady, } 2002\end{array}$ \\
\hline Salticidae & Arachnomura hyeroglyphica & Mello-Leitão & 1917 & registro único & Rinaldi \& Forti, 1997 \\
\hline Salticidae & Arnoliseus calcarifer & Braul \& Lise & 2002 & & Indicatti \& Brescovit 2008 \\
\hline Salticidae & $\begin{array}{l}\text { Arnoliseus } \\
\text { graciosa }\end{array}$ & Braul \& Lise & 2002 & & $\begin{array}{c}\text { Braul \& Lise, 2002; } \\
\text { Indicatti \& Brescovit, } 2008\end{array}$ \\
\hline Salticidae & Asaphobelis fasciiventris & Simon & 1902 & & Rinaldi \& Forti, 1997 \\
\hline Salticidae & $\begin{array}{l}\text { Asaphobelis } \\
\text { physonychus }\end{array}$ & Simon & 1902 & & $\begin{array}{c}\text { Rinaldi \& Forti, 1997; } \\
\text { Indicatti \& Brescovit, } 2008\end{array}$ \\
\hline Salticidae & Asaracus rufociliatus & (Simon) & 1902 & & Galiano, 1963a \\
\hline Salticidae & $\begin{array}{l}\text { Ashtabula } \\
\text { sexguttata }\end{array}$ & Simon & 1901 & & $\begin{array}{l}\text { Braul, Rocha-Silveira \& Lise, 1997; } \\
\text { Rinaldi \& Forti, } 1997\end{array}$ \\
\hline Salticidae & Atelurius segmentatus & Simon & 1901 & & Galiano, 1988a; Rinaldi \& Forti, 1997 \\
\hline Salticidae & Balmaceda anulipes & Soares & 1942 & registro único & Soares, 1942 \\
\hline Salticidae & Beata aenea & (Mello-Leitão) & 1945 & & Rinaldi \& Forti, 1997 \\
\hline Salticidae & Beata cinereonitida & Simon & 1902 & & Rinaldi \& Forti, 1997 \\
\hline Salticidae & $\begin{array}{c}\text { Breda } \\
\text { apicalis }\end{array}$ & Simon & 1901 & & $\begin{array}{c}\text { Galiano, 1963a; } \\
\text { Indicatti \& Brescovit, } 2008\end{array}$ \\
\hline Salticidae & Breda bistriata & (C.L.Koch) & 1846 & registro único & C.L. Koch, 1846 \\
\hline Salticidae & Chira distincta & Bauab & 1983 & registro único & Bauab, 1983 \\
\hline Salticidae & $\begin{array}{l}\text { Chira } \\
\text { lanei }\end{array}$ & $\begin{array}{l}\text { Soares \& } \\
\text { Camargo }\end{array}$ & 1948 & & $\begin{array}{c}\text { Galiano, 1961b; } \\
\text { Rinaldi \& Forti, } 1997\end{array}$ \\
\hline Salticidae & Chira micans & (Simon) & 1902 & & Galiano, 1965a; Rinaldi \& Forti, 1997 \\
\hline Salticidae & Chira simoni & Galiano & 1961 & & Rinaldi \& Forti, 1997 \\
\hline Salticidae & Chira spinosa & (Mello-Leitão) & 1939 & & Galiano, 1961b; Rinaldi \& Forti, 1997 \\
\hline Salticidae & Chira thysbe & Simon & 1902 & & Soares \& Camargo, 1948b \\
\hline Salticidae & Chirothecia botucatuensis & Bauab & 1980 & registro único & Bauab, 1980 \\
\hline Salticidae & Chirothecia soaresi & Bauab & 1980 & registro único & Bauab, 1980 \\
\hline Salticidae & $\begin{array}{c}\text { Chirothecia } \\
\text { uncata }\end{array}$ & $\begin{array}{l}\text { Soares \& } \\
\text { Camargo }\end{array}$ & 1948 & registro único & Galiano, 1972b \\
\hline Salticidae & Chloridusa viridiaurea & Simon & 1902 & & Galiano, 1963a \\
\hline Salticidae & Consingis semicana & Simon & 1900 & & Rinaldi \& Forti, 1997 \\
\hline Salticidae & $\begin{array}{l}\text { Coryphasia } \\
\text { melloleitaoi }\end{array}$ & $\begin{array}{l}\text { Soares \& } \\
\text { Camargo }\end{array}$ & 1948 & & Rinaldi \& Forti, 1997 \\
\hline Salticidae & $\begin{array}{c}\text { Cylistella } \\
\text { sanctipauli }\end{array}$ & $\begin{array}{l}\text { Soares \& } \\
\text { Camargo }\end{array}$ & 1948 & & Soares \& Camargo, 1948b \\
\hline Salticidae & $\begin{array}{l}\text { Dendryphantes } \\
\text { sexguttatus }\end{array}$ & (Mello-Leitão) & 1945 & & $\begin{array}{l}\text { Rinaldi \& Forti, 1997; } \\
\text { Rinaldi, Mendes \& Cady, } 2002\end{array}$ \\
\hline Salticidae & Descanso sobrius & Galiano & 1986 & & Galiano, 1986; Rinaldi \& Forti, 1997 \\
\hline Salticidae & $\begin{array}{c}\text { Erica } \\
\text { eugenia }\end{array}$ & $\begin{array}{c}\text { Peckham \& } \\
\text { Peckham }\end{array}$ & 1892 & & Rinaldi \& Forti, 1997 \\
\hline Salticidae & Euophrys sutrix & Holmberg & 1875 & sinantrópica & Indicatti \& Brescovit 2008 \\
\hline Salticidae & Freya decorata & (C.L. Koch) & 1846 & & Rinaldi \& Forti, 1996 \\
\hline Salticidae & Frigga coronigera & (C.L.Koch) & 1979 & & Indicatti \& Brescovit 2008 \\
\hline Salticidae & Frigga quintensis & (Tullgren) & 1905 & & Rinaldi \& Forti, 1997 \\
\hline Salticidae & Gastromicans albopilosa & (Simon) & 1903 & & Bauab \& Soares, 1979b \\
\hline
\end{tabular}


Tabela 1. Continuação...

\begin{tabular}{|c|c|c|c|c|c|}
\hline Família & spp. & Autor & Data & Destaque & Referências \\
\hline Salticidae & $\begin{array}{l}\text { Hasarius } \\
\text { adansoni }\end{array}$ & (Audouin) & 1826 & $\begin{array}{l}\text { introduzida, } \\
\text { sinantrópica }\end{array}$ & Indicatti \& Brescovit 2008 \\
\hline Salticidae & Helvetia albovittata & Simon & 1901 & & Ruiz \& Brescovit, 2008 \\
\hline Salticidae & Helvetia cancrimana & (Taczanowski) & 1872 & & Ruiz \& Brescovit, 2008 \\
\hline Salticidae & Helvetia rinaldiae & Ruiz \& Brescovit & 2008 & & Ruiz \& Brescovit, 2008 \\
\hline Salticidae & Helvetia semialba & (Simon) & 1901 & & Rinaldi \& Forti, 1997 \\
\hline Salticidae & Hisukattus alienus & Galiano & 1987 & & Galiano, 1987b \\
\hline Salticidae & $\begin{array}{l}\text { Ilargus } \\
\text { coccineus }\end{array}$ & Simon & 1955 & & $\begin{array}{c}\text { Rinaldi \& Forti, 1997; } \\
\text { Indicatti \& Brescovit, 2008 }\end{array}$ \\
\hline Salticidae & Lyssomanes boraceia & Galiano & 1984 & & Galiano, 1984b \\
\hline Salticidae & $\begin{array}{l}\text { Lyssomanes } \\
\text { elegans }\end{array}$ & $\begin{array}{l}\text { F.O.P. - } \\
\text { Cambridge }\end{array}$ & 1900 & & Logunov, 2002 \\
\hline Salticidae & Lyssomanes elongatus & Galiano & 1980 & & Galiano, 1980a \\
\hline Salticidae & $\begin{array}{l}\text { Lyssomanes } \\
\text { leucomellas }\end{array}$ & Mello-Leitão & 1917 & & $\begin{array}{c}\text { Logunov, 2002; } \\
\text { Indicatti \& Brescovit, } 2008\end{array}$ \\
\hline Salticidae & $\begin{array}{l}\text { Lyssomanes } \\
\text { miniaceus }\end{array}$ & $\begin{array}{l}\text { Peckham \& } \\
\text { Wheeller }\end{array}$ & 1889 & & Indicatti \& Brescovit 2008 \\
\hline Salticidae & Lyssomanes nigrofimbriatus & Mello-Leitão & 1941 & & Galiano, 1980b; Rinaldi \& Forti, 1997 \\
\hline Salticidae & $\begin{array}{l}\text { Lyssomanes } \\
\text { nigropictus }\end{array}$ & $\begin{array}{l}\text { Peckham \& } \\
\text { Wheeller }\end{array}$ & 1889 & & Indicatti \& Brescovit 2008 \\
\hline Salticidae & Lyssomanes pauper & Mello-Leitão & 1945 & & Galiano, 1980a; Rinaldi \& Forti, 1997 \\
\hline Salticidae & Lyssomanes penicillatus & Mello-Leitão & 1927 & & Galiano, 1962b; Galiano, 1980b \\
\hline Salticidae & $\begin{array}{l}\text { Lyssomanes } \\
\text { tristis }\end{array}$ & $\begin{array}{l}\text { Peckham \& } \\
\text { Wheeller }\end{array}$ & 1889 & & $\begin{array}{c}\text { Galiano, 1980b; } \\
\text { Rinaldi \& Forti, } 1997\end{array}$ \\
\hline Salticidae & Lyssomanes unicolor & (Taczanowski) & 1871 & & Galiano, 1980a \\
\hline Salticidae & $\begin{array}{l}\text { Lyssomanes } \\
\text { velox }\end{array}$ & $\begin{array}{c}\text { Peckham \& } \\
\text { Wheeller }\end{array}$ & 1889 & & Galiano, $1962 b$ \\
\hline Salticidae & Lyssomanes yacui & Galiano & 1984 & & Galiano, 1984b \\
\hline Salticidae & Mago vicanus & Simon & 1900 & & Galiano, $1968 \mathrm{c}$ \\
\hline Salticidae & $\begin{array}{l}\text { Menemerus } \\
\text { bivittatus }\end{array}$ & Dufour & 1831 & $\begin{array}{l}\text { introduzida, } \\
\text { sinantrópica }\end{array}$ & Indicatti \& Brescovit 2008 \\
\hline Salticidae & $\begin{array}{l}\text { Metaphidippus } \\
\text { albopilosus }\end{array}$ & $\begin{array}{l}\text { (Peckham \& } \\
\text { Peckham) }\end{array}$ & 1901 & & Peckham \& Peckham, 1901a \\
\hline Salticidae & $\begin{array}{l}\text { Mopiopia } \\
\text { comatula }\end{array}$ & Simon & 1902 & registro único & $\begin{array}{c}\text { Galiano, 1963a; } \\
\text { Indicatti \& Brescovit } 2008\end{array}$ \\
\hline Salticidae & Myrmarachne brasiliensis & Mello-Leitão & 1923 & & Galiano, 1969b; Rinaldi \& Forti, 1997 \\
\hline Salticidae & Naubolus albopunctatus & Mello-Leitão & 1943 & & Galiano, 1981a \\
\hline Salticidae & $\begin{array}{l}\text { Naubolus } \\
\text { sawayai }\end{array}$ & $\begin{array}{l}\text { Soares \& } \\
\text { Camargo }\end{array}$ & 1948 & registro único & Soares \& Camargo, 1948b \\
\hline Salticidae & Noegus australis & Mello-Leitão & 1940 & & Indicatti \& Brescovit 2008 \\
\hline Salticidae & Noegus bidens & Simon & 1900 & & Rinaldi \& Forti, 1997 \\
\hline Salticidae & Noegus fuscimanus & Simon & 1900 & & Indicatti \& Brescovit 2008 \\
\hline Salticidae & Noegus vulpio & Simon & 1900 & & Indicatti \& Brescovit 2008 \\
\hline Salticidae & Nycerella volucripes & Galiano & 1982 & & Galiano, 1975 \\
\hline Salticidae & $\begin{array}{l}\text { Parnaenus } \\
\text { metallicus }\end{array}$ & (C.L. Koch) & 1846 & & $\begin{array}{c}\text { Scioscia, 1997; } \\
\text { Indicatti \& Brescovit } 2008\end{array}$ \\
\hline Salticidae & $\begin{array}{l}\text { Pensacolops } \\
\text { rubrovittata }\end{array}$ & Bauab & 1983 & registro único & $\begin{array}{c}\text { Bauab, 1983; } \\
\text { Indicatti \& Brescovit } 2008\end{array}$ \\
\hline Salticidae & Phiale bipunctata & Mello-Leitão & 1947 & & Rinaldi \& Forti, 1997 \\
\hline Salticidae & Phiale mimica & (C.L.Koch) & 1846 & & Galiano, $1980 \mathrm{e}$ \\
\hline Salticidae & Phiale tristis & Mello-Leitão & 1945 & & Rinaldi \& Forti, 1997 \\
\hline Salticidae & $\begin{array}{l}\text { Plexippus } \\
\text { paykulli }\end{array}$ & (Audouin) & 1826 & $\begin{array}{l}\text { introduzida, } \\
\text { sinantrópica }\end{array}$ & Indicatti \& Brescovit 2008 \\
\hline
\end{tabular}


Tabela 1. Continuação...

\begin{tabular}{|c|c|c|c|c|c|}
\hline Família & spp. & Autor & Data & Destaque & Referências \\
\hline Salticidae & Proctonemesia multicaudata & Bauab \& Soares & 1978 & registro único & Bauab \& Soares, 1978b \\
\hline Salticidae & $\begin{array}{l}\text { Proctonemesia } \\
\text { secunda }\end{array}$ & $\begin{array}{l}\text { (Soares \& } \\
\text { Camargo) }\end{array}$ & 1948 & registro único & Galiano, 1986 \\
\hline Salticidae & Rhyphelia variegata & Simon & 1902 & & Rinaldi \& Forti, 1997 \\
\hline Salticidae & $\begin{array}{c}\text { Rudra } \\
\text { baurensis }\end{array}$ & Badcock & 1932 & & $\begin{array}{c}\text { Badcock, 1932, } \\
\text { Bauab \& Soares, 1980b }\end{array}$ \\
\hline Salticidae & $\begin{array}{c}\text { Rudra } \\
\text { dagostinae }\end{array}$ & Braul \& Lise & 1999 & & $\begin{array}{c}\text { Braul \& Lise, 1999; } \\
\text { Indicatti \& Brescovit, } 2008\end{array}$ \\
\hline Salticidae & Saitis cyanipes & Simon & 1901 & & Indicatti \& Brescovit 2008 \\
\hline Salticidae & Saitis spinosus & (Mello-Leitão) & 1945 & registro único & Rinaldi \& Forti, 1997 \\
\hline Salticidae & Sarinda marcosi & Piza & 1939 & registro único & Galiano, 1965b \\
\hline Salticidae & $\begin{array}{c}\text { Sarinda } \\
\text { nigra }\end{array}$ & $\begin{array}{l}\text { Peckham \& } \\
\text { Peckham }\end{array}$ & 1892 & & $\begin{array}{l}\text { Mello-Leitão, 1939h; } \\
\text { Trinaldi \& Forti, } 1997\end{array}$ \\
\hline Salticidae & Sassacus glyphochela & Bauab & 1979 & registro único & Bauab \& Soares, 1979b \\
\hline Salticidae & Sassacus helenicus & (Mello-Leitão) & 1943 & & Bauab \& Soares, 1978c \\
\hline Salticidae & $\begin{array}{l}\text { Selimus } \\
\text { venustus }\end{array}$ & $\begin{array}{l}\text { Peckham \& } \\
\text { Peckham }\end{array}$ & 1901 & & Peckham \& Peckham, 1901a \\
\hline Salticidae & Semiopyla cataphracta & Simon & 1901 & registro único & Rinaldi \& Forti, 1997 \\
\hline Salticidae & Semiopyla viperina & Galiano & 1985 & & Rinaldi \& Forti, 1997 \\
\hline Salticidae & Semnolius chrysotrichus & Simon & 1902 & & Rinaldi \& Forti, 1997 \\
\hline Salticidae & Synemosyna aurantiaca & (Mello-Leitão) & 1917 & & Piza, 1937a; Rinaldi \& Forti, 1997 \\
\hline Salticidae & $\begin{array}{c}\text { Synemosyna } \\
\text { lauretta }\end{array}$ & $\begin{array}{l}\text { Peckham \& } \\
\text { Peckham }\end{array}$ & 1892 & & Galiano, 1966a \\
\hline Salticidae & Synemosyna magniscuti & Mello-Leitão & 1939 & & Galiano, 1966a \\
\hline Salticidae & Synemosyna scutata & (Mello-Leitão) & 1943 & & Galiano, 1966a \\
\hline Salticidae & $\begin{array}{l}\text { Tacuna } \\
\text { delecta }\end{array}$ & $\begin{array}{l}\text { Peckham \& } \\
\text { Peckham }\end{array}$ & 1901 & & Galiano, 1995a \\
\hline Salticidae & Thiodina germaini & Simon & 1900 & & Rinaldi \& Forti, 1997 \\
\hline Salticidae & Thiodina melanogaster & Mello-Leitão & 1917 & & Rinaldi \& Forti, 1997 \\
\hline Salticidae & Thiodina vaccula & Simon & 1900 & & Galiano, 1963a \\
\hline Salticidae & Tullgrenella gertschi & Galiano & 1981 & & Galiano, 1984a \\
\hline Salticidae & Uspachus juqiuaensis & Galiano & 1995 & & Galiano, 1995b \\
\hline Salticidae & $\begin{array}{l}\text { Vinnius } \\
\text { uncatus }\end{array}$ & Simon & 1902 & & $\begin{array}{l}\text { Rinaldi \& Forti, 1997; } \\
\text { Braul \& Lise, } 2002\end{array}$ \\
\hline Salticidae & Wedoquella punctata & (Tullgren) & 1905 & registro único & Rinaldi \& Forti, 1997 \\
\hline Salticidae & $\begin{array}{l}\text { Zuniga } \\
\text { magna }\end{array}$ & $\begin{array}{l}\text { Peckham \& } \\
\text { Peckham }\end{array}$ & 1892 & & $\begin{array}{c}\text { Galiano, 1964a; } \\
\text { Rinaldi \& Forti, } 1997\end{array}$ \\
\hline Scytodidae & $\begin{array}{l}\text { Scytodes } \\
\text { antonina }\end{array}$ & $\begin{array}{l}\text { Rheims \& } \\
\text { Brescovit }\end{array}$ & 2009 & & Rheims \& Brescovit, 2009 \\
\hline Scytodidae & $\begin{array}{l}\text { Scytodes } \\
\text { auricula }\end{array}$ & $\begin{array}{l}\text { Rheims \& } \\
\text { Brescovit }\end{array}$ & 2000 & & Brescovit \& Rheims, 2000 \\
\hline Scytodidae & $\begin{array}{l}\text { Scytodes } \\
\text { bocaina }\end{array}$ & $\begin{array}{l}\text { Rheims \& } \\
\text { Brescovit }\end{array}$ & 2009 & & Rheims \& Brescovit, 2009 \\
\hline Scytodidae & $\begin{array}{l}\text { Scytodes } \\
\text { bonito }\end{array}$ & $\begin{array}{l}\text { Rheims \& } \\
\text { Brescovit }\end{array}$ & 2009 & & Rheims \& Brescovit, 2009 \\
\hline Scytodidae & $\begin{array}{l}\text { Scytodes } \\
\text { brignolii }\end{array}$ & $\begin{array}{l}\text { Rheims \& } \\
\text { Brescovit }\end{array}$ & 2009 & & Rheims \& Brescovit, 2009 \\
\hline Scytodidae & $\begin{array}{l}\text { Scytodes } \\
\text { chopim }\end{array}$ & $\begin{array}{l}\text { Rheims \& } \\
\text { Brescovit }\end{array}$ & 2009 & & Rheims \& Brescovit, 2009 \\
\hline Scytodidae & $\begin{array}{l}\text { Scytodes } \\
\text { fusca }\end{array}$ & Walckenaer & 1837 & sinantrópica & $\begin{array}{l}\text { Brescovit \& Rheims, 2000; } \\
\text { Rinaldi, Mendes \& Cady, 2002; } \\
\text { Rheims \& Brescovit, } 2006\end{array}$ \\
\hline Scytodidae & $\begin{array}{l}\text { Scytodes } \\
\text { genebra }\end{array}$ & $\begin{array}{l}\text { Rheims \& } \\
\text { Brescovit }\end{array}$ & 2009 & & Rheims \& Brescovit, 2009 \\
\hline
\end{tabular}


Tabela 1. Continuação...

\begin{tabular}{|c|c|c|c|c|c|}
\hline Família & spp. & Autor & Data & Destaque & Referências \\
\hline Scytodidae & $\begin{array}{l}\text { Scytodes } \\
\text { globula }\end{array}$ & Nicolet & 1849 & sinantrópica & $\begin{array}{l}\text { Brescovit \& Rheims, 2000; } \\
\text { Rheims \& Brescovit, 2001; } \\
\text { Rheims \& Brescovit, } 2006\end{array}$ \\
\hline Scytodidae & $\begin{array}{l}\text { Scytodes } \\
\text { itapecerica }\end{array}$ & $\begin{array}{l}\text { Rheims \& } \\
\text { Brescovit }\end{array}$ & 2009 & & Rheims \& Brescovit, 2009 \\
\hline Scytodidae & $\begin{array}{l}\text { Scytodes } \\
\text { itapevi }\end{array}$ & $\begin{array}{l}\text { Brescovit \& } \\
\text { Rheims }\end{array}$ & 2000 & sinantrópica & Brescovit \& Rheims, 2000 \\
\hline Scytodidae & $\begin{array}{c}\text { Scytodes } \\
\text { jurubatuba }\end{array}$ & $\begin{array}{l}\text { Rheims \& } \\
\text { Brescovit }\end{array}$ & 2009 & & Rheims \& Brescovit, 2009 \\
\hline Scytodidae & $\begin{array}{l}\text { Scytodes } \\
\text { mapia }\end{array}$ & $\begin{array}{l}\text { Rheims \& } \\
\text { Brescovit }\end{array}$ & 2000 & & Brescovit \& Rheims, 2000 \\
\hline Scytodidae & $\begin{array}{c}\text { Scytodes } \\
\text { nambiobyrassu }\end{array}$ & $\begin{array}{l}\text { Rheims \& } \\
\text { Brescovit }\end{array}$ & 2009 & & Rheims \& Brescovit, 2009 \\
\hline Scytodidae & $\begin{array}{l}\text { Scytodes } \\
\text { nambiussu }\end{array}$ & $\begin{array}{l}\text { Rheims \& } \\
\text { Brescovit }\end{array}$ & 2006 & & Rheims \& Brescovit, 2006 \\
\hline Scytodidae & $\begin{array}{c}\text { Scytodes } \\
\text { pintodarochai }\end{array}$ & $\begin{array}{l}\text { Rheims \& } \\
\text { Brescovit }\end{array}$ & 2009 & & Rheims \& Brescovit, 2009 \\
\hline Scytodidae & $\begin{array}{l}\text { Scytodes } \\
\text { tyaia }\end{array}$ & $\begin{array}{l}\text { Rheims \& } \\
\text { Brescovit }\end{array}$ & 2009 & & Rheims \& Brescovit, 2009 \\
\hline Scytodidae & $\begin{array}{l}\text { Scytodes } \\
\text { univittata }\end{array}$ & Simon & 1882 & $\begin{array}{l}\text { introduzida, } \\
\text { sinantrópica }\end{array}$ & Brescovit \& Rheims, 2000 \\
\hline Scytodidae & $\begin{array}{c}\text { Scytodes } \\
\text { vassununga }\end{array}$ & $\begin{array}{l}\text { Rheims \& } \\
\text { Brescovit }\end{array}$ & 2009 & & Rheims \& Brescovit, 2009 \\
\hline Scytodidae & Scytodes vittata & Keyserling & 1877 & & Mello-Leitão, 1918c \\
\hline Segestriidae & Ariadna bicolor & (Hentz) & 1877 & sinantrópica & Indicatti \& Brescovit 2008 \\
\hline Segestriidae & Ariadna crassipalpa & (Blackwall) & 1863 & registro único & Camargo, 1950a \\
\hline Selenopidae & Selenops cocheleti & Simon & 1880 & sinantrópica & Corronca, 1998d \\
\hline Selenopidae & Selenops hebraicus & Mello-Leitão & 1945 & & Corronca, 1998d \\
\hline Selenopidae & Selenops maranhensis & Mello-Leitão & 1918 & sinantrópica & Corronca, 1998d \\
\hline Selenopidae & Selenops melanurus & Mello-Leitão & 1923 & & Corronca, 1998d \\
\hline Selenopidae & Selenops occultus & Mello-Leitão & 1918 & & Corronca, 1998d \\
\hline Selenopidae & $\begin{array}{l}\text { Selenops } \\
\text { rapax }\end{array}$ & Mello-Leitão & 1929 & & $\begin{array}{c}\text { Corronca, 1998d; } \\
\text { Rinaldi \& Forti, } 1997\end{array}$ \\
\hline Selenopidae & Selenops spixi & Perty & 1833 & sinantrópica & Indicatti \& Brescovit 2008 \\
\hline Selenopidae & Selenops zumac & Corronca & 1996 & registro único & Corronca, 1998d \\
\hline Senoculidae & Senoculus darwini & (Holmberg) & 1883 & & Baptista, 1992 \\
\hline Senoculidae & Senoculus gracilis & (Keyserling) & 1879 & & Baptista, 1992 \\
\hline Senoculidae & Senoculus iricolor & (Simon) & 1880 & & Baptista, 1992 \\
\hline Senoculidae & $\begin{array}{l}\text { Senoculus } \\
\text { monastoides }\end{array}$ & $\begin{array}{c}\text { (O.P.- } \\
\text { Cambridge) }\end{array}$ & 1873 & & Baptista, 1992 \\
\hline Sicariidae & $\begin{array}{l}\text { Loxosceles } \\
\text { adelaida }\end{array}$ & Gertsch & 1967 & & $\begin{array}{l}\text { Brignoli, 1972c; Pinto-Da-Rocha, } \\
\text { 1995; Zeppelini Filho et al., } 2003\end{array}$ \\
\hline Sicariidae & $\begin{array}{l}\text { Loxosceles } \\
\text { gaucho }\end{array}$ & Gertsch & 1967 & sinantrópica & $\begin{array}{c}\text { Gertsch, 1967a, Gnaspini \& Trajano, } \\
\text { 1994; Pinto-Da-Rocha, 1995; } \\
\text { Indicatti \& Brescovit, } 2008\end{array}$ \\
\hline Sicariidae & Loxosceles immodesta & (Mello-Leitão) & 1917 & registro único & Mello-Leitão, 1917a \\
\hline Sicariidae & Loxosceles intermedia & Mello-Leitão & 1934 & sinantrópica & Gertsch, 1967a \\
\hline Sicariidae & $\begin{array}{l}\text { Loxosceles } \\
\text { laeta }\end{array}$ & (Nicolet) & 1849 & $\begin{array}{l}\text { introduzida, } \\
\text { sinantrópica }\end{array}$ & $\begin{array}{l}\text { Mello-Leitão, 1918c; } \\
\text { Gertsch, 1967a }\end{array}$ \\
\hline Sicariidae & Loxosceles similis & Moenkhaus & 1898 & & Camargo, 1953 \\
\hline Sparassidae & $\begin{array}{l}\text { Heteropoda } \\
\text { venatoria }\end{array}$ & (Linnaeus) & 1767 & $\begin{array}{l}\text { introduzida, } \\
\text { sinantrópica }\end{array}$ & $\begin{array}{c}\text { Mello-Leitão, 1919; } \\
\text { Indicatti \& Brescovit, } 2008\end{array}$ \\
\hline Sparassidae & Macrinus pollexensis & (Schenkel) & 1953 & & Rheims, 2007 \\
\hline Sparassidae & Macrinus succineus & Simon & 1887 & & Rheims, 2007 \\
\hline
\end{tabular}


Tabela 1. Continuação...

\begin{tabular}{|c|c|c|c|c|c|}
\hline Família & spp. & Autor & Data & Destaque & Referências \\
\hline Sparassidae & Olios albus & Mello-Leitão & 1918 & & Indicatti \& Brescovit 2008 \\
\hline Sparassidae & Olios antiguensis & (Keyserling) & 1880 & & Rinaldi \& Forti, 1997 \\
\hline Sparassidae & Olios caprinus & Mello-Leitão & 1918 & & Indicatti \& Brescovit 2008 \\
\hline Sparassidae & Olios fasciatus & (Keyserling) & 1880 & & Mello-Leitão, 1918a \\
\hline Sparassidae & Olios hyeroglyphicus & Mello-Leitão & 1918 & & Indicatti \& Brescovit 2008 \\
\hline Sparassidae & Olios macroepigynus & Soares & 1944 & registro único & Soares, 1944a \\
\hline Sparassidae & Olios plumipes & Mello-Leitão & 1937 & registro único & Mello-Leitão, 1937a \\
\hline Sparassidae & $\begin{array}{l}\text { Polybetes } \\
\text { germaini }\end{array}$ & Simon & 1896 & sinantrópica & $\begin{array}{c}\text { Rinaldi \& Forti, 1997; } \\
\text { Indicatti \& Brescovit 2008 }\end{array}$ \\
\hline Sparassidae & Polybetes pythagoricus & (Holmberg) & 1875 & sinantrópica & Mello-Leitão, 1918a \\
\hline Sparassidae & $\begin{array}{l}\text { Polybetes } \\
\text { rapidus }\end{array}$ & (Keyserling) & 1880 & sinantrópica & $\begin{array}{c}\text { Mello-Leitão, 1919; } \\
\text { Indicatti \& Brescovit 2008 }\end{array}$ \\
\hline Sparassidae & Polybetes rubrosignatus & Mello-Leitão & 1943 & & Indicatti \& Brescovit 2008 \\
\hline Sparassidae & Prusias brasiliensis & Mello-Leitão & 1915 & registro único & Mello-Leitão, 1915a \\
\hline Sparassidae & Quemedice enigmaticus & Mello-Leitão & 1942 & & Rheims, Labarque \& Ramírez, 2008 \\
\hline Sparassidae & Nolavia rubriventris & Piza & 1939 & registro único & Piza, 1939b \\
\hline Symphytognathidae & $\begin{array}{l}\text { Symphytognatha } \\
\text { carstica }\end{array}$ & $\begin{array}{c}\text { Brescovit, } \\
\text { Álvares \& Lopes } \\
\text { Ferreira }\end{array}$ & 2004 & & $\begin{array}{l}\text { Brescovit, Álvares \& Lopes Ferreira, } \\
\text { 2004; Indicatti \& Brescovit, } 2008\end{array}$ \\
\hline Synotaxidae & Synotaxus longicaudatus & (Keyserling) & 1891 & & Indicatti \& Brescovit 2008 \\
\hline Tetragnathidae & Azilia boudeti & Simon & 1895 & & Indicatti \& Brescovit 2008 \\
\hline Tetragnathidae & $\begin{array}{c}\text { Chrysometa } \\
\text { boraceia }\end{array}$ & Levi & 1986 & & $\begin{array}{l}\text { Levi, 1986a; Pinto-Da-Rocha, 1995; } \\
\text { Indicatti \& Brescovit, } 2008\end{array}$ \\
\hline Tetragnathidae & $\begin{array}{l}\text { Chrysometa } \\
\text { cambara }\end{array}$ & Levi & 1986 & & $\begin{array}{l}\text { Gnaspini \& Trajano, 1994; } \\
\text { Pinto-Da-Rocha, 1995; } \\
\text { Indicatti \& Brescovit, } 2008\end{array}$ \\
\hline Tetragnathidae & Chrysometa itaimba & Levi & 1986 & & Levi, 1986a \\
\hline Tetragnathidae & Chrysometa jordao & Levi & 1986 & registro único & Levi, 1986a \\
\hline Tetragnathidae & $\begin{array}{l}\text { Chrysometa } \\
\text { ludibunda }\end{array}$ & (Keyserling) & 1893 & & $\begin{array}{l}\text { Levi, 1986a; } \\
\text { Indicatti \& Brescovit, } 2008\end{array}$ \\
\hline Tetragnathidae & Chrysometa sumare & Levi & 1986 & & Levi, 1986a \\
\hline Tetragnathidae & $\begin{array}{l}\text { Cyrtognatha } \\
\text { eberhardi }\end{array}$ & $\begin{array}{l}\text { Dimitrov \& } \\
\text { Hormiga }\end{array}$ & 2009 & & Dimitrov \& Hormiga 2009 \\
\hline Tetragnathidae & $\begin{array}{l}\text { Dolichognatha } \\
\quad \text { pinheiral }\end{array}$ & $\begin{array}{l}\text { Brescovit \& } \\
\text { Cunha }\end{array}$ & 2001 & & $\begin{array}{l}\text { Brescovit \& Cunha, 2001; } \\
\text { Indicatti \& Brescovit } 2008\end{array}$ \\
\hline Tetragnathidae & Leucauge argyra & (Walckenaer) & 1842 & & Indicatti \& Brescovit 2008 \\
\hline Tetragnathidae & Leucauge atrostricta & Badcock & 1932 & registro único & Badcock, 1932 \\
\hline Tetragnathidae & Tetragnatha longidens & Mello-Leitão & 1945 & & Camargo, 1950b; Camargo, 1953 \\
\hline Tetragnathidae & Tetragnatha mandibulata & Walckenaer & 1842 & & Bock in Mello-Leitão, 1915 b \\
\hline Tetragnathidae & Tetragnatha nitens & (Audouin) & 1826 & & Indicatti \& Brescovit 2008 \\
\hline Theraphosidae & Acanthoscurria atrox & Vellard & 1924 & & Indicatti \& Brescovit 2008 \\
\hline Theraphosidae & Acanthoscurria aurita & Piza & 1939 & registro único & Piza, 1939a \\
\hline Theraphosidae & $\begin{array}{l}\text { Acanthoscurria } \\
\text { chicacanthia }\end{array}$ & Mello-Leitão & 1923 & & $\begin{array}{c}\text { Mello-Leitão, 1923a; } \\
\text { Indicatti \& Brescovit, 2008 }\end{array}$ \\
\hline Theraphosidae & Acanthoscurria gomesiana & Mello-Leitão & 1923 & sinantrópica & Mello-Leitão, 1923a \\
\hline Theraphosidae & $\begin{array}{l}\text { Acanthoscurria } \\
\text { paulensis }\end{array}$ & Mello-Leitão & 1923 & $\begin{array}{l}\text { sinantrópica, } \\
\text { registro único }\end{array}$ & Mello-Leitão, 1923a \\
\hline Theraphosidae & Acanthoscurria pheopygus & Mello-Leitão & 1923 & & Mello-Leitão, 1923a \\
\hline Theraphosidae & Acanthoscurria sternalis & Pocock & 1903 & & Mello-Leitão, 1923a \\
\hline Theraphosidae & Acanthoscurria violacea & Mello-Leitão & 1923 & & Mello-Leitão, 1923a \\
\hline Theraphosidae & Cyclosternum garbei & (Mello-Leitão) & 1923 & registro único & Mello-Leitão, 1923a \\
\hline Theraphosidae & Cyrtopholis zorodes & Mello-Leitão & 1923 & & Mello-Leitão, 1923a \\
\hline Theraphosidae & Eupalaestrus campestratus & (Simon) & 1891 & & Bertani, 2001 \\
\hline
\end{tabular}


Tabela 1. Continuação...

\begin{tabular}{|c|c|c|c|c|c|}
\hline Família & spp. & Autor & Data & Destaque & Referências \\
\hline Theraphosidae & Eupalaestrus dubium & Mello-Leitão & 1903 & & Mello-Leitão, 1923a \\
\hline Theraphosidae & Eupalaestrus spinosissimus & Mello-Leitão & 1849 & & Bertani, 2001 \\
\hline Theraphosidae & Eupalaestrus vellutinum & Mello-Leitão & 1891 & & Mello-Leitão, 1923a \\
\hline Theraphosidae & $\begin{array}{l}\text { Sickius } \\
\text { longibulbi }\end{array}$ & $\begin{array}{l}\text { (Soares \& } \\
\text { Camargo) }\end{array}$ & 1948 & & Bertani \& Junior, 2002 \\
\hline Theraphosidae & Hemiercus proximus & Mello-Leitão & 1923 & & Mello-Leitão, 1923a \\
\hline Theraphosidae & Homoeomma brasilianum & (Chamberlin) & 1917 & & Indicatti \& Brescovit 2008 \\
\hline Theraphosidae & Hoтоеотта montanum & (Mello-Leitão) & 1923 & & Indicatti \& Brescovit 2008 \\
\hline Theraphosidae & Homoeomma stradlingi & O.P.- Cambridge & 1881 & & Mello-Leitão, 1923a \\
\hline Theraphosidae & Lasiodora acanthognatha & Mello-Leitão & 1921 & & Mello-Leitão, 1921b \\
\hline Theraphosidae & Lasiodora citharacantha & Mello-Leitão & 1917 & & Mello-Leitão, 1921b \\
\hline Theraphosidae & Lasiodora cryptostigma & Mello-Leitão & 1921 & & Mello-Leitão, 1921b \\
\hline Theraphosidae & Lasiodora difficilis & Mello-Leitão & 1921 & & Mello-Leitão, 1921b \\
\hline Theraphosidae & Lasiodora dolichosterna & Mello-Leitão & 1921 & & Mello-Leitão, 1921b \\
\hline Theraphosidae & Lasiodora erythrocithara & Mello-Leitão & 1921 & & Mello-Leitão, 1921b \\
\hline Theraphosidae & Lasiodora pleoplectra & Mello-Leitão & 1921 & & Mello-Leitão, 1921b \\
\hline Theraphosidae & Lasiodora spinipes & Ausserer & 1871 & & Mello-Leitão, 1921b \\
\hline Theraphosidae & Lasiodora sternalis & (Mello-Leitão) & 1923 & registro único & Mello-Leitão, 1923a \\
\hline Theraphosidae & Lasiodora striatipes & (Ausserer) & 1871 & & Mello-Leitão, 1921b \\
\hline Theraphosidae & $\begin{array}{l}\text { Magulla } \\
\text { buecherli }\end{array}$ & $\begin{array}{l}\text { Indicatti, Lucas, } \\
\text { Guadanucci \& } \\
\text { Yamamoto }\end{array}$ & 2008 & & $\begin{array}{c}\text { Indicatti, Lucas, Guadanucci \& } \\
\text { Yamamoto, } 2008\end{array}$ \\
\hline Theraphosidae & $\begin{array}{l}\text { Magulla } \\
\text { obesa }\end{array}$ & Simon & 1892 & & $\begin{array}{c}\text { Indicatti, Lucas, Guadanucci \& } \\
\text { Yamamoto, } 2008\end{array}$ \\
\hline Theraphosidae & Nhandu carapoensis & Lucas & 1983 & & Bertani, 2001 \\
\hline Theraphosidae & Pamphobeteus benedeni & (Bertkau) & 1880 & & Mello-Leitão, 1923a \\
\hline Theraphosidae & $\begin{array}{l}\text { Plesiopelma } \\
\text { insulare }\end{array}$ & (Mello-Leitão) & 1923 & & $\begin{array}{c}\text { Mello-Leitão, 1923a; } \\
\text { Mello-Leitão, 1923b; Bücherl, 1947; } \\
\text { Bücherl, 1949; Indicatti, Lucas } \\
\text { Guadanucci \& Yamamoto, } 2008\end{array}$ \\
\hline Theraphosidae & Proshapalopus amazonicus & Mello-Leitão & 1923 & & Bertani, 2001 \\
\hline Theraphosidae & Vitalius buecherli & Bertani & 2001 & & Bertani, 2001 \\
\hline Theraphosidae & Vitalius cesteri & (Mello-Leitão) & 1923 & & Bertani, 2001 \\
\hline Theraphosidae & Vitalius dubius & (Mello-Leitão) & 1923 & sinantrópica & Mello-Leitão, 1923a; Bertani, 2001 \\
\hline Theraphosidae & Vitalius longisternalis & Bertani & 2001 & & Bertani, 2001 \\
\hline Theraphosidae & Vitalius lucasae & Bertani & 2001 & & Bertani, 2001 \\
\hline Theraphosidae & Vitalius platyomma & (Mello-Leitão) & 1923 & & Piza, 1939a \\
\hline Theraphosidae & Vitalius roseus & (Mello-Leitão) & 1923 & & Piza, 1944 \\
\hline Theraphosidae & Vitalius sorocabae & (Mello-Leitão) & 1923 & & Bertani, 2001 \\
\hline Theraphosidae & Vitalius tetracanthus & (Mello-Leitão) & 1923 & & Piza, 1944 \\
\hline Theraphosidae & Vitalius vellutinus & (Mello-Leitão) & 1923 & & Bertani, 2001 \\
\hline Theraphosidae & Vitalius wacketi & (Mello-Leitão) & 1923 & & Bertani, 2001 \\
\hline Theridiidae & $\begin{array}{l}\text { Achaearanea } \\
\text { dea }\end{array}$ & $\begin{array}{l}\text { Buckup \& } \\
\text { Marques }\end{array}$ & 2006 & & Buckup, Marques \& Ott, 2006 \\
\hline Theridiidae & $\begin{array}{l}\text { Achaearanea } \\
\text { digitus }\end{array}$ & $\begin{array}{l}\text { Buckup \& } \\
\text { Marques }\end{array}$ & 2006 & & Buckup, Marques \& Ott, 2006 \\
\hline Theridiidae & $\begin{array}{l}\text { Achaearanea } \\
\text { triguttata }\end{array}$ & (Keyserling) & 1891 & & $\begin{array}{c}\text { Levi, 1963c; } \\
\text { Indicatti \& Brescovit, } 2008\end{array}$ \\
\hline Theridiidae & Anelosimus dubiosus & (Keyserling) & 1891 & & Gonzaga \& Santos, 1999 \\
\hline Theridiidae & $\begin{array}{l}\text { Anelosimus } \\
\text { ethicus }\end{array}$ & (Keyserling) & 1884 & & $\begin{array}{l}\text { Levi, 1956b; Levi, 1967d; } \\
\text { Ignarsson, } 2004\end{array}$ \\
\hline Theridiidae & Anelosimus eximius & (Keyserling) & 1884 & & Levi, 1956b \\
\hline Theridiidae & Anelosimus jabaquara & Levi & 1956 & & Levi, 1956b; Gonzaga \& Santos, 1999 \\
\hline
\end{tabular}


Tabela 1. Continuação...

\begin{tabular}{|c|c|c|c|c|c|}
\hline Família & spp. & Autor & Data & Destaque & Referências \\
\hline Theridiidae & $\begin{array}{l}\text { Anelosimus } \\
\text { jucundus }\end{array}$ & $\begin{array}{c}\text { (O.P.- } \\
\text { Cambridge) }\end{array}$ & 1896 & & Indicatti \& Brescovit 2008 \\
\hline Theridiidae & Anelosimus lorenzo & Fowler \& Levi & 1979 & & Indicatti \& Brescovit 2008 \\
\hline Theridiidae & Anelosimus nigrescens & (Keyserling) & 1884 & & Ignarsson, 2004 \\
\hline Theridiidae & Anelosimus studiosus & (Hentz) & 1850 & & Levi, 1967d \\
\hline Theridiidae & Argyrodes elevatus & Taczanowski & 1873 & & Exline \& Levi, 1962 \\
\hline Theridiidae & Ariamnes longissimus & (Keyserling) & 1891 & & Exline \& Levi, 1962 \\
\hline Theridiidae & Chrosiothes niteroi & Levi & 1964 & & Marques \& Buckup, 1997 \\
\hline Theridiidae & $\begin{array}{c}\text { Chrosiothes } \\
\text { perfidus }\end{array}$ & $\begin{array}{l}\text { Marques \& } \\
\text { Buckup }\end{array}$ & 1997 & & Marques \& Buckup, 1997 \\
\hline Theridiidae & Chrysso compressa & (Keyserling) & 1884 & & Levi, 1962b \\
\hline Theridiidae & $\begin{array}{c}\text { Chrysso } \\
\text { intervales }\end{array}$ & $\begin{array}{l}\text { Gonzaga, Leiner } \\
\text { \& Santos }\end{array}$ & 2006 & registro único & Gonzaga, Leiner \& Santos, 2006 \\
\hline Theridiidae & $\begin{array}{c}\text { Chrysso } \\
\text { pulcherrima }\end{array}$ & Mello-Leitão & 1917 & & $\begin{array}{c}\text { Levi, 1962b; } \\
\text { Rinaldi, Mendes \& Cady, } 2002\end{array}$ \\
\hline Theridiidae & Chrysso pulchra & (Keyserling) & 1891 & & Indicatti \& Brescovit 2008 \\
\hline Theridiidae & Chrysso riberao & Levi & 1962 & & Levi, 1962b \\
\hline Theridiidae & Coleosoma acutiventer & (Keyserling) & 1884 & & Mello-Leitão, 1919 \\
\hline Theridiidae & $\begin{array}{l}\text { Coleosoma } \\
\text { floridanum }\end{array}$ & Banks & 1900 & sinantrópica & $\begin{array}{l}\text { Rinaldi, Mendes \& Cady, 2002; } \\
\text { Indicatti \& Brescovit, } 2008\end{array}$ \\
\hline Theridiidae & Craspedisia cornuta & (Keyserling) & 1891 & & Indicatti \& Brescovit 2008 \\
\hline Theridiidae & Cryptachaea altiventer & (Keyserling) & 1884 & & Levi, 1963b; Yoshida, 2008 \\
\hline Theridiidae & $\begin{array}{l}\text { Cryptachaea } \\
\text { canionis }\end{array}$ & $\begin{array}{c}\text { (Chamberlin \& } \\
\text { Gertsch) }\end{array}$ & 1929 & & $\begin{array}{l}\text { Brignoli, 1972c; } \\
\text { Yoshida, } 2008\end{array}$ \\
\hline Theridiidae & Cryptachaea cinnabarina & (Levi) & 1963 & sinantrópica & Levi, 1963b; Yoshida, 2008 \\
\hline Theridiidae & $\begin{array}{c}\text { Cryptachaea } \\
\text { hirta }\end{array}$ & (Taczanowski) & 1873 & & $\begin{array}{l}\text { Levi, 1963b; Rinaldi, Mendes \& } \\
\text { Cady, 2002; Yoshida, } 2008\end{array}$ \\
\hline Theridiidae & Cryptachaea jequirituba & (Levi) & 1963 & & Levi, 1963b; Yoshida, 2008 \\
\hline Theridiidae & Cryptachaea migrans & (Keyserling) & 1884 & & Levi, 1957c; Yoshida, 2008 \\
\hline Theridiidae & $\begin{array}{l}\text { Cryptachaea } \\
\text { passiva }\end{array}$ & (Keyserling) & 1891 & & $\begin{array}{l}\text { Levi, 1963b; Levi, 1967b; } \\
\text { Yoshida, } 2008\end{array}$ \\
\hline Theridiidae & Cryptachaea pinguis & (Keyserling) & 1886 & & Indicatti \& Brescovit 2008 \\
\hline Theridiidae & Cryptachaea rioensis & (Levi) & 1963 & & Indicatti \& Brescovit 2008 \\
\hline Theridiidae & Dipoena cordiformis & Keyserling & 1886 & & Levi, 1963a \\
\hline Theridiidae & Dipoena granulata & (Keyserling) & 1886 & & Indicatti \& Brescovit 2008 \\
\hline Theridiidae & Dipoena kuyuwini & Levi & 1963 & & Indicatti \& Brescovit 2008 \\
\hline Theridiidae & Dipoena pumicata & (Keyserling) & 1886 & & Indicatti \& Brescovit 2008 \\
\hline Theridiidae & Dipoena taeniatipes & Keyserling & 1891 & & Buckup \& Marques, 1996 \\
\hline Theridiidae & Dipoena variabilis & (Keyserling) & 1886 & & Indicatti \& Brescovit 2008 \\
\hline Theridiidae & Dipoena woytkowskii & Levi & 1963 & & Indicatti \& Brescovit 2008 \\
\hline Theridiidae & Dipoenata conica & (Chickering) & 1943 & & Indicatti \& Brescovit 2008 \\
\hline Theridiidae & Emertonella taczanowskii & (Keyserling) & 1886 & sinantrópica & Indicatti \& Brescovit 2008 \\
\hline Theridiidae & Episinus cognatus & O.P.- Cambridge & 1893 & & Indicatti \& Brescovit 2008 \\
\hline Theridiidae & Episinus malachinus & (Simon) & 1895 & & Indicatti \& Brescovit 2008 \\
\hline Theridiidae & Episinus teresopolis & Levi & 1964 & & Indicatti \& Brescovit 2008 \\
\hline Theridiidae & $\begin{array}{l}\text { Faiditius } \\
\text { affinis }\end{array}$ & $\begin{array}{c}\text { (O.P.- } \\
\text { Cambridge) }\end{array}$ & 1880 & & Exline \& Levi, 1962 \\
\hline Theridiidae & Faiditius caudatus & (Taczanowski) & 1874 & & Exline \& Levi, 1962 \\
\hline Theridiidae & Faiditius striatus & (Keyserling) & 1891 & & Exline \& Levi, 1962 \\
\hline Theridiidae & Faiditus acuminatus & (Keyserling) & 1891 & & Indicatti \& Brescovit 2008 \\
\hline Theridiidae & Faiditus americanus & (Taczanowski) & 1874 & & Indicatti \& Brescovit 2008 \\
\hline Theridiidae & Helvibis longicauda & Keyserling & 1891 & & Gonzaga, Leiner \& Santos, 2006 \\
\hline
\end{tabular}


Tabela 1. Continuação...

\begin{tabular}{|c|c|c|c|c|c|}
\hline Família & spp. & Autor & Data & Destaque & Referências \\
\hline Theridiidae & Hetschkia gracilis & Keyserling & 1866 & & Indicatti \& Brescovit 2008 \\
\hline Theridiidae & $\begin{array}{l}\text { Keijia } \\
\text { mneon }\end{array}$ & $\begin{array}{l}\text { (Bösenberg \& } \\
\text { Strand) }\end{array}$ & 1906 & sinantrópica & $\begin{array}{l}\text { Rinaldi, Mendes \& Cady, 2002; } \\
\text { Indicatti \& Brescovit, } 2008\end{array}$ \\
\hline Theridiidae & $\begin{array}{l}\text { Latrodectus } \\
\text { geometricus }\end{array}$ & C.L.Koch & 1841 & sinantrópica & $\begin{array}{c}\text { Badcock, 1932; } \\
\text { Rinaldi, Mendes \& Cady, 2002; } \\
\text { Indicatti \& Brescovit, } 2008\end{array}$ \\
\hline Theridiidae & Nesticodes rufipes & (Lucas) & 1846 & sinantrópica & Indicatti \& Brescovit 2008 \\
\hline Theridiidae & Parasteatoda tepidariorum & (C.L.Koch) & 1841 & sinantrópica & Levi, $1963 b$ \\
\hline Theridiidae & Parasteatoda tesselata & (Keyserling) & 1884 & & Indicatti \& Brescovit 2008 \\
\hline Theridiidae & $\begin{array}{l}\text { Phoroncidia } \\
\text { reimoseri }\end{array}$ & Levi & 1964 & & $\begin{array}{c}\text { Levi, 1964d; } \\
\text { Indicatti \& Brescovit } 2008\end{array}$ \\
\hline Theridiidae & Phycosoma altum & Keyserling & 1886 & & Levi, 1963a \\
\hline Theridiidae & $\begin{array}{c}\text { Rhomphaea } \\
\text { procera }\end{array}$ & $\begin{array}{c}\text { (O.P.- } \\
\text { Cambridge) }\end{array}$ & 1898 & & Indicatti \& Brescovit 2008 \\
\hline Theridiidae & Spintharus gracilis & Keyserling & 1886 & & Levi, 1963e \\
\hline Theridiidae & Steatoda ancorata & (Holmberg) & 1876 & & Indicatti \& Brescovit 2008 \\
\hline Theridiidae & $\begin{array}{c}\text { Steatoda } \\
\text { diamantina }\end{array}$ & Levi & 1962 & & $\begin{array}{c}\text { Levi, 1967d; } \\
\text { Indicatti \& Brescovit } 2008\end{array}$ \\
\hline Theridiidae & Steatoda grossa & (C.L. Koch) & 1838 & sinantrópica & Mello-Leitão, 1919 \\
\hline Theridiidae & Styposis selis & Levi & 1964 & & Indicatti \& Brescovit 2008 \\
\hline Theridiidae & Theridion apostoli & Mello-Leitão & 1945 & & Indicatti \& Brescovit 2008 \\
\hline Theridiidae & Theridion aulos & Levi & 1963 & registro único & Levi, $1963 \mathrm{c}$ \\
\hline Theridiidae & $\begin{array}{l}\text { Theridion } \\
\text { bergi }\end{array}$ & Levi & 1963 & & $\begin{array}{c}\text { Gnaspini \& Trajano, 1994; } \\
\text { Xavier, Baptista \& Trajano, } 1995\end{array}$ \\
\hline Theridiidae & Theridion biezankoi & Levi & 1963 & & Indicatti \& Brescovit 2008 \\
\hline Theridiidae & Theridion calcynatum & Holmberg & 1876 & & Levi, 1967d \\
\hline Theridiidae & Theridion evexum & Keyserling & 1884 & & Levi, 1959b \\
\hline Theridiidae & Theridion hispidum & O.P.- Cambridge & 1898 & & Zeppelini Filho et al., 2003 \\
\hline Theridiidae & Theridion nigriceps & Keyserling & 1891 & & Keyserling, 1891 \\
\hline Theridiidae & Theridion olaup & Levi & 1963 & registro único & Levi, $1963 \mathrm{c}$ \\
\hline Theridiidae & Theridion opolon & Levi & 1963 & & Levi, $1963 \mathrm{c}$ \\
\hline Theridiidae & Theridion orgea & (Levi) & 1967 & & Buckup \& Marques, 1996 \\
\hline Theridiidae & Theridion pernambucum & Levi & 1963 & & Rinaldi, Mendes \& Cady, 2002 \\
\hline Theridiidae & Theridion pires & Levi & 1963 & registro único & Levi, $1963 \mathrm{c}$ \\
\hline Theridiidae & Theridion plaumanni & Levi & 1963 & & Levi, 1963c; Levi, 1967d \\
\hline Theridiidae & Theridion positivum & Chamberlin & 1924 & & Levi, $1963 \mathrm{c}$ \\
\hline Theridiidae & $\begin{array}{c}\text { Theridion } \\
\text { quadripartitum }\end{array}$ & Keyserling & 1891 & & $\begin{array}{c}\text { Keyserling, 1891; } \\
\text { Indicatti \& Brescovit } 2008\end{array}$ \\
\hline Theridiidae & Theridion striatum & Keyserling & 1884 & & Levi, $1963 \mathrm{c}$ \\
\hline Theridiidae & Theridion tungurahua & Levi & 1963 & & Levi, $1963 \mathrm{c}$ \\
\hline Theridiidae & Theridion volubile & Keyserling & 1884 & registro único & Rinaldi, Mendes \& Cady, 2002 \\
\hline Theridiidae & Theridula gonygaster & (Simon) & 1873 & & Indicatti \& Brescovit 2008 \\
\hline Theridiidae & Thwaitesia affinis & O.P.- Cambridge & 1882 & & Levi, 1963e; Levi, 1967d \\
\hline Theridiidae & Thymoites anicus & Levi & 1964 & & Levi, 1964b \\
\hline Theridiidae & Thymoites ilvan & Levi & 1964 & registro único & Levi, 1964b \\
\hline Theridiidae & Thymoites ipiranga & Levi & 1964 & registro único & Levi, 1964b \\
\hline Theridiidae & Thymoites palo & Levi & 1967 & registro único & Levi, 1967d \\
\hline Theridiidae & Tidarren haemorrhoidale & (Bertkau) & 1880 & & Indicatti \& Brescovit 2008 \\
\hline Theridiidae & Tidarren sisyphoides & (Walckenaer) & 1841 & & Indicatti \& Brescovit 2008 \\
\hline Theridiidae & Wamba congener & O.P.- Cambridge & 1896 & & Levi, $1963 \mathrm{c}$ \\
\hline Theridiidae & Wamba crispulus & (Simon) & 1895 & sinantrópica & Levi, 1963c \\
\hline Theridiidae & Wirada tijuca & Levi & 1967 & & Indicatti \& Brescovit 2008 \\
\hline
\end{tabular}


Tabela 1. Continuação...

\begin{tabular}{|c|c|c|c|c|c|}
\hline Família & spp. & Autor & Data & Destaque & Referências \\
\hline Theridiosomatidae & $\begin{array}{l}\text { Epilineutes } \\
\text { globosus }\end{array}$ & $\begin{array}{c}\text { (O.P.- } \\
\text { Cambridge) }\end{array}$ & 1896 & & $\begin{array}{l}\text { Gnaspini \& Trajano, 1994; } \\
\text { Pinto-Da-Rocha, 1995; } \\
\text { Indicatti \& Brescovit, } 2008\end{array}$ \\
\hline Theridiosomatidae & Wendilgarda clara & Keyserling & 1886 & & Brignoli, 1972c \\
\hline Thomisidae & Acentroscelus albipes & Simon & 1886 & & Rinaldi, 1984 \\
\hline Thomisidae & Acentroscelus versicolor & Soares & 1942 & registro único & Soares, 1942 \\
\hline Thomisidae & Aphantochilus rogersi & O.P.- Cambridge & 1870 & & Mello-Leitão, 1929d; Piza, 1937a \\
\hline Thomisidae & Bucranium taurifrons & O.P.- Cambridge & 1881 & & Rinaldi \& Forti, 1997 \\
\hline Thomisidae & Ceraarachne germaini & Simon & 1886 & & Rinaldi \& Forti, 1997 \\
\hline Thomisidae & Epicadinus tuberculatus & Petrunkevitch & 1910 & registro único & Petrunkevitch, 1910 \\
\hline Thomisidae & Epicadus heterogaster & (Guérin) & 1829 & sinantrópica & Piza, 1944 \\
\hline Thomisidae & $\begin{array}{c}\text { Epicadus heterogaster } \\
\text { scholagricolae }\end{array}$ & Piza & 1933 & & Piza, 1933b \\
\hline Thomisidae & Epicadus pallidus & Mello-Leitão & 1929 & & Mello-Leitão, 1929d \\
\hline Thomisidae & Erissus bateae & Soares & 1941 & registro único & Soares, 1941 \\
\hline Thomisidae & Erissus truncatifrons & Simon & 1895 & & Mello-Leitão, 1929d \\
\hline Thomisidae & Martus albolineatus & Mello-Leitão & 1943 & registro único & Mello-Leitão, 1943e \\
\hline Thomisidae & Misumenoides corticatus & Mello-Leitão & 1929 & registro único & Mello-Leitão, 1929d \\
\hline Thomisidae & Misumenoides illotus & Soares & 1944 & registro único & Soares, $1944 \mathrm{c}$ \\
\hline Thomisidae & Misumenoides similis & (Keyserling) & 1881 & registro único & Keyserling, 1881c \\
\hline Thomisidae & Misumenops argenteus & Mello-Leitão & 1929 & & Rinaldi, 1988 \\
\hline Thomisidae & Misumenops lenis & (Keyserling) & 1880 & & Indicatti \& Brescovit 2008 \\
\hline Thomisidae & $\begin{array}{l}\text { Misumenops } \\
\text { pallens }\end{array}$ & (Keyserling) & 1880 & sinantrópica & $\begin{array}{c}\text { Badcock, 1932; Piza, 1934; } \\
\text { Rinaldi, } 1983\end{array}$ \\
\hline Thomisidae & Misumenops pallidus & (Keyserling) & 1880 & sinantrópica & Rinaldi, 1983 \\
\hline Thomisidae & Misumenops spinifer & (Piza) & 1937 & registro único & Piza, 1937b \\
\hline Thomisidae & Misumenops temibilis & (Holmberg) & 1876 & registro único & Lehtinen\& Marusik, 2008 \\
\hline Thomisidae & Misumenops variegatus & Mello-Leitão & 1917 & & Mello-Leitão, 1917a \\
\hline Thomisidae & Onocolus echinatus & (Taczanowski) & 1873 & & Lise, 1981a \\
\hline Thomisidae & Onocolus intermedius & (Mello-Leitão) & 1929 & & Rinaldi \& Forti, 1997 \\
\hline Thomisidae & Onocolus simoni & Mello-Leitão & 1915 & & Mello-Leitão, 1929d \\
\hline Thomisidae & $\begin{array}{c}\text { Runcinioides } \\
\text { litteratus }\end{array}$ & Piza & 1933 & & $\begin{array}{l}\text { Piza, 1933b; Rinaldi, 1988; } \\
\text { Lehtinen \& Marusik, 2008; } \\
\text { Indicatti \& Brescovit, } 2008\end{array}$ \\
\hline Thomisidae & Sidymella jordanensis & (Soares) & 1944 & registro único & Soares, $1944 \mathrm{c}$ \\
\hline Thomisidae & Sidymella kolpogaster & (Lise) & 1973 & & Indicatti \& Brescovit 2008 \\
\hline Thomisidae & Sidymella longispina & (Mello-Leitão) & 1943 & & Rinaldi \& Forti, 1997 \\
\hline Thomisidae & Sidymella multispinulosa & (Mello-Leitão) & 1944 & & Rinaldi \& Forti, 1997 \\
\hline Thomisidae & Stephanopoides mirabilis & Soares & 1942 & & Soares, 1942 \\
\hline Thomisidae & Strophius levyi & Soares & 1943 & & Soares, 1943b \\
\hline Thomisidae & Strophius melloleitaoi & Soares & 1943 & registro único & Soares, 1943a \\
\hline Thomisidae & Strophius nigricans & Keyserling & 1880 & & Rinaldi \& Forti, 1997 \\
\hline Thomisidae & Synaemops nigridorsi & Mello-Leitão & 1929 & & Mello-Leitão, 1939h \\
\hline Thomisidae & Synema bellum & Soares & 1944 & & Soares, $1944 \mathrm{c}$ \\
\hline Thomisidae & Synema glaucothorax & Piza & 1934 & registro único & Piza, 1944 \\
\hline Thomisidae & Synema pereirai & Soares & 1943 & & Soares, 1943a \\
\hline Thomisidae & Synstrophius blanci & (Mello-Leitão) & 1917 & & Rinaldi \& Forti, 1997 \\
\hline Thomisidae & Tmarus albifrons & Piza & 1944 & registro único & Piza, 1944 \\
\hline Thomisidae & Tmarus albolineatus & Keyserling & 1880 & & Rinaldi \& Forti, 1997 \\
\hline Thomisidae & Tmarus alticola & Mello-Leitão & 1929 & & Indicatti \& Brescovit 2008 \\
\hline Thomisidae & Tmarus bisectus & Piza & 1944 & registro único & Piza, 1944 \\
\hline Thomisidae & Tmarus caxambuensis & Mello-Leitão & 1929 & & Mello-Leitão, 1939h \\
\hline
\end{tabular}


Tabela 1. Continuação...

\begin{tabular}{|c|c|c|c|c|c|}
\hline Família & spp. & Autor & Data & Destaque & Referências \\
\hline Thomisidae & Tmarus clavipes & Keyserling & 1891 & & Rinaldi \& Forti, 1997 \\
\hline Thomisidae & Tmarus estyliferus & Mello-Leitão & 1929 & & Rinaldi \& Forti, 1997 \\
\hline Thomisidae & Tmarus mutabilis & Soares & 1944 & & Soares, 1944a; Rinaldi \& Forti, 1997 \\
\hline Thomisidae & Tmarus nigroviridis & Mello-Leitão & 1929 & & Rinaldi \& Forti, 1997 \\
\hline Thomisidae & Tmarus parki & Chickering & 1950 & registro único & Rinaldi \& Forti, 1997 \\
\hline Thomisidae & Tmarus paulensis & Piza & 1935 & registro único & Piza, 1935 \\
\hline Thomisidae & Tmarus pizai & Soares & 1941 & registro único & Soares, 1941 \\
\hline Thomisidae & Tmarus pleuronotatus & Mello-Leitão & 1941 & & Rinaldi \& Forti, 1997 \\
\hline Thomisidae & Tmarus polyandrus & Mello-Leitão & 1929 & & Indicatti \& Brescovit 2008 \\
\hline Thomisidae & Tmarus primitivus & Mello-Leitão & 1929 & & Rinaldi \& Forti, 1997 \\
\hline Thomisidae & Tmarus pugnax & Mello-Leitão & 1929 & & Rinaldi \& Forti, 1997 \\
\hline Thomisidae & Tmarus striolatus & Mello-Leitão & 1943 & & Rinaldi \& Forti, 1997 \\
\hline Thomisidae & Tobias gradiens & Mello-Leitão & 1929 & & Rinaldi \& Forti, 1996 \\
\hline Thomisidae & Urarachne longa & Keyserling & 1880 & & Rinaldi, 1988 \\
\hline Trechaleidae & $\begin{array}{l}\text { Dossenus } \\
\text { guapore }\end{array}$ & $\begin{array}{l}\text { Silva, Lise \& } \\
\text { Carico }\end{array}$ & 2007 & & Silva, Lise \& Carico, 2007 \\
\hline Trechaleidae & Dossenus marginellus & Badcock & 1932 & registro único & Badcock, 1932 \\
\hline Trechaleidae & Neoctenus comosus & Simon & 1897 & & Indicatti \& Brescovit 2008 \\
\hline Trechaleidae & Neoctenus eximius & Mello-Leitão & 1938 & registro único & Mello-Leitão, 1938b \\
\hline Trechaleidae & Paradossenus longipes & (Taczanowski) & 1874 & & Brescovit, Raizer \& Amaral, 2000 \\
\hline Trechaleidae & $\begin{array}{c}\text { Paratrechalea } \\
\text { azul }\end{array}$ & Carico & 2005 & & $\begin{array}{l}\text { Silva, Lise, Buckup \& Brescovit, } \\
2006\end{array}$ \\
\hline Trechaleidae & $\begin{array}{l}\text { Paratrechalea } \\
\text { galianoae }\end{array}$ & Carico & 2005 & & $\begin{array}{c}\text { Silva, Lise, Buckup \& Brescovit, } \\
2006\end{array}$ \\
\hline Trechaleidae & $\begin{array}{l}\text { Paratrechalea } \\
\text { saopaulo }\end{array}$ & Carico & 2005 & & $\begin{array}{c}\text { Carico, 2005; Silva, Lise, Buckup \& } \\
\text { Brescovit, } 2006\end{array}$ \\
\hline Trechaleidae & Trechalea bucculenta & Mello-Leitão & 1931 & & Indicatti \& Brescovit 2008 \\
\hline Trechaleidae & Trechaleoides biocellata & (Mello-Leitão) & 1926 & & Indicatti \& Brescovit 2008 \\
\hline Trechaleidae & Trechaleoides keyserlingi & $\begin{array}{l}\text { F.O.P. - } \\
\text { Cambridge }\end{array}$ & 1903 & & Indicatti \& Brescovit 2008 \\
\hline Uloboridae & Miagrammopes correai & Piza & 1944 & registro único & Piza, 1944 \\
\hline Uloboridae & Miagrammopes guttatus & Mello-Leitão & 1937 & registro único & Mello-Leitão, 1937a \\
\hline Uloboridae & Petrunkevitchia venusta & Mello-Leitão & 1915 & & Mello-Leitão, 1915a \\
\hline Uloboridae & Uloborus minutus & Mello-Leitão & 1915 & registro único & Mello-Leitão, 1915a \\
\hline Uloboridae & Zozis geniculata & (Olivier) & 1926 & sinantrópica & Indicatti \& Brescovit 2008 \\
\hline Zodariidae & $\begin{array}{l}\text { Cybaeodamus } \\
\text { meridionalis }\end{array}$ & $\begin{array}{l}\text { Lise, Ott \& } \\
\text { Rodrigues }\end{array}$ & 2009 & & Lise, Ott \& Rodrigues, 2009 \\
\hline Zodariidae & $\begin{array}{l}\text { Tenedos } \\
\text { garoa }\end{array}$ & $\begin{array}{c}\text { Candiani, } \\
\text { Bonaldo \& } \\
\text { Brescovit }\end{array}$ & 2008 & registro único & Candiani, Bonaldo \& Brescovit, 2008 \\
\hline Zodariidae & Tenedos procreator & Jocque \& Baert & 2002 & & Candiani, Bonaldo \& Brescovit, 2008 \\
\hline Zoridae & Odo obscurus & Mello-Leitão & 1936 & registro único & Strand, 1936 \\
\hline
\end{tabular}

\section{Resultados e Discussão}

\section{Lista das espécies do Estado de São Paulo}

A lista de espécies do estado é apresentada na Tabela 1 e consta de 875 espécies descritas (Figura 1), distribuídas em 50 famílias, com dados atualizados para esta listagem até o primeiro semestre de 2010.

A região neotropical possui 11.280 espécies, ou seja, quase $1 / 3$ das espécies propostas para o mundo. O Brasil é o país da região com maior diversidade (3.203 spp.), seguido do México (1.951 spp.) e Panamá (1.325 spp.). Contabilizando apenas a América do Sul, teríamos atualmente mais de 7.500 espécies de aranhas. Neste caso, o Brasil também apresenta a maior diversidade de aranhas entre os países, seguido da Argentina (1.316 spp.) e Peru (1.066 spp.).

O Brasil apresenta hoje 3.203 espécies registradas em 659 gêneros e 72 famílias. Destas, 2.784 espécies são conhecidas apenas para o Brasil. O Rio de Janeiro é o estado com maior número de espécies do país até 2008 (756 spp.), seguido por São Paulo (728 spp.), Amazonas (694 spp.) e Rio Grande do Sul (662 spp.) (Figura 1).

A riqueza em espécies por quadrículas no Estado de São Paulo variou entre 1 e 246 espécies, desconsiderando-se 13 quadrículas que não apresentaram registros de ocorrência de aranhas (Figuras 2 e 3). 
As quadrículas com maior diversidade observada englobam a capital do estado e a região de Botucatu, exatamente onde estão localizadas as coleções do estado. Isto indica que a maior diversidade nestes locais está associada ao esforço amostral intenso empreendido por pesquisadores e colaboradores associados a estas instituições. Além disso, as quadrículas com maior riqueza (com 98 a 246 espécies) estão situadas na Mata Atlântica, que como será discutido adiante, a fitofisionomia melhor amostrada no estado. A riqueza em espécies é menor nas quadrículas que englobam a Mata Atlântica semidecídua, no interior do estado, e as áreas de cerrado. A variação na diversidade de aranhas observada entre as quadrículas está diretamente relacionada a diferenças de esforço amostral, como se observa pela distribuição no número de registros de ocorrência no estado (Figura 3).

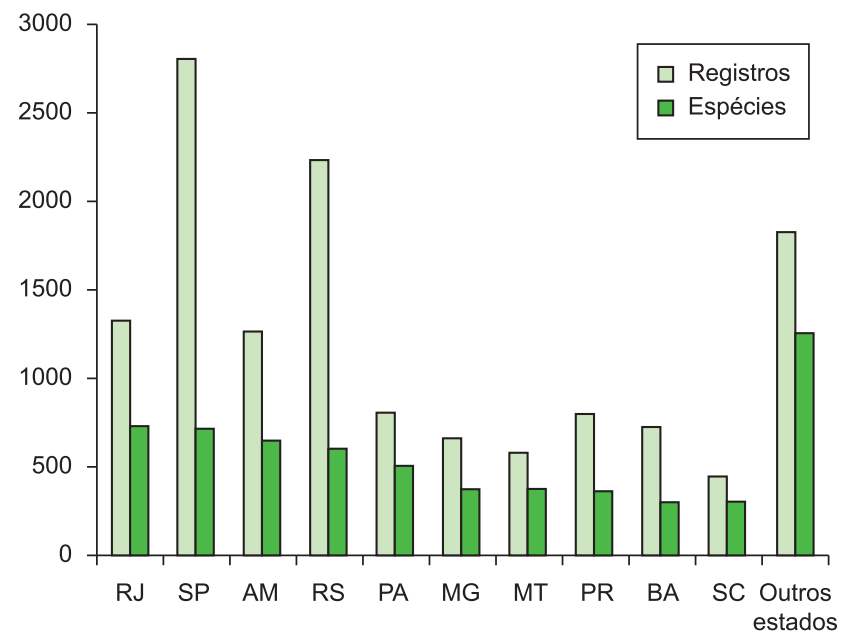

Figura 1. Número de registros e de espécies aranhas por estados do Brasil.

Figure 1. Number of records and species of spiders per states in Brazil.
Comparado aos demais estados do país, São Paulo é o melhor amostrado, considerando-se a concentração de registros de ocorrência de aranhas (Figuras 1 e 3), São Paulo apresenta 3.122 registros de ocorrência, seguido dos estados do Rio Grande do Sul (2.347), Rio de Janeiro (1.408) e Amazonas (1.346) (Figura 1). Esses estados são exatamente aqueles que abrigam as principais instituições de pesquisa em sistemática de Arachnida, com coleções significativas, com fartos acervos regionais, e com um longo histórico de atuação de aracnólogos. Em São Paulo estão às três instituições que abrigam coleções com mais de 200.000 lotes de aranhas tombadas, o que significa mais de 400.000 exemplares estocados (Tabela 2). Isto mostra que as diferenças de riqueza em espécies de aranhas entre os estados do país podem ser explicadas principalmente por diferenças de esforço amostral, o que também ocorre dentro de cada estado. No Estado de São Paulo, a riqueza em espécies por quadrícula é fortemente correlacionada com o número de registros observado em cada uma (Figuras 2 e 3). O número de registros é particularmente baixo em áreas de Mata Atlântica semidecídua, no interior do estado, e nas áreas de cerrado. Vale lembrar que o último é uma das fitofisionomias mais ameaçadas do estado, que já teve mais de $90 \%$ da sua área transformada em cidades ou áreas de cultivo (Klink \& Machado, 2005).

No geral a maioria das espécies brasileiras é conhecida por poucos registros (Figura 5). Embora em média cada espécie tenha quatro registros no país, 57\% delas são representadas por apenas um registro (ver espécies na Tabela 1) e apenas 114 espécies são conhecidas por mais de 20 registros (Figura 7). Um padrão similar pode ser observado para a fauna de aranhas de São Paulo (Figura 6). Apenas 21 espécies apresentam mais de 20 registros (Figura 7) das quais as que apresentam maior número de registros são Vitalius dubius (MelloLeitão) (142); Vitalius sorocabae (Mello-Leitão) (104); Vitalius vellutinus (Mello-Leitão) (89); Ancylometes concolor (Perty) (74); Phoneutria nigriventer (Keyserling) (64); Vitalius wacketi (Mello-

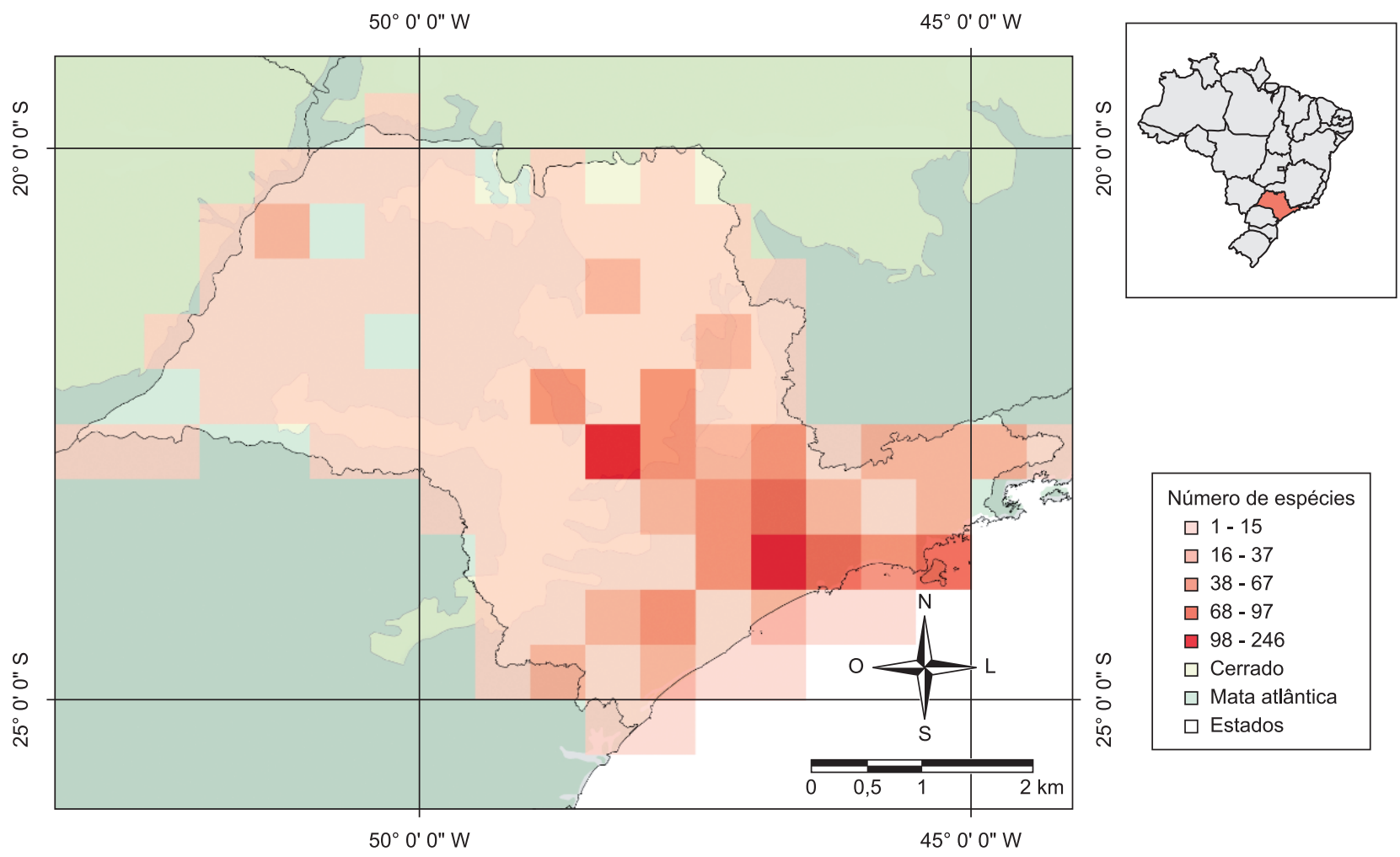

Figura 2. Riqueza em espécies de aranhas por quadriculas no Estado de São Paulo.

Figure 2. Species richness per squares in the state of São Paulo. 
Leitão) (64); Ctenus ornatus (Keyserling) (54); Scytodes globula Nicolet (52); Ctenus medius Keyserling (46) sendo estas também as espécies com distribuição mais ampla no estado.

O baixo número de registros para a maioria das espécies indica claramente deficiência amostral na maioria das regiões do estado, com exceção talvez ao redor da capital do estado. A Figura 3 mostra áreas de onde não há registro de aranhas para o estado. Obviamente essas regiões abrigam comunidades de aranhas, mas atualmente não há conhecimento sobre as espécies que ocorrem nessas áreas. Esta questão deve ser estudada e revertida, já que historicamente o esforço de amostragem da fauna paulista, e mesmo do país, nunca foi homogêneo. Esta deficiência amostral dificulta a determinação, na maioria dos casos, da área de distribuição, status de conservação, endemismo e raridade de nossas espécies.

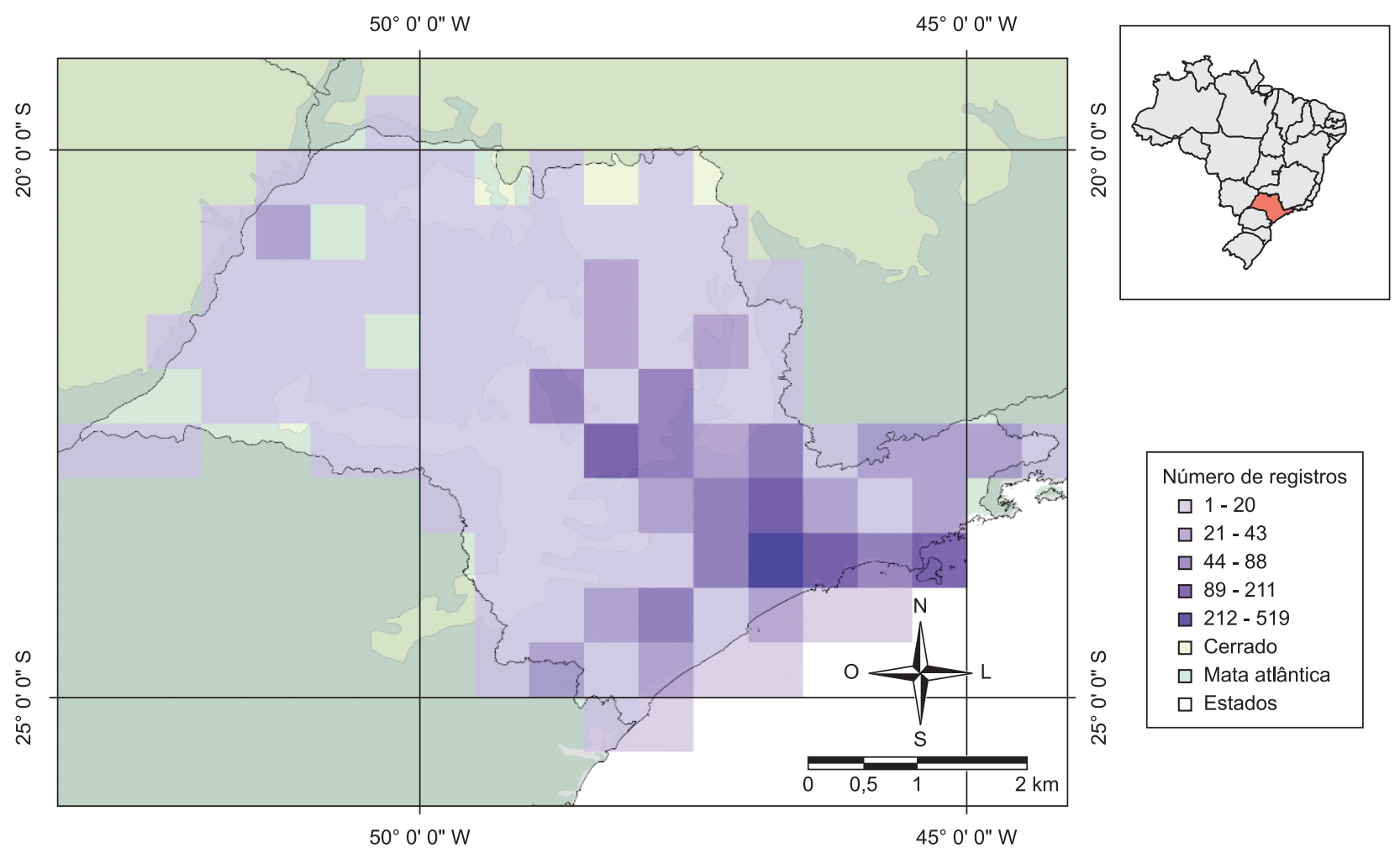

Figura 3. Número de registros de espécies de aranhas por quadriculas no Estado de São Paulo.

Figure 3. Number of records of species of spiders per squares in the state of São Paulo.

Tabela 2. Lista das coleções brasileiras de Araneae.

Table 2. List of Brazilian collections of Araneae.

\begin{tabular}{lccccccc}
\hline \multicolumn{1}{c}{ Coleções } & $\begin{array}{c}\text { Lotes } \\
\text { tombados }\end{array}$ & $\begin{array}{c}\text { Lotes não } \\
\text { tombados }\end{array}$ & Tipos & Curador & Instituição & Informatização Conservação \\
\hline IBSP - São Paulo, SP & 165.000 & 25.000 & Sim & I. Knysak & Estadual & Parcial & Ver nota $^{1}$ \\
MCN-FZB/RS - Porto Alegre, RS & 47.200 & 5.000 & Sim & E.H. Buckup & Estadual & Total & Ótimo \\
MZSP - São Paulo, SP & 19.640 & 3.000 & Sim & R. Pinto da Rocha & Estadual & Total & Ótimo \\
MCTP/PUCRS - Porto Alegre, RS & 28.660 & 500 & Sim & A.A. Lise & Particular & Total & Ótimo \\
MNRJ - Rio de Janeiro, RJ & 8.200 & 23.000 & Sim & A.B. Kury & Federal & Total & Ótimo \\
MHCI - Curitiba, PR & 6.000 & 1.000 & Sim & J.C. Moura-Leite & Municipal & LT & Bom \\
UEFS - Feira de Santana, BA & 1.070 & 200 & Não & I. Biondi & Estadual & NI & Bom \\
UFBA - Salvador, BA & 2.660 & 4.000 & Sim & T. Kobler & Federal & NI & Ótimo \\
UBTU - Botucatu, SP & 3.360 & 1.000 & Sim & I.M.P. Rinaldi & Estadual & NI & Bom \\
INPA - Manaus, AM & 6.280 & 22.000 & Sim & C. Magalhães & Federal & NI & Bom \\
MPEG - Belém, PA & 16.700 & 20.000 & Sim & A.B. Bonaldo & Federal & Total & Ótimo \\
UA-UFAM - Manaus, AM & 1.500 & 400 & Sim & N.O. Aguiar & Federal & NI & Bom \\
UFMG - Belo Horizonte, MG & 4.038 & 5.000 & Sim & A.J. Santos & Federal & Total & Ótimo
\end{tabular}




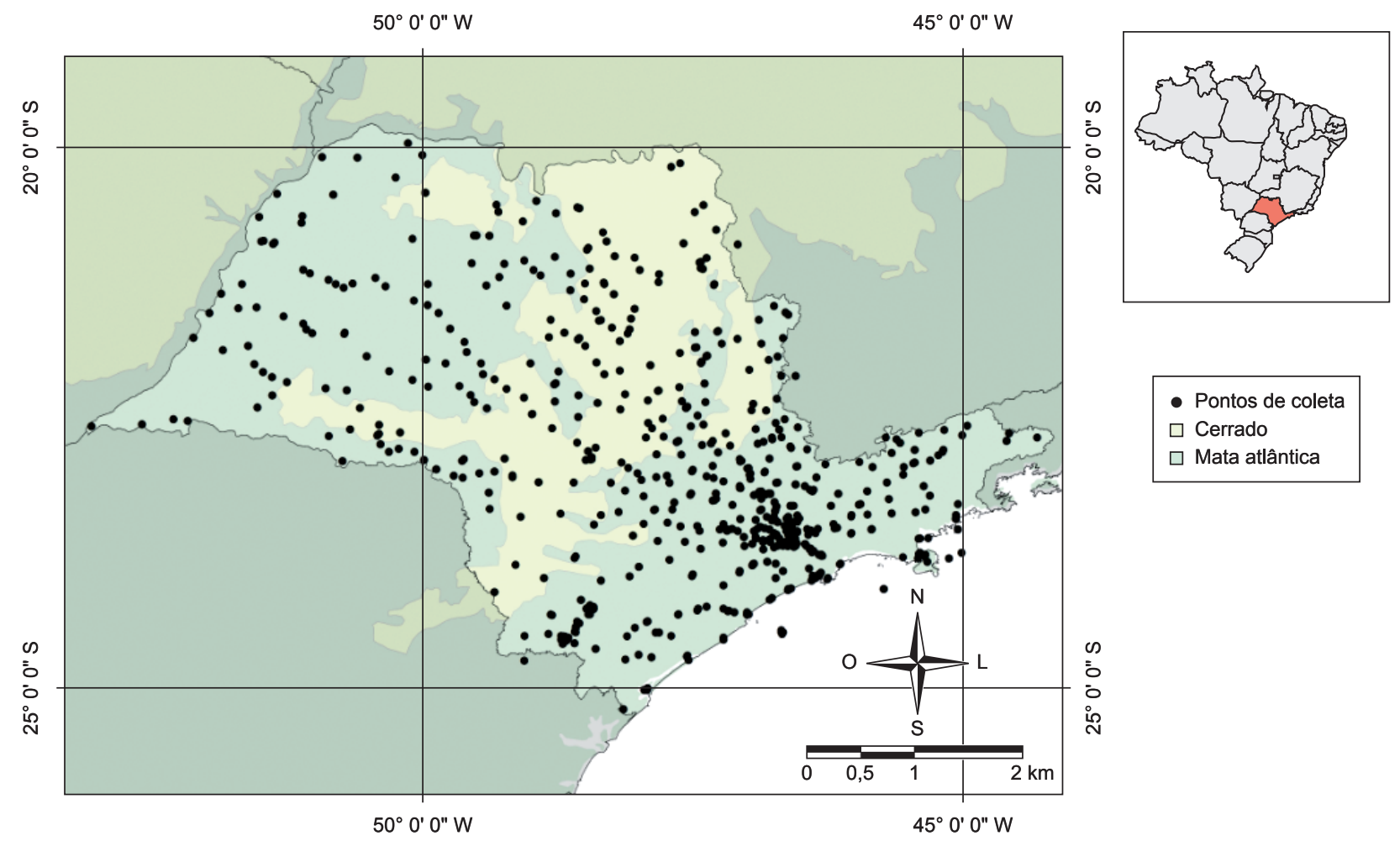

Figura 4. Pontos de ocorrência de espécies de aranhas no estado de São Paulo. Cada ponto representa pelo menos um registro de ocorrência de pelo menos uma espécie de aranha.

Figure 4. Records of species of spiders in the state of São Paulo. Each record represents at least one occurrence of at least one species of spider.

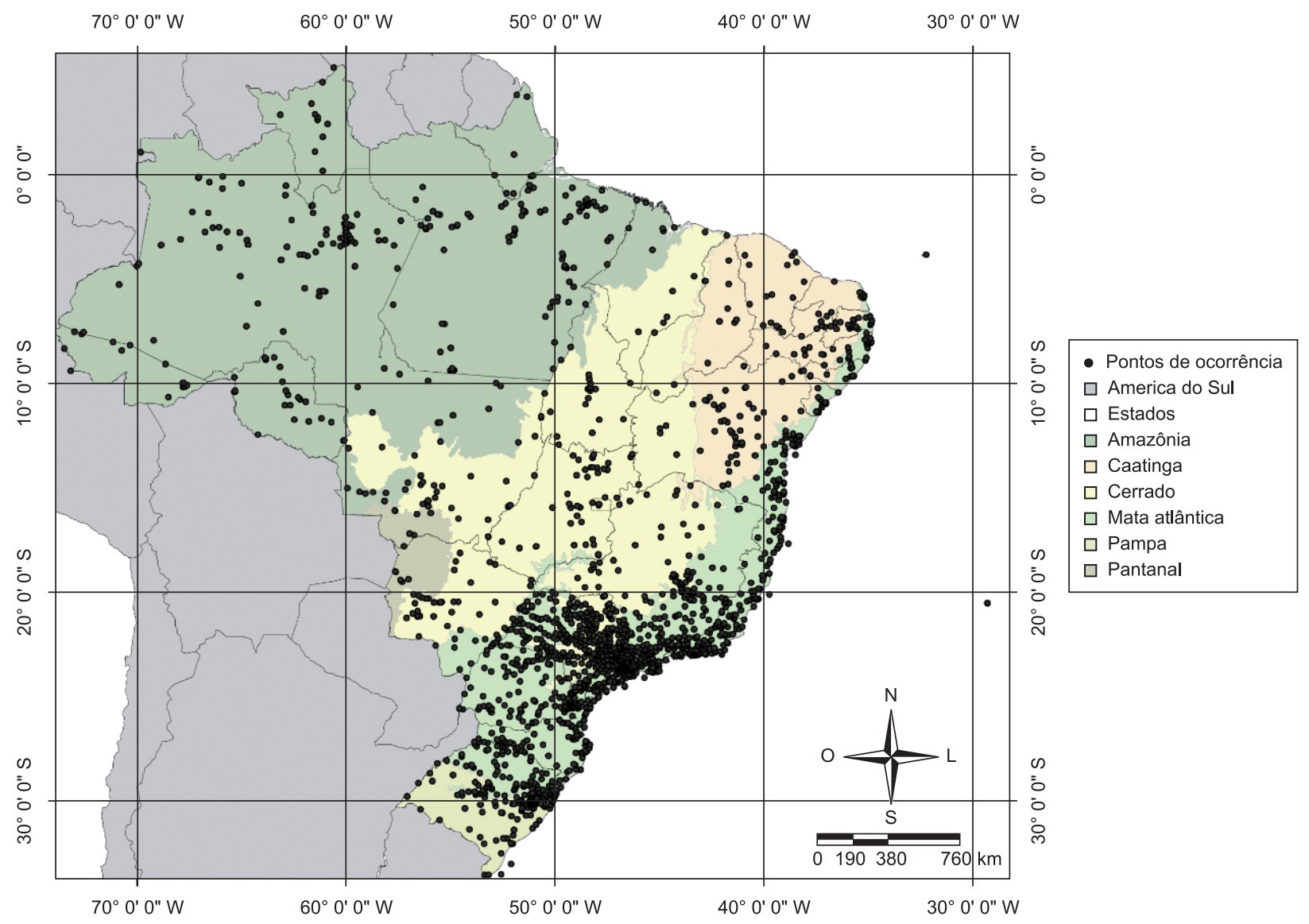

Figura 5. Pontos de ocorrência de espécies de aranhas no Brasil. Cada ponto representa pelo menos um registro de ocorrência de pelo menos uma espécie de aranha.

Figure 5. Records of species of spiders in Brazil. Each record represents at least one record of at least one species of spider. 
Dentre as 50 famílias de aranhas registradas para São Paulo, Araneidae é a mais rica em espécies, seguida por Salticidae e Theridiidae (Figura 8). Embora essas famílias estejam entre as mais ricas em espécies em todo o planeta (Platnick 2010), é digno de nota que o número de espécies de Araneidae supera aquele de Salticidae tanto no Brasil como um todo, como no Estado de São Paulo em particular. Em grande parte isto está ligado a diferenças de esforço de estudo. Os gêneros de Araneidae da região Neotropical foram sistematicamente revisados por Herbert W. Levi, do "Museum of Comparative Zoology (Harvard University)", entre 1968 e 2007 (Calixto \& Levi 2006, Levi 2005a, 2005b, 2007, Santos et al. 2005, e referências em Levi 2002: Tabela 2). Além disso, esta família é a melhor representada em registros de ocorrência, o que está ligado ao fato de ter sido mais estudada que as demais (já que o banco de dados se baseia em registros publicados) e também por ser composta por espécies abundantes, vistosas e que constroem teias particularmente visíveis, em habitats facilmente acessíveis.

Dentre as espécies de aranhas conhecidas para o Estado de São Paulo, cerca de 70 podem ser consideradas sinantrópicas, já que vivem juntas ou ao redor das habitações humanas (Brescovit, 2002). Isto indica que apesar da simplificação ambiental advinda da urbanização, algumas espécies de aranhas podem ocorrer em habitats formados nessas áreas. Parte dessas espécies, como Menemerus bivittatus Dufour (Salticidae), Oecobius navus Blackwall (Oecobiidae) e Pholcus phalangioides (Fuesslin) (Pholcidae), são cosmopolitas e ocorrem predominantemente em ambientes urbanos ou fortemente alterados. Pelo menos 17 espécies registradas no Estado de São Paulo foram introduzidas de outras partes do planeta, particularmente da Europa e Ásia.

Com o atual estado de conhecimento para a fauna de aranhas do Brasil, é bastante difícil determinar se as espécies registradas apenas em São Paulo são endêmicas do estado. Apenas uma espécie,
Mesabolivar cuarassu Huber, Brescovit \& Rheims (Pholcidae) pode ser caracterizada como endêmica de São Paulo. Esta espécie foi descrita da Ilha da Queimada Grande, no litoral de São Paulo (Huber et al., 2005), e não foi encontrada em outras áreas no continente em várias expedições de coleta realizadas no estado. A Ilha de Queimada Grande é conhecida por abrigar outras espécies endêmicas, como a jararacailhoa (Duarte et al. 1995), duas espécies de diplópodos (Schubart 1949), dois quilópodos (Bücherl, 1949) e um anfíbio (Lutz \& Lutz 1939).

\section{Principais avanços relacionados ao Programa BIOTA/FAPESP}

Neste tópico cabe destacar o projeto Biodiversidade de Arachnida e Myriapoda do Estado de São Paulo (PROCESSO: 1999/05446-8) desenvolvido entre dezembro de 2001 e novembro de 2006. Durante este período foram realizadas 42 expedições de campo, em áreas de cerrado e mata atlântica no Brasil, sendo que destas $40 \%$ foram em solo paulista. Foram também incluídas amostras de outros projetos, utilizando o mesmo protocolo de coleta, o que enriqueceu a coleção do Instituto Butantan e do Museu de Zoologia da USP. Das 42 expedições, foram obtidos mais de 390.000 aracnídeos, dos quais 350.000 eram aranhas (55.000 indivíduos adultos) que hoje fazem parte dos acervos de São Paulo.

Além da ampliação dos acervos, o projeto Biota/Arachnida e Myriapoda ajudou a equipar a coleção do Instituto Butantan com armários deslizantes. Foram também adquiridos instrumentos óticos e de informática para os laboratórios envolvidos no projeto, e digitalizado $75 \%$ das informações do acervo do Instituto Butantan. Durante este projeto foi construído o bancos de dados discutido neste estudo, foram desenvolvidos vários projetos paralelos de curta e longa duração e formados pelo menos 7 mestres e 3 doutores em aracnologia. A partir do material coletado neste projeto, foram

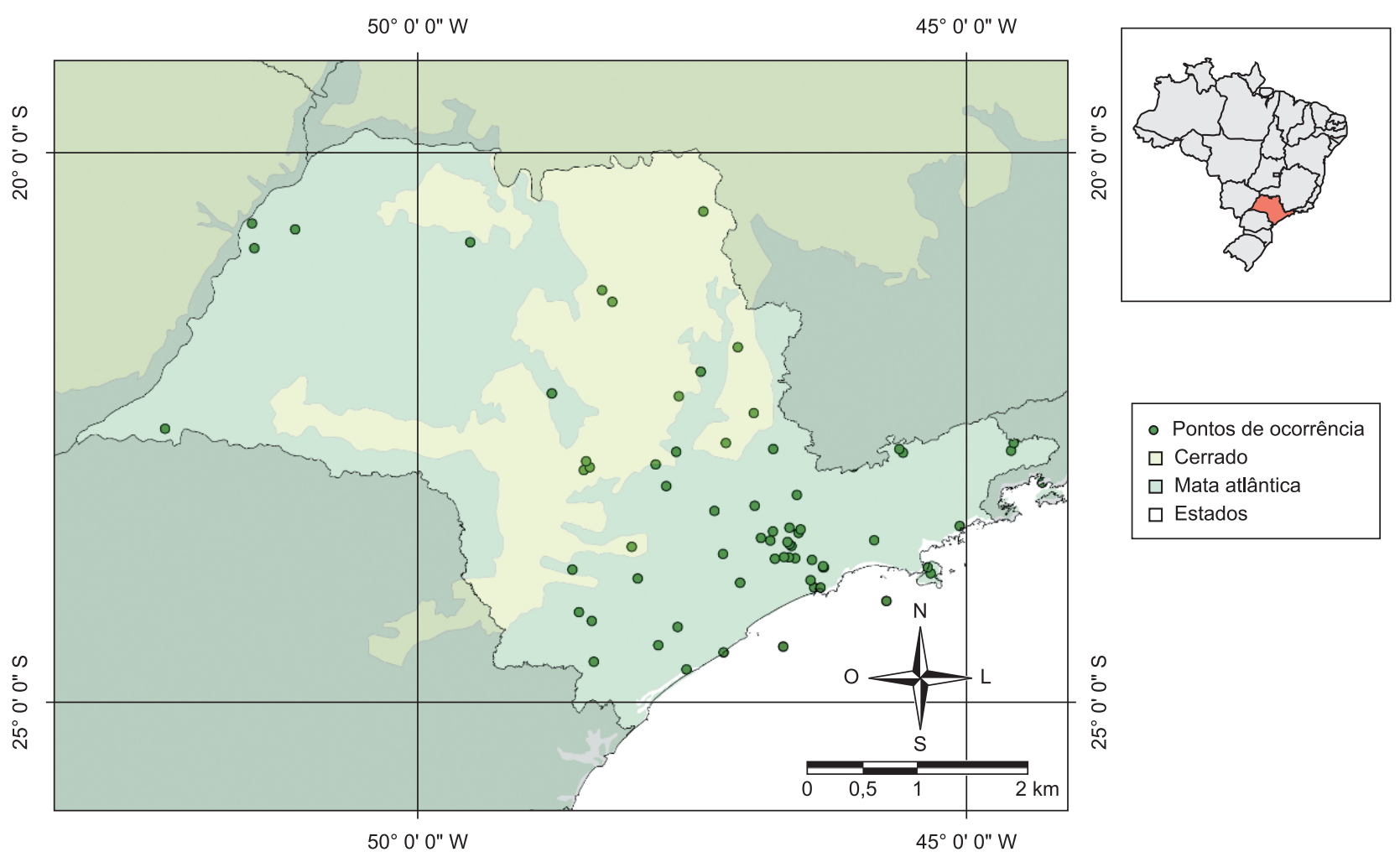

Figura 6. Pontos de ocorrência de espécies pouco conhecidas no Estado de São Paulo. Cada ponto representa a ocorrência de pelo menos uma espécie conhecida apenas para aquela localidade.

Figure 6. Records of occurrence of species poorly known in the state of São Paulo. Each record represents at least one record of at least one species of spider. 


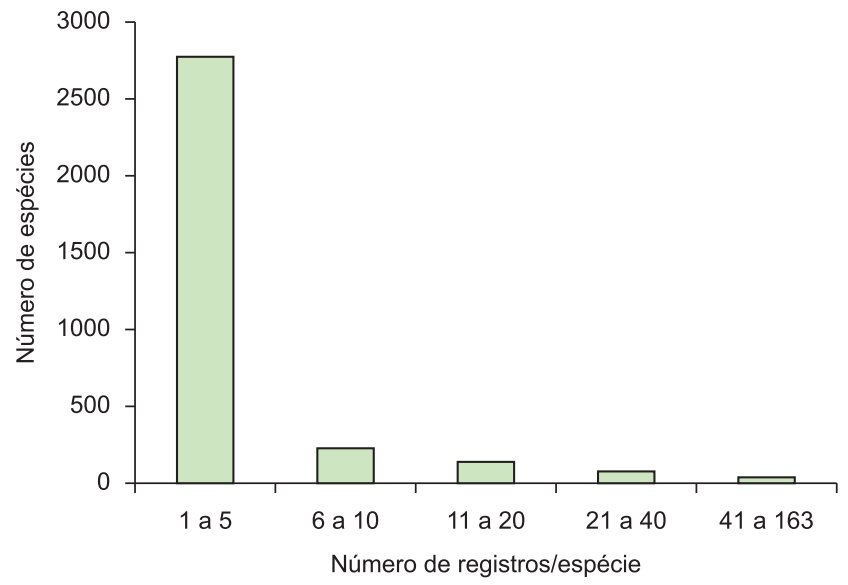

Figura 7. Número de registros por espécies de aranhas para o Estado de São Paulo.

Figure 7. Number of records per species of spider for the state of São Paulo.

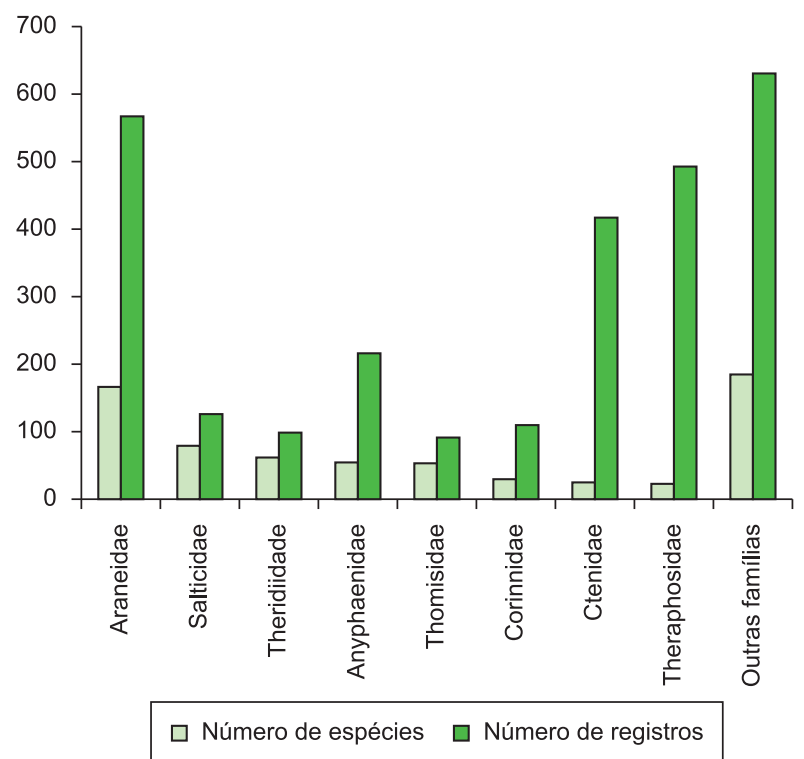

Figura 8. Número de registros e riqueza em espécies para famílias de aranhas no Estado de São Paulo.

Figure 8. Number of records and richness of families of spiders in the state of São Paulo.

descritas mais de 100 espécies novas em Arachnida, das quais 85 aranhas. A produção científica resultante do projeto inclui mais de 90 artigos científicos, dois livros e mais de 90 resumos em diversos congressos nacionais e internacionais.

\section{Principais grupos de pesquisa}

Em São Paulo, podemos destacar apenas três grupos diretamente ligados à sistemática de aranhas. No Instituto Butantan há quatro taxonomistas empregados, três com título de Doutor: Antonio Domingos Brescovit (várias famílias de Araneomorphae, com destaque para Anyphaenidae, Ctenidae e Scytodidae), Cristina Anne Rheims (Sparassidae, Scytodidae), Sylvia Marlene Lucas (Theraphosidae, Nemesiidae) e Rogério Bertani (Theraphosidae). No Museu de Zoologia atua Ricardo Pinto da Rocha, especialista em opiliões que eventualmente orienta na taxonomia e inventários de aranhas no Estado de São Paulo. Outro grupo atuante é coordenado por Isabela M.P. Rinaldi, na UNESP de Botucatu, com estudos esporádicos em taxonomia de Thomisidae e Salticidae.

Além de grupos atuantes em taxonomia, pelo menos três grupos de pesquisa atuam em inventários de araneofauna no Estado de São Paulo. Em Botucatu, Isabela M.P. Rinaldi tem realizado alguns estudos de inventários, alguns em agroecossistemas (e.g. Rinaldi \& Forti 1996, 1997). Dois pesquisadores atuam no Departamento de Biologia Animal da Unicamp, João Vasconcellos-Neto, que tem trabalhado intensamente na Serra do Japi (Jundiaí), e Gustavo Q. Romero, que desenvolve projetos relacionados a interações entre aranhas e plantas. Esses pesquisadores têm interagido frequentemente com colegas taxonomistas e seus projetos frequentemente resultam na adição de novos espécimes às coleções do estado.

\section{Principais acervos}

Após o diagnostico de Brescovit (1999) ocorreram várias modificações em relação ao inventário das coleções brasileiras na época. Na Tabela 2 observa-se que das 14 instituições citadas anteriormente, somente 12 estão na lista atual. Houve a inclusão de duas coleções, a do Museu Paraense Emílio Goeldi (MPEG), que em 1999 não existia no moldes atuais de coleções científicas. Sua formação se deve à contratação em 2000 do aracnólogo Alexandre B. Bonaldo, que iniciou uma serie de inventários no estado do Pará e hoje detém um acervo de mais de 35.000 lotes de aranhas. A outra coleção incluída é da Universidade Federal de Minas Gerais (UFMG), em Belo Horizonte, que tem crescido desde a contratação do aracnólogo Adalberto J. Santos, em 2006.

Por outro lado, três coleções citadas anteriormente já não existem de forma independente. A única coleção privada citada na lista, de Renner Baptista, foi doada e incorporada ao acervo da coleção MNRJ. As coleções da UFPB, de João Pessoa, Paraíba e do MZLQ, de Piracicaba, São Paulo, foram doadas e incorporadas ao acervo do Instituto Butantan (IBSP).

As demais coleções mantêm o status anterior, sendo que algumas foram amplamente modernizadas e hoje se apresentam numa situação ótima em relação ao período anterior. Todos os acervos foram incrementados e mantém um curador regular, mesmo não sendo um aracnólogo, como é o caso do Museu de História do Capão da Imbuia (MHCI) cujo curador é herpetólogo, e a do Instituto Nacional de Pesquisas da Amazônia (INPA), um entomólogo

No Estado de São Paulo, são mantidas três coleções, uma vez que a coleção da ESALQ de Piracicaba foi doada e incorporada à coleção do Instituto Butantan. Em relação aos acervos, as duas coleções de São Paulo suplantam em numero todas as demais coleções, somando mais de 180.000 lotes e mais de 400.000 exemplares, mesmo após o incêndio ocorrido na coleção do IBSP, onde $30 \%$ da coleção de Araneae foram perdidos. Nestas, temos no acervo material do país inteiro com abundância de espécimes da maioria das localidades. Já o mesmo não se pode dizer do material do Estado de São Paulo representado nas demais coleções. Das listadas na Tabela 2, apenas o MNRJ, MCN e MCTP tem material representativo do Estado de São Paulo, mas em geral de poucos locais. Sendo assim a melhor representatividade de aranhas do estado em coleções científicas ainda se encontra no próprio estado.

\section{Principais lacunas do conhecimento}

Apesar das coletas intensas dos últimos anos, os biomas mal amostrados ainda são os mesmos. Cabe destacar o Cerrado que, apesar das muitas áreas amostradas no Programa BIOTA/FAPESP, ainda carece de informações relevantes, uma vez que boa parte do material coletado ainda não foi totalmente examinado e relacionado em listas faunísticas. Ao observarmos as Figuras 3 e 4, percebemos que o meio sul e meio norte, onde há extensas áreas de cerrado estão carentes 
de registros de espécies. Cabe destacar que boa parte destas áreas teve seu cerrado original modificado em áreas urbanizadas ou em extensas monoculturas, como as de cana-de-açúcar ou de pastagens nas ultimas décadas (Klink \& Machado, 2005).

Outros dois biomas que deveriam ser investigados com mais critério no futuro são as Restingas e as Ilhas Litorâneas, ambientes dos quais a representatividades de aranhas em coleções é irrisória. A Restinga é uma das fitofisionomias que mais tem sofrido com a devastação nas regiões litorâneas e estudos têm mostrado sua fragilidade frente à ação antrópica e alterações climáticas (Araújo \& Maciel 1998, Rocha et al. 2007). Sua vegetação esta situada em áreas privilegiados do litoral, sendo constantemente ameaçada pela especulação imobiliária e industrial (Santos et al. 2004). Esta região possui características e funções ecológicas únicas que fazem deste ecossistema uma zona de transição e de comunicação entre outros ecossistemas da Mata Atlântica. O litoral do Estado de São Paulo se estende por $622 \mathrm{~km}$ e possui áreas extremamente alteradas pelo crescimento das cidades, localizadas nas regiões centrais, e regiões preservadas, localizadas nos extremos sul e norte. Por possuir cadeias de montanhas que subdividem o litoral, possuem áreas de restinga descontínuas e com grande variação na extensão desta para o interior do continente. É dentre todos os ecossistemas litorâneos o mais impactado e também pouco estudado com relação à biodiversidade de aranhas (Platnick \& Rocha 1995).

O Estado de São Paulo possui em seu litoral cerca de 140 formas insulares emersas e exclusivamente marinhas, entre ilhas, ilhotas, lajes e rochedos. Quase todas carecem de estudos padronizados e representativos da fauna de aranhas. Estes dados são importantes, pois poderiam ser utilizados na implantação de bancos de dados das espécies que ocorrem neste ambientes, na detecção de espécies ameaçadas ou endêmicas (como a detectada na Ilha da Queimada Grande por Huber et al. 2005) e até no delineamento de estratégias de conservação e proteção destes ambientes.

\section{Perspectivas de pesquisa em aranhas para os próximos 10 anos}

Nos últimos 10 anos houve grande incremento na formação de taxonomistas de Araneae no Brasil. Hoje contamos com mais de 10 taxonomistas, tanto formados como em fase final de pósgraduação. O Estado de São Paulo tem colaborado muito nesta formação, com aracnólogos formados via USP e Instituto Butantan, assim como o Museu Nacional do Rio de Janeiro, a PUC do Rio Grande do Sul e o Museu Paraense Emílio Goeldi no Pará. Sendo assim, as perspectivas de que inventários e estudos de sistemática do grupo cresçam são alentadoras. Muitos dos profissionais formados têm mantido suas linhas de pesquisa e trabalhado bastante com a fauna paulista. Mesmo assim gostaríamos de sugerir alguns tópicos que poderiam ser avaliados no futuro.

- Concentrar os esforços de coleta no futuro em áreas onde há pouco ou nenhum registro. Isto pode ser observado na Figura 3 que mostra ainda o cerrado como área pouco amostrada, assim como as restingas, as ilhas litorâneas e as áreas residuais de Floresta de Araucária de São Paulo.

- As pesquisas futuras poderiam ser direcionadas, via Programa BIOTA/FAPESP, por exemplo, com projetos de pesquisa para áreas mal estudadas (como as citadas acima) como foi realizado recentemente para áreas oceânicas (BIOTA/FAPESP - Chamada de Propostas do Programa de Pesquisa em Caracterização, Conservação, Restauração e Uso Sustentável da Biodiversidade -Ambientes Marinhos do Estado de São Paulo).

- Outro reflexo do crescimento do número de aracnólogos no estado é o incremento dos acervos. O fluxo de material que tem sido incorporado às coleções paulistas tem sido enorme, mas sua manutenção é dificultada pela carência de recursos financeiros e de pessoal especializado. Duas coleções do estado concentram a imensa maioria dos espécimes coletados no estado, sendo que uma delas, a do Instituto Butantan, perdeu quase $40 \%$ de seu acervo em um incêndio em maio de 2010. É importante que mais recursos sejam liberados pelo estado para os acervos e que haja formação e contratação de técnicos para curadoria de material tão importante. Além disso, o incêndio do Instituto Butantan mostra claramente a importância dos investimentos voltados para a melhoria das condições de preservação dos acervos, com ênfase em sistemas de segurança.

\section{Agradecimentos}

Ao Programa BIOTA/FAPESP pelo convite para preparação deste diagnóstico. Aos curadores pelas informações dos dados das coleções e a Cristina A. Rheims pela tradução do Abstract. Ao CNPQ, bolsa PQ para A.D. Brescovit (Proc. 301776/2004-0). A.J. Santos foi financiado por CNPq (Procs. 472976/2008-7 e 300498/2009-8) e pelo Instituto Nacional de Ciência e Tecnologia dos Hymenoptera Parasitóides da Região Sudeste Brasileira (http://www.hympar.ufscar.br/).

\section{Referências Bibliográficas}

ARAÚJO, D.S.D. \& MACIEL, N.C. 1998. Restingas fluminenses: biodiversidade e preservação. Bol. Soc. Bras. Conserv. Nat. 25:27-51.

BAPTISTA, R.L.C. 1992. Revisão da família Senoculidae Simon, 1898 (Araneae). Dissertação de Mestrado, Universidade de São Paulo.

BONNET, P. 1956. Bibliographia Araneorum. Ed. Douladoure, Toulouse, v.2, pte.2, p.919-1926.

BONNET, P. 1957. Bibliographia Araneorum. Ed. Douladoure, Toulouse, v.2, pte.3, p.1927-3026.

BONNET, P. 1958. Bibliographia Araneorum. Ed. Douladoure, Toulouse, v.2, pte.4, p.3027-4230.

BONNET, P. 1959. Bibliographia Araneorum. Ed. Douladoure, Toulouse, v.2, pte.5, p.4231-5058.

BRESCOVIT, A.D. 1999. Araneae. In Biodiversidade do Estado de São Paulo, Brasil: síntese do conhecimento ao final do século XX. Invertebrados terrestres. (C.A. Joly \& C.E.M. Bicudo, org.). FAPESP, São Paulo, v.5, p.45-56.

BRESCOVIT, A.D. 2002. Aranhas da cidade de São Paulo: espécies de importância médica, sinantrópicas e controle. Biológico 64 (1):31-32.

BRIGNOLI, P.M. 1983. A Catalogue of the Araneae described between 1940 and 1981. Manchester Acad. Press, Manchester, 755p.

BÜCHERL, W. 1949. Chilopoda das Ilhas da Queimada Grande e Pequena. Mem. Inst.Butantan 21:1-8.

CALIXTO, A. \& LEVI, H.W. 2006. Notes on the natural history of Aspidolasius branicki (Araneae: Araneidae) at Tinigua National Park, Colombia, with a revision of the genus. Bull. Br. arachnol. Soc. 13:314-320.

CANHOS, V.P. 2001. Sistema de Informação Distribuído para Coleções Biológicas: a Integração do Species. CRIA/FAPESP. http://splink.cria. org.br/ (último acesso em 09/08/2010).

CODDINGTON, J.A. \& LEVI, H.W. 1991. Systematics and evolution of spiders (Araneae). Ann. Rev. Ecol. Syst. 22:565-592. http://dx.doi. org/10.1146/annurev.es.22.110191.003025

DUARTE, M.R., PUORTO, G. \& FRANCO, F. L. 1995. A biological survey of the pitviper Bothrops insularis Amaral (Serpentes, Viperidae): an endemic and threatened offshore island snake of Southeastern Brazil. Stud. Neotrop. Fauna E. 30:1-13. http://dx.doi.org/10.1080/01650529509360936

FOELIX, R.F. 1996. Biology of spiders. 2nd ed. Oxford University Press, Oxford. 
GONZAGA, M.O. \& VASCONCELLOS-NETO, J. 2005. Orb-web spiders (Araneae: Araneomorphae; Orbiculariae) captured by huntingwasps (Hymenoptera: Sphecidae) in an area of Atlantic Forest in south-eastern Brazil. J. Nat. Hist. 31:2913-2933.* http://dx.doi. org/10.1080/00222930500183520

HIJMANS, R.J., GUARINO, L., JARVIS, A., O’BRIEN, R., MATHUR, P., BUSSINK, C., CRUZ, M., BARRANTES, I. \& ROJAS, E. 2005. DIVA GIS, versão 5.2. Programa e documentação disponíveis em http://www. diva-gis.org (último acesso em 12/02/2011).

HUBER, B., A.D. BRESCOVIT, \& C.A. RHEIMS. 2005. Exaggerated female genitalia in two new spider species (Araneae: Pholcidae), with comments on genital evolution by female choice versus antagonistic coevolution. Ins. Syst. Evol. 36(3):285-292. http://dx.doi. org/10.1163/187631205788838375

KESSLER, C.C. 1990. Contribuição ao conhecimento do gênero Verrucosa McCook, 1888 (Araneae, Araneidae). Dissertação de Mestrado, Instituto de Biologia, PUC/RS, 180p.*

KLINK, C.A. \& MACHADO, R.B. 2005. A conservação do Cerrado brasileiro. Megadiversidade 1:147-155.

LEVI, H.W. 2002. Keys to the genera of araneid orbweavers (Araneae, Araneidae) of the Americas. J. Arachnol. 30:527-562. http://dx.doi. org/10.1636/0161-8202(2002)030[0527:KTTGOA]2.0.CO;2

LEVI, H.W. 2005a. The orb-weaver genus Mangora of Mexico, Central America, and the West Indies (Araneae: Araneidae). Bull. Mus. Comp. Zool. 158:139-182. http://dx.doi.org/10.3099/0027-4100(2005)158[139:TOG MOM]2.0.CO;2

LEVI, H.W. 2005b. The spider genera Heterognatha, Testudinaria and Ursa in South America (Araneae: Araneoidea). Bull. Br. Arachnol. Soc. 13:185-198.

LEVI, H.W. 2007. The orb weaver genus Mangora in South America (Araneae, Araneidae). Bull. Mus. Comp. Zool. 159, 1-144.

LUTZ, A. \& LUTZ, B. 1939. New Hylidae from Brazil. Ann. Acad. Bras. Sci. 11:67-89.

MILLER, J.A., CARMICHAEL, A. RAMÍREZ, M.J. SPAGNA, J.C. HADDAD, C.R. REZAK, M. JOHANNESEN, J. KRÁL, J. WANG, X.P. \& GRISWOLD, C.E. 2010. Phylogeny of entelegyne spiders: affinities of the family Penestomidae (NEW RANK), generic phylogeny of Eresidae, and asymmetric rates of change in spinning organ evolution (Araneae, Araneoidea, Entelegynae). Mol. Phylogenet. Evol. 55:786-804. http:// dx.doi.org/10.1016/j.ympev.2010.02.021

PINTO-DA-ROCHA, R. 1995. Sinopse da fauna cavernícola do Brasil (19071994). Pap. Avulsos Zool 39(6):61-173.*
PLATNICK, N.I. 1989. Advances in Spider Taxonomy 1981-1987: A Supplement to Brignoli's A Catalogue of the Araneae described between 1940 and 1981. Manchester Univ. Press, 673p.

PLATNICK, N.I. 1993. Advances in spider taxonomy 1988-1991, with synonymies and transfers 1940-1980. New York, 846p.

PLATNICK, N.I. 1999. Dimensions of biodiversity: targeting megadiverse groups. In The living planet in crisis: biodiversity science. and policy. (J. Cracraft \& T. Grifo, eds). Columbia University Press, p.33-52.

PLATNICK, N.I. 2010. The world spider catalog, version 10.5. American Museum of Natural History http://research.amnh.org/entomology/spiders/ catalog/index.html (ultimo acesso em 15/08/2010).

PLATNICK, N.I. \& ROCHA, C.F.D. 1995. On a new Brazilian spider of the genus Trachelopachys (Araneae, Corinnidae), with notes on misplaced taxa. Am. Mus. Novit. 3153:1-8.

RINALDI, I.M.P. \& FORTI, L.C. 1996. Strategies for habitat use among species of hunting spiders (Araneomorphae, Dionycha) in natural and artificial biotopes from southeastern Brazil. Acta Biol. Par. 25(1-4):115-139.*

RINALDI, I.M.P. \& FORTI, L.C. 1997. Hunting Spiders of Woodland Fragments and Agricultural Habitats in the Atlantic Rain Forest Region of Brazil. Stud. Neotrop. Fauna E. 32:244-255.*

ROCHA, C.F.D., BERGALLO, H.G., VAN SLUYS, M., ALVES, M.A.S. \& JAMEL, C.E. 2007. The remnants of restinga habitats in the Brazilian Atlantic forest of Rio de Janeiro state, Brazil: habitat loss and risk of disappearance. Braz. J. Biol. 67(2):263-273. http://dx.doi.org/10.1590/ S1519-69842007000200011

ROEWER, C.F. 1954. Katalog der Araneae von 1758 bis 1940. Bruxelles, v.2, 923 p.

SANTOS, A.J., BRESCOVIT, A.D. \& LEVI, H.W. 2005. Melychiopharis: an atypical orb-weaving spider from South América (Araneae: Araneidae). Zootaxa 1016:57-64.

SANTOS, M.G., SYLVESTRE, L.S. \& ARAUJO, D.S.D. 2004. Análise florística das pteridófitas do Parque Nacional da Restinga de Jurubatiba, Rio de Janeiro, Brasil. Acta Bot. Bras. 18:271-280. http://dx.doi. org/10.1590/S0102-33062004000200007

SCHUBART, O. 1949. Os diplópodas de algumas ilhas do litoral paulista. Mem. Inst. Butantan 21:203-254. 